\title{
Reorientação Induzida por Tensão Devido a Oxigênio e Nitrogênio em Ligas de Nb-Ta
}

\section{Luciano Henrique de Almeida}

\author{
Dissertação apresentada à Área \\ Interunidades em Ciência e \\ Engenharia de Materiais, da \\ Universidade de São Paulo, para a \\ obtenção do título de Mestre em \\ Ciência e Engenharia de Materiais.
}

Orientador: Prof. Dr. Carlos Roberto Grandini

uspnFscrse1

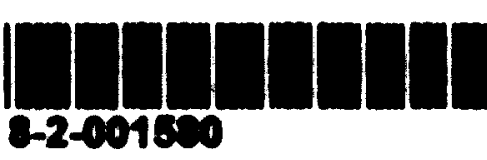

São Carlos - 2004

IFSC-USP SERVICCO DE BIBLIOTECA 
Almeida, Luciano Henrique de

"Reorientação induzida por tensão devido a oxigênio e nitrogênio em ligas de NbTa" / Luciano Henrique de Almeida - São Carlos, 2004

Dissertação (Mestrado) - Interunidades Ciência e Engenharia de Materiais da Universidade de São Paulo, 2004 - páginas: 132

Área: Ciência e Engenharia de Materiais

Orientador: Prof. Dr. Carlos Roberto Grandini

1. Ligas de $\mathrm{Nb}-\mathrm{Ta}$

1. Título 
MEMBROS DA COMISSÃO JULGADORA DA DISSERTAÇÃO DE MESTRADO DE LUCIANO HENRIQUE DE ALMEIDA, APRESENTADA À ÁREA INTERUNIDADES CIÊNCIA E ENGENHARIA DE MATERIAIS, UNIVERSIDADE DE SÃO PAULO, EM 11/03/2004.

COMISSÃO JULGADORA:

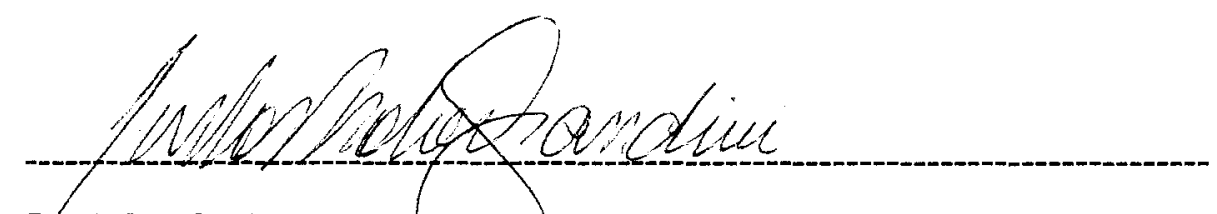

Prof. Dr. Carlos Roberto Grandini ( Orientador e Presidente) - UNESP

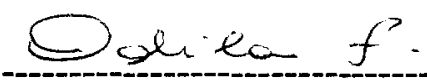

Profa. Dra. Odila Florêncio - UFSCar

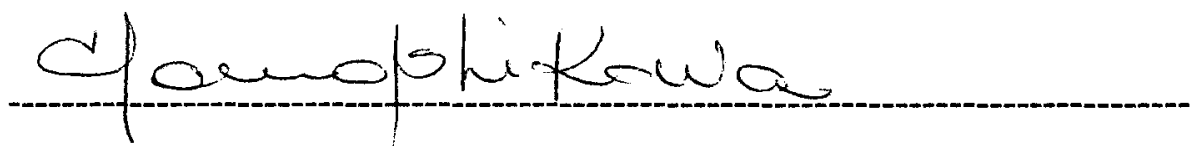

Prof. Dr. Tomaz Toshimi Ishikawa - UFSCar 
À Liege, Ana e Luisinho 


\section{Agradecimentos}

É com grande satisfação que faço esses agradecimentos às pessoas que muito contribuíram para a execução deste trabalho.

À minha família, minha mãe Ana e meu irmão Luisinho pelo imenso apoio e incentivo que me fizeram chegar onde cheguei.

Ao meu grande amigo e orientador Beto Grandini pela sua dedicação, paciência e orientação nos trabalhos realizados desde a graduação. À sua esposa Nádia pela amizade e momentos de descontração propiciados pela sua alegria.

Aos amigos Terlize, Kelly, Renata, Roberto, Tiago, Daniel e Gustavo pelo excelente convívio no laboratório e valorosas discussões.

À minha grande amiga e companheira Juliana que em muito me ajudou desde meu ingresso na graduação, pelas discussões e alegrias compartilhadas neste período, e principalmente pela amizade.

Aos meus irmãos de república Ronaldo, Thiago (giba), Renato, Flavio, Marcos Viatroski pelas proveitosas conversas, baladas, bebedeiras, peladas de futebol, enfim todo apoio e amizade desde a graduação.

Aos amigos Álex, Emerson e Moacir com quem passei bons momentos na graduação.

Como não poderia deixar de agradecer a uma das pessoas mais importantes em minha carreira cientifica a minha querida "Catia" que me ajudou em muitos momentos de dificuldade.

Ao Willian e Carlos técnicos do laboratório pelo auxilio na resolução de problemas dos equipamentos do laboratório.

Ao pessoal de Lorena, Durval e João Paulo, pelo fornecimento das amostras e informações valiosas. 
À FAPESP pelo importante apoio financeiro.

Ao IFSC que me proporcionou fazer um excelente curso de mestrado com ótimas instalações.

À UNESP por ceder as instalações onde desenvolvi meus trabalhos.

À pessoa que me dedicou carinho, compreensão, incentivo e amor durante os períodos difíceis que passei, a pessoa que já faz parte da minha vida Liege.

Ao ser mais importante que tudo, o Criador, que deu ao homem a capacidade para entender os fenômenos que acontecem a sua volta.

Enfim, a todos que contribuíram para a execução deste trabalho

Muito Obrigado. 
ALMEIDA, L. H. Reorientação induzida por tensão devido a oxigênio e nitrogênio em ligas de Nb-Ta. São Carlos, 2004. 132p. Dissertação (Mestrado em Ciência e Engenharia de Materiais) - Instituto de Física de São Carlos, Universidade de São Paulo.

\section{RESUMO}

O estudo da interação de metais com impurezas intersticiais como oxigênio e nitrogênio em solução sólida tem despertado o interesse de pesquisadores de diversas áreas, pois tais impurezas modificam algumas propriedades mecânicas destes metais. A presença destes intersticiais causa um desvio na elasticidade perfeita, chamada anelasticidade. Estudos de espectroscopia anelástica nos fornecem informações a respeito do comportamento destas impurezas na matriz metálica. Nesta dissertação foram analisadas amostras policristalinas da liga $\mathrm{Nb}-8,9 \%$ p.Ta com diferentes concentrações de elementos intersticiais. Foram efetuadas medidas de espectroscopia anelástica utilizando um pêndulo torção invertido, operando com frequêencia de 2,0 a $27,0 \mathrm{~Hz}$, num intervalo de temperatura compreendido entre 300 a $700 \mathrm{~K}$. Observamos a presença de estruturas de relaxação que foram atribuídas a processos de relaxação devido à reorientação induzida por tensão de átomos intersticiais em torno de átomos da matriz metálica. Constatamos, também, a existência de uma relação entre a intensidade da estrutura de relaxação e a concentração de intersticiais. As estruturas de relaxação foram decompostas em seus picos constituintes, que nos permitiu identificar os seguintes processos de relaxação: $\mathrm{Ta}-\mathrm{O}, \mathrm{Nb}-\mathrm{O}, \mathrm{Nb}-\mathrm{O}-\mathrm{O}$ e $\mathrm{Nb}-\mathrm{N}$.

Palavras-chave: atrito interno, espectroscopia anelástica, gases em metais 
ALMEIDA, L. H. Stress induced ordering due the oxygen and nitrogen in Nb-Ta alloys. São Carlos, 2004. 132p. Dissertação (Mestrado em Ciência e Engenharia de Materiais) Instituto de Física de São Carlos, Universidade de São Paulo.

\begin{abstract}
The study of the metal interaction with interstitial impurities as oxygen and nitrogen in solid solution has aroused the interest of researchers of diverse areas, therefore such impurities modify some mechanical properties of these metals. The presence of these interstitials causes a deviation in the perfect elasticity, called anelasticity. Studies of anelastic spectroscopy provide information of the behaviour of these impurities in the metallic matrix. In this dissertation, polycrystalline samples of $\mathrm{Nb}-8.9 \% \mathrm{p}$. Ta alloy have been analysed with different concentrations of interstitials elements. Measurements of anelastic spectroscopy were carried out using an inverted torsion pendulum, operating with frequency of 2.0 to $27.0 \mathrm{~Hz}$ and in a temperature range between 300 and $700 \mathrm{~K}$. It was observed the presence of relaxation structures that have been attributed to stress induced ordering due to interstitial atoms around atoms of the metallic matrix. It is also evidenced the existence of a relation between the intensity of the relaxation's structures and the interstitials concentration. The relaxation structures have been decomposed in its constituents peaks, what it allowed to identify the following processes of relaxation: $\mathrm{Ta}-\mathrm{O}, \mathrm{Nb}-\mathrm{O}, \mathrm{Nb}-\mathrm{O}-\mathrm{O}$ and $\mathrm{Nb}-\mathrm{N}$.
\end{abstract}

Keywords: internal friction, anelastic spectroscopy, gases in metals 


\section{ÍNDICE}

CAPÍTULO I - INTRODUÇÃo

CAPÍTULO II - FUNDAMENTOS TEÓRICOS

II. 1. O Significado da Anelasticidade

II. 2. Funções Resposta Quase-Estáticas

II. 3. Funções Resposta Dinâmicas 22

II. 4. Vibrações Livres de um Sistema 28

II. 5. Modelos Mecânicos 30

II. 5.1. Equação Diferencial de Tensão-Deformação30

II. 5.2. Modelo de Voigt 32

II. 5.3. Modelo de Maxwell 33

II. 5.4. O Modelo dos Três Parâmetros 34

II. 6. Propriedades Dinâmicas de um Sólido Anelástico Padrão

CAPÍTULO III - REAÇÃO METAL-GÁS 39

III. 1. Aspectos Gerais da Reação Metal-Gás 39

III. 2. Mecanismos de Gaseificação com Oxigênio e Nitrogênio 41

III. 3. Difusão

CAPÍTULO IV - PARTE EXPERIMENTAL 45

IV. 1. Densidade 46

IV. 2. Difração de Raios X 48

IV. 3. Tratamentos Térmicos 52

IV. 4. Atrito Interno 55

IV. 5. Caracterização das Amostras 60

CAPÍTULO V - RESULTADOS E DISCUSSÕES 80

CAPÍTULO VI - CONSIDERAÇÕES FINAIS 122 


\section{LISTA DE FIGURAS}

Figura 1 - Diagrama de fase entre $\mathrm{Nb}-\mathrm{Ta}$.

Figura 2 - Diagrama de fase entre $\mathrm{J}_{1}$ e $\mathrm{J}_{2}$.

Figura 3 - Modelos de Voigt e Maxwell para representar um sólido anelástico.

Figura 4 - Modelo dos Três Parâmetros.

Figura 5 - Comparação entre $\mathrm{J}_{1}$ e $\mathrm{J}_{2}$ como função do logaritmo de $\omega \tau_{\sigma}$ para um sólido anelástico padrão.

Figura 6 - Etapas do processo de gaseificação e desgaseificação: a) reação metal-oxigênio; b) reação metal-nitrogênio.

Figura 7 - Diagrama esquemático do difratômetro de raios X.

Figura 8 - Difração de raios X nos planos cristalinos.

Figura 9 - Diagrama esquemático do sistema de tratamento térmico e dopagem de amostra.

Figura 10 - Diagrama de corte do Pêndulo de Torção.

Figura 11 - Difratograma de raios $\mathrm{X}$ obtido para amostra da liga Nb-8,9\%p.Ta (como recebida).

Figura 12 - Análise de atmosfera dentro do tubo de quartzo, para o tratamento térmico .

Figura 13 - Análise de gases efetuado pelo RGA durante o processo de recozimento.

Figura 14 - Difratograma de raios X para amostra da liga obtido após o tratamento térmico de recozimento.

Figura 15 - Análise da atmosfera do tubo de quartzo antes do aquecimento para a primeira dopagem.

Figura 16 - Análise de gases durante o aquecimento para a primeira dopagem com oxigênio.

Figura 17 - Difratograma de raios X para amostra da liga obtido após a primeira dopagem.

Figura 18 - Análise da atmosfera do tubo de quartzo antes do aquecimento para a segunda dopagem.

Figura 19 - Análise de gases durante o aquecimento para a segunda dopagem com oxigênio.

Figura 20 - Difratograma de raios X para amostra da liga obtido após a segunda dopagem.

Figura 21 - Análise da atmosfera do tubo de quartzo antes do aquecimento para a terceira dopagem.

Figura 22 - Análise de gases durante o aquecimento para a terceira dopagem com oxigênio.

Figura 23 - Difratograma de raios X para amostra da liga obtido após a terceira dopagem.

Figura 24 - Análise da atmosfera do tubo de quartzo antes do aquecimento para a quarta dopagem. 
Figura 25 - Análise de gases durante o aquecimento para a quarta dopagem com oxigênio.

Figura 26 - Difratograma de raios X para amostra da liga obtido após a quarta dopagem.

Figura 27 - Relação entre o parâmetro de rede e a concentração de oxigênio.

Figura 28 - Espectro de atrito interno como função da temperatura para amostra da liga $\mathrm{Nb}$ $8,9 \%$ p.Ta medido com freqüência de $2,47 \mathrm{~Hz}$, da maneira como recebida.

Figura 29 - Espectro de atrito interno como função da temperatura para amostra da liga $\mathrm{Nb}$ $8,9 \%$ p. Ta medido com freqüência de $4,81 \mathrm{~Hz}$, da maneira como recebida.

Figura 30 - Espectro de atrito interno como função da temperatura para amostra da liga $\mathrm{Nb}$ $8,9 \%$ p. Ta medido com freqüência de $15,47 \mathrm{~Hz}$, da maneira como recebida.

Figura 31 - Espectros anelásticos com "background" extraído para amostra da liga Nb$8,9 \%$ p.Ta medidos com diferentes freqüências, da maneira como recebida.

Figura 32 - Gráfico do logaritmo da frequiência em função do inverso da temperatura para a amostra da liga $\mathrm{Nb}-8,9 \%$ p.Ta.

Figura 33 - Análise do espectro anelástico com "background" extraído para a amostra da liga $\mathrm{Nb}-8,9 \%$ p.Ta medido com freqüência de oscilação de $2,47 \mathrm{~Hz}$, da maneira como recebida, decomposto em seus processos de relaxação constituintes.

Figura 34 - Análise do espectro anelástico com "background" extraído para a amostra da liga $\mathrm{Nb}-8,9 \%$ p.Ta medido com freqüência de oscilação de $4,81 \mathrm{~Hz}$, da maneira como recebida, decomposto em seus processos de relaxação constituintes.

Figura 35 - Análise do espectro anelástico com "background" extraído para a amostra da liga $\mathrm{Nb}-8,9 \%$ p.Ta medido com freqüência de oscilação de $15,47 \mathrm{~Hz}$, da maneira como recebida, decomposto em seus processos de relaxação constituintes.

Figura 36 - Espectro de atrito interno como função da temperatura para amostra da liga Nb$8,9 \%$ p.Ta medido com freqüência de $3,51 \mathrm{~Hz}$, após o recozimento.

Figura 37 - Espectro de atrito interno como função da temperatura para amostra da liga Nb$8,9 \%$ p.Ta medido com freqüência de $7,70 \mathrm{~Hz}$, após o recozimento.

Figura 38 - Espectro de atrito interno como função da temperatura para amostra da liga $\mathrm{Nb}$ $8,9 \%$ p.Ta medido com freqüência de $22,58 \mathrm{~Hz}$, após o recozimento.

Figura 39 - Espectros anelásticos com o "background" extraído para amostra da liga Nb$8,9 \%$ p.Ta medidos com diferentes freqüências após o recozimento.

Figura 40 - Análise do espectro anelástico com "background" extraído para a amostra da liga $\mathrm{Nb}-8,9 \%$ p.Ta medido com freqüência de oscilação de $3,51 \mathrm{~Hz}$, após o recozimento, decomposto em quatro processos de relaxação. 
Figura 41 - Análise do espectro anelástico com "background" extraído para a amostra da liga $\mathrm{Nb}-8,9 \%$ p.Ta medido com frequiência de oscilação de $7,70 \mathrm{~Hz}$, após o recozimento, decomposto em quatro processos de relaxação.

Figura 42 - Análise do espectro anelástico com "background" extraído para a amostra da liga $\mathrm{Nb}-8,9 \%$ p.Ta medido com freqüência de oscilação de $22,58 \mathrm{~Hz}$, após o recozimento, decomposto em quatro processos de relaxação.

Figura 43 - Espectro de atrito interno como função da temperatura para amostra da liga $\mathrm{Nb}$ $8,9 \%$ p.Ta medido com freqüência de $3,28 \mathrm{~Hz}$, após a primeira dopagem.

Figura 44 - Espectro de atrito interno como função da temperatura para amostra da liga $\mathrm{Nb}$ $8,9 \%$ p.Ta medido com frequiência de $7,14 \mathrm{~Hz}$, após a primeira dopagem.

Figura 45 - Espectro de atrito interno como função da temperatura para amostra da liga $\mathrm{Nb}$ $8,9 \%$ p.Ta medido com frequêencia de $20,40 \mathrm{~Hz}$, após a primeira dopagem.

Figura 46 - Espectros anelásticos com "background" extraído para amostra da liga $\mathrm{Nb}$ $8,9 \%$ p.Ta medidos com diferentes freqüências após a primeira dopagem.

Figura 47 - Análise do espectro anelástico com "background" extraído para a amostra da liga $\mathrm{Nb}-8,9 \%$ p.Ta medido com frequeência de oscilação de $3,28 \mathrm{~Hz}$ após a primeira dopagem, decomposto em quatro processos de relaxação.

Figura 48 - Análise do espectro anelástico com "background" extraído para a amostra da liga $\mathrm{Nb}-8,9 \%$ p.Ta medido com freqüência de oscilação de $7,14 \mathrm{~Hz}$ após a primeira dopagem, decomposto em quatro processos de relaxação.

Figura 49 - Análise do espectro anelástico com "background" extraído para a amostra da liga $\mathrm{Nb}-8,9 \%$ p.Ta medido com freqüência de oscilação de $20,40 \mathrm{~Hz}$ após a primeira dopagem, decomposto em quatro processos de relaxação.

Figura 50 - Espectro de atrito interno como função da temperatura para amostra da liga $\mathrm{Nb}$ $8,9 \%$ p.Ta medido com frequiência de $3,44 \mathrm{~Hz}$, após a segunda dopagem.

Figura 51 - Espectro de atrito interno como função da temperatura para amostra da liga $\mathrm{Nb}$ $8,9 \%$ p.Ta medido com freqüência de $8,86 \mathrm{~Hz}$, após a segunda dopagem.

Figura 52 - Espectro de atrito interno como função da temperatura para amostra da liga $\mathrm{Nb}$ $8,9 \%$ p.Ta medido com frequêencia de $21,75 \mathrm{~Hz}$, após a segunda dopagem.

Figura 53 - Espectros anelásticos com "background" extraído para amostra da liga $\mathrm{Nb}$ $8,9 \%$ p.Ta medidos com diferentes freqüências após a segunda dopagem.

Figura 54 - Análise do espectro anelástico com "background" extraído para a amostra da liga $\mathrm{Nb}-8,9 \%$ p.Ta medido com freqüência de oscilação de $3,44 \mathrm{~Hz}$ após a segunda dopagem, decomposto em quatro processos de relaxação. 
Figura 55 - Análise do espectro anelástico com "background" extraído para a amostra da liga $\mathrm{Nb}-8,9 \%$ p.Ta medido com freqüência de oscilação de $8,86 \mathrm{~Hz}$ após a segunda dopagem, decomposto em quatro processos de relaxação.

Figura 56 - Análise do espectro anelástico com "background" extraído para a amostra da liga $\mathrm{Nb}-8,9 \%$ p.Ta medido com freqüência de oscilação de $21,75 \mathrm{~Hz}$ após a segunda dopagem, decomposto em quatro processos de relaxação.

Figura 57 - Espectro de atrito interno como função da temperatura para amostra da liga Nb$8,9 \%$ p.Ta medido com freqüência de $5,52 \mathrm{~Hz}$, após a terceira dopagem.

Figura 58 - Espectro de atrito interno como função da temperatura para amostra da liga Nb$8,9 \%$ p.Ta medido com freqüência de $10,41 \mathrm{~Hz}$, após a terceira dopagem.

Figura 59 - Espectro de atrito interno como função da temperatura para amostra da liga Nb$8,9 \%$ p.Ta medido com freqüência de $26,48 \mathrm{~Hz}$, após a terceira dopagem.

Figura 60 - Espectros anelásticos com "background" extraído para amostra da liga $\mathrm{Nb}$ $8,9 \%$ p.Ta medidos com diferentes freqüências após a terceira dopagem.

Figura 61 - Análise do espectro anelástico com "background" extraído para a amostra da liga $\mathrm{Nb}-8,9 \%$ p.Ta medido com freqüência de oscilação de $5,52 \mathrm{~Hz}$ após a terceira dopagem, decomposto em quatro processos de relaxação.

Figura 62 - Análise do espectro anelástico com "background" extraído para a amostra da liga $\mathrm{Nb}-8,9 \%$ p.Ta medido com frequiência de oscilação de $10,41 \mathrm{~Hz}$ após a terceira dopagem, decomposto em quatro processos de relaxação.

Figura 63 - Análise do espectro anelástico com "background" extraído para a amostra da liga $\mathrm{Nb}-8,9 \%$ p.Ta medido com frequiência de oscilação de $26,48 \mathrm{~Hz}$ após a terceira dopagem, decomposto em quatro processos de relaxação.

Figura 64 - Espectro de atrito interno como função da temperatura para amostra da liga $\mathrm{Nb}$ $8,9 \%$ p.Ta medido com freqüência de $4,24 \mathrm{~Hz}$, após a quarta dopagem.

Figura 65 - Espectro de atrito interno como função da temperatura para amostra da liga Nb$8,9 \%$ p.Ta medido com freqüência de $10,47 \mathrm{~Hz}$, após a quarta dopagem.

Figura 66 - Espectro de atrito interno como função da temperatura para amostra da liga Nb$8,9 \%$ p.Ta medido com freqüência de $25,90 \mathrm{~Hz}$, após a quarta dopagem.

Figura 67 - Espectros anelásticos com "background" extraído para amostra da liga $\mathrm{Nb}$ $8,9 \%$ p.Ta medidos com diferentes freqüências após a quarta dopagem.

Figura 68 - Análise do espectro anelástico com "background" extraído para a amostra da liga $\mathrm{Nb}-8,9 \%$ p.Ta medido com freqüência de oscilação de $4,24 \mathrm{~Hz}$ após a quarta dopagem, decomposto em quatro processos de relaxação. 
Figura 69 - Análise do espectro anelástico com "background" extraído para a amostra da liga $\mathrm{Nb}-8,9 \%$ p.Ta medido com frequiência de oscilação de $10,47 \mathrm{~Hz}$ após a quarta dopagem, decomposto em quatro processos de relaxação.

Figura 70 - Análise do espectro anelástico com "background" extraído para a amostra da liga $\mathrm{Nb}-8,9 \%$ p.Ta medido com frequiência de oscilação de $25,90 \mathrm{~Hz}$ após a quarta dopagem, decomposto em quatro processos de relaxação.

Figura 71 - Variação da intensidade do pico de relaxação com o aumento da concentração de intersticiais. 


\section{LISTA DE TABELAS}

Tabela 1 - Composição química da amostra Nb-8,9\%p.Ta.

Tabela 2 - Medidas de massa e densidade da amostra.

Tabela 3 - Parâmetro de rede da amostra como recebida.

Tabela 4 - Teores de oxigênio e nitrogênio na amostra Nb-8,9\%p.Ta.

Tabela 5 - Teores de oxigênio e nitrogênio na amostra $\mathrm{Nb}-8,9 \%$ p.Ta, após o tratamento térmico.

Tabela 6 - Parâmetro de rede da amostra após o recozimento.

Tabela 7 - Teores de oxigênio e nitrogênio na amostra Nb-8,9\%p.Ta, após a primeira dopagem.

Tabela 8 - Parâmetro de rede da amostra após a primeira dopagem.

Tabela 9 - Teores de oxigênio e nitrogênio na amostra $\mathrm{Nb}-8,9 \%$ p.Ta, após a segunda dopagem.

Tabela 10 - Parâmetro de rede da amostra após a segunda dopagem.

Tabela 11 - Teores de oxigênio e nitrogênio na amostra Nb-8,9\%p.Ta, após a terceira dopagem.

Tabela 12 - Parâmetro de rede da amostra após a terceira dopagem.

Tabela 13 - Teores de oxigênio e nitrogênio na amostra $\mathrm{Nb}-8,9 \%$ p.Ta, após a quarta dopagem.

Tabela 14 - Parâmetro de rede da amostra após a quarta dopagem.

Tabela 15 - Energia de ativação dos processos de relaxação encontrada na literatura.

Tabela 16 - Parâmetros de relaxação (amostra como recebida).

Tabela 17 - Parâmetros de relaxação (após o recozimento).

Tabela 18 - Parâmetros de relaxação (após a primeira dopagem).

Tabela 19 - Parâmetros de relaxação (após a segunda dopagem).

Tabela 20 - Parâmetros de relaxação (após a terceira dopagem).

Tabela 21 - Parâmetros de relaxação (após a quarta dopagem).

Tabela 22 - Parâmetros de relaxação para o processo $\mathrm{Ta}-\mathrm{O}$.

Tabela 23 - Parâmetros de relaxação para o processo $\mathrm{Nb}$ - O.

Tabela 24 - Parâmetros de relaxação para o processo $\mathrm{Nb}-\mathrm{O}-\mathrm{O}$.

Tabela 25 - Parâmetros de relaxação para o processo $\mathrm{Nb}-\mathrm{N}$. 


\section{LISTA DE SÍMBOLOS}

$\sigma$ é a tensão aplicada ao material

$\varepsilon$ é a deformação sofrida pelo material

M é o módulo de elasticidade

$\mathbf{J}$ é a flexibilidade do material

$\sigma_{0}$ é a amplitude da tensão

$\omega=2 \pi \mathrm{f}$ é a freqüência angular de

vibração

f é a freqüência de oscilação do sistema

t é o tempo

$\varepsilon_{0}$ é a amplitude de deformação

$\phi$ é o ângulo de perda

J* é a flexibilidade complexa

$\varepsilon_{1}$ é a amplitude da componente $\varepsilon$ em fase com a tensão

$\varepsilon_{2}$ é amplitude da componente de

deformação $90^{\circ}$ fora da fase com a tensão

$J_{1}$ é a parte real da flexibilidade

$\mathbf{J}_{2}$ é a parte imaginária da flexibilidade

$\mathbf{M}^{*}$ é o módulo de elasticidade complexo

Jr é a flexibilidade relaxada

Ju é a flexibilidade não relaxada

$\Delta W$ é a energia dissipada no ciclo todo

W é a energia máxima armazenada

$\delta$ é uma constante chamada decremento

logarítmico

$\mathbf{Q}^{-1}$ é o atrito interno

$\tau$ é o tempo de relaxação

$\Delta$ é a intensidade de relaxação
E é a energia de ativação

k é constante de Boltzmann

$\mathrm{T}$ é a temperatura em $\mathrm{K}$

$\mathbf{Q}_{\mathbf{m}}{ }^{-1}$ é a máxima intensidade do atrito interno

$\mathbf{T}_{\mathbf{m}}$ é a temperatura correspondente a $\mathbf{Q}_{\mathbf{m}}{ }^{-1}$

$\mathbf{A}_{2}$ representa moléculas de um gás

diatômico

$K_{p}$ é a constante de equilíbrio da reação

$a_{\mathrm{A}}$ é a atividade química dos átomos gasosos dissolvidos

$\mathbf{P}_{\mathbf{A}_{2}}$ é a pressão parcial do gás

$\Delta G^{0}$ é a variação da energia de Gibbs.

$\boldsymbol{X}_{\mathrm{A}}$ é a concentração do gás

K (T) representa a constante de Sieverts, que depende da temperatura.

$\Delta \mathbf{S}^{0}$ é a entropia da reação

$\Delta \mathbf{H}^{0}$ é a entalpia da reação

$\mathbf{R}$ é a constante dos gases

D é o coeficiente de difusão

J é o fluxo do soluto

$\frac{d C}{d x}$ é o gradiente de concentração do

soluto

c $_{\text {s }}$ é a concentração de átomos na superfície do material

$\mathbf{c}_{0}$ é a concentração inicial de átomos no material 
$\mathbf{c}_{\mathrm{x}}$ é a concentração de átomos localizados a $x$ abaixo da superfície após um tempo $t$ erf é a função erro

L é o raio do cilindro ou esfera, ou ainda, a meia espessura da placa

Pé o peso de um corpo

m é massa do corpo no ar

g é aceleração da gravidade

$\mathbf{P}_{\text {Liq }}$ é o peso do corpo imerso no líquido;

$\mathbf{m}_{\text {liq }}$ é a massa do corpo imerso no líquido

$\mathbf{E}_{\mathbf{p}}$ é o empuxo

$\rho_{\text {Liq }}$ é a densidade do líquido;

V é o volume de líquido deslocado;

$\rho_{\text {obj }}$ é a densidade do corpo. n é um número inteiro positivo

$\lambda$ é o comprimento de onda

d é a distância interplanar

$\theta$ ângulo entre feixe de raios $\mathrm{X}$ incidente e o plano cristalino

$a$ parâmetro de rede para o sistema cúbico

$\mathbf{T}_{\max }$ é a temperatura máxima no qual o

metal é aquecido

$\mathbf{t}_{\mathbf{h}}$ tempo de permanência em $\mathbf{T}_{\max }$

$\mathbf{v}_{\mathbf{h}}$ velocidade de aquecimento

$\mathbf{v}_{\mathbf{c}}$ velocidade de resfriamento

$\Gamma$ é o período

$\mathbf{s}$ distância entre dois fotisensores

$c$ a concentração de oxigênio (\% p.) 


\section{CAPÍTULO I - INTRODUÇÃO}

Os fenômenos envolvendo gases em metais apresentam um grande interesse técnico e científico. Desde o século XIX existem relatos de trabalhos científicos nessa área, como por exemplo, a permeação do hidrogênio através do ferro. Os sistemas metal-oxigênio apresentam características interdisciplinares que envolvem pesquisadores de diversas áreas ${ }^{1}$.

As interações metal-gás são responsáveis por inúmeras mudanças nas propriedades químicas, físicas e mecânicas dos materiais. Entretanto, elementos como oxigênio, nitrogênio, carbono e hidrogênio são de particular interesse, pois podem estar presentes em fases condensadas ou dissolvidos intersticialmente em solução sólida na matriz, sendo que para o nosso trabalho consideraremos apenas o último caso.

Os metais de transição como nióbio, tântalo e suas ligas, são altamente reativos com o oxigênio e necessitam de uma tecnologia sofisticada para sua produção ${ }^{2}$. O interesse tecnológico no estudo de gases em metais possibilitou a descoberta de fenômenos envolvendo os sistemas metais-gases. Sabemos que a introdução de gases em um metal ou liga pode 
melhorar sua resistência ao desgaste. No entanto, a dissolução incontrolada destes gases pode piorar consideravelmente suas propriedades e sob certas condições causar uma total fragilização dos metais ${ }^{3,4}$.

A presença de elementos intersticiais, vacâncias e outras imperfeições na rede cristalina produzem um desvio na elasticidade perfeita, chamado anelasticidade ${ }^{5,6}$. Devido à anelasticidade, a resposta da deformação em relação a uma tensão aplicada, que no caso elástico é instantânea, será dependente do tempo e a dissipação de energia no sólido é chamada atrito interno.

Medidas de atrito interno têm sido usadas como uma rica fonte de informação a respeito do comportamento de elementos dissolvidos intersticialmente em solução sólida na matriz metálica. As medidas de atrito interno são obtidas em experimentos não destrutivos nos quais obtemos informações a respeito de difusão, concentração de soluto, interações entre solutos intersticiais e outras imperfeições de rede cristalina ${ }^{7-13}$.

$\mathrm{O}$ interesse na relaxação mecânica de átomos intersticiais, como $\mathrm{O}, \mathrm{N}$ e $\mathrm{C}$, em metais com estrutura cristalina cúbica de corpo centrado (CCC) iniciou-se com a publicação de um trabalho de Snoek ${ }^{6,7}$, no qual mostrou que os picos de atrito interno observados em ferro- $\alpha$ eram devido a carbono e nitrogênio presentes intersticialmente em solução sólida.

Alguns anos depois, Snoek postulou que os picos eram devido à reorientação induzida por tensão de átomos de intersticiais em torno de átomos da matriz metálica ${ }^{6,14,15}$. A partir deste postulado, esse efeito ficou conhecido como relaxação de Snoek ou pico de Snoek $^{15-17}$. Em metais com estrutura CCC os átomos de solutos intersticiais estão 
posicionados preferencialmente nos sítios octaedrais causando distorção local na rede com simetria tetragonal ${ }^{18,19}$.

Existem várias técnicas para se medir atrito interno, cada qual adequada para se obter diferentes tipos de informações. Por exemplo, utiliza-se a técnica de alta freqüência para obter informações a respeito de linhas de discordância e a técnica de baixa freqüência para investigar intersticiais ${ }^{14}$.

Experimentos em baixa frequiência são realizados utilizando um pêndulo de torção. $O$ princípio de medida é relativamente simples, a amostra é colocada a oscilar em seu modo fundamental, no nosso caso vibrações livres, o que causa dissipação de energia devido ao atrito interno. Essa dissipação de energia, no caso do pêndulo de torção, é medida através do decremento logarítmico que, a menos de uma constante, é o próprio atrito interno da amostra.

Atualmente o Brasil possui as maiores reservas mundiais de nióbio e tântalo. Segundo dados de 2001 do Departamento Nacional de Produção Mineral ${ }^{20}$, as reservas brasileiras de nióbio e tântalo, concentram respectivamente $90 \%$ e $50 \%$ das reservas mundiais. O país lidera a produção mundial de nióbio com quase $95 \%$, porém a produção de tântalo ainda é baixa.

O país é auto suficiente e um líder na produção mundial de nióbio, o que já não acontece com o tântalo. A produção brasileira de tântalo é muito baixa e as exportações são feitas na forma de concentrados de columbita e tantalita, sendo o país um importador de concentrados de tântalo e produtos industrializados. 
O nióbio é utilizado na fabricação de super ligas, na indústria nuclear e aeroespacial, bem como na fabricação de ligas para a aplicação em biomedicina. Ele se torna supercondutor a temperaturas muito baixas. O tântalo é utilizado em materiais cirúrgicos devido à sua excelente resistência a corrosão à temperatura ambiente e em componentes eletrônicos.

Em virtude do Brasil ser um exportador de minério e importador de produtos manufaturados a base de nióbio e tântalo, é muito importante o investimento em pesquisa e desenvolvimento de tecnologia tanto na área de produção quanto na área de processamento e utilização destes metais em produtos manufaturados. Do ponto de vista técnico - econômico é uma área estratégica já que o país possui as maiores reservas mundiais destes dois elementos.

Nióbio e tântalo possuem características importantes e muito bem exploradas pela indústria. Um levantamento experimental mostra que diversas características do nióbio puro são afetadas pela adição de impurezas ${ }^{21,22}$.

Ligas de Nb-Ta possibilitam, entre outras coisas, a obtenção de supercondutores com maior campo magnético crítico, levando a maiores densidades de correntes críticas $^{25}$. De modo que conhecer quais modificações elementos intersticiais causam nestas ligas é muito importante.

O tântalo tem sido escolhido como soluto substitucional ao nióbio devido a semelhanças existentes entre estes dois metais, possui mesma valência, parâmetro de rede com valores muito próximos e por formar solução sólida contínua $a^{21,23,24}$. A figura 1 mostra o diagrama de fase que comprova a solução sólida contínua. 


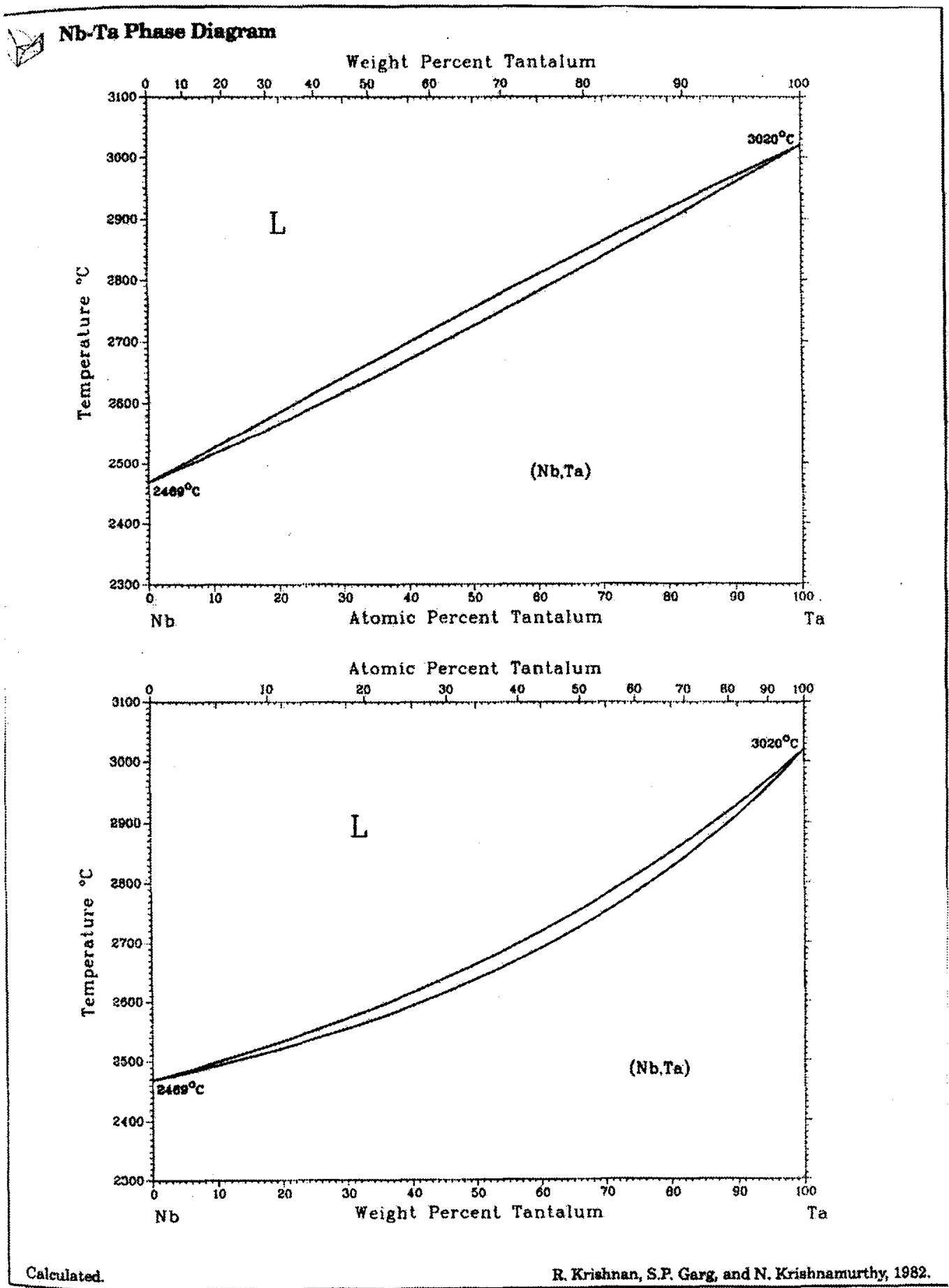

Figura 1 - Diagrama de fase $\mathrm{Nb}-\mathrm{Ta}$.

Este trabalho teve como objetivo principal o estudo do comportamento de elementos intersticiais presentes em solução sólida na matriz metálica da liga $\mathrm{Nb}-8,9 \%$ p.Ta utilizando técnicas de espectroscopia anelástica. Como complementação, foi realizado um trabalho de 
caracterização da amostra através de medidas de densidade, difração de raios $\mathrm{X}$ e análises químicas.

Esta dissertação foi estruturada em quatro partes. Na primeira parte são apresentados os fundamentos teóricos necessários à compreensão da relaxação anelástica devido a defeitos pontuais. Na segunda é feita uma abordagem sobre a interação metal-gás e os mecanismos de gaseificação. $\mathrm{Na}$ terceira parte é apresentada a parte experimental descrevendo todas as técnicas utilizadas para a caracterização das amostras e medidas de espectroscopia anelástica. Na quarta parte são apresentados os resultados obtidos e análise destes resultados, além das considerações finais e sugestões para trabalhos futuros. 


\section{CAPÍTULO II - FUNDAMENTOS TEÓRICOS}

\section{1. O Significado da Anelasticidade:}

Antes de se definir anelasticidade, é conveniente considerar o caso de um material elástico ideal, para o qual a Lei de Hooke define a relação entre a tensão $\sigma$ e a deformação $\varepsilon$, isto é $^{7}$ :

$$
\begin{aligned}
& \sigma=\mathrm{M} \varepsilon \\
& \varepsilon=\mathrm{J} \sigma
\end{aligned}
$$

com

$$
\mathrm{M}=\frac{1}{\mathrm{~J}}
$$

onde: $\mathrm{M}$ é o módulo de elasticidade e J é a flexibilidade do material. 
Existem três condições que definem um comportamento elástico ideal:

1) A resposta da deformação, para cada nível de tensão aplicada (ou vice-versa), tem um único valor de equilíbrio;

2) A resposta do equilíbrio é alcançada instantaneamente (veja que as equações (1) e (2) não contém a variável tempo);

3) Esta resposta é linear.

Se levantarmos a condição de instantaneidade e introduzirmos a variável tempo nas equações tem-se o caso conhecido como anelasticidade.

Uma breve definição de anelasticidade deve seguir os seguintes postulados:

1) Para cada tensão aplicada existe único valor de equilíbrio de deformação, ou vice-versa;

2) A resposta de equilíbrio é conseguida somente após uma passagem de tempo suficiente;

3) A relação tensão-deformação é linear.

O primeiro e o segundo postulados são meramente uma repetição das condições iniciais da elasticidade ideal, porém agora a volta ao estado normal será dependente do tempo. Note que a condição de linearidade não é quebrada, ou seja, se dobrarmos a tensão a cada instante de tempo, também a deformação será dobrada a cada instante de tempo.

Do ponto de vista termodinâmico devemos relembrar que uma substância termodinâmica é aquela que pode assumir uma sucessão contínua de estados de equilíbrio, em resposta a uma série de mudanças infinitesimais em uma variável externa. Como 
conseqüência, o primeiro postulado da anelasticidade envolvendo um único valor de equilíbrio na relação de tensão-deformação e a completa reversibilidade, é satisfeito por todo sólido termodinâmico.

O segundo postulado da anelasticidade, significa que, a resposta a uma mudança na força mecânica aplicada, necessitará de um certo tempo para que o equilíbrio seja atingido. Em geral, o auto-ajuste de um sistema termodinâmico para um novo estado de equilíbrio em resposta a uma mudança na variável externa é chamado de relaxação. Especificamente se a variável externa é mecânica os fenômenos são conhecidos como relaxações anelásticas.

A relaxação anelástica é o resultado de fenômenos termodinâmicos, os quais surgem da relação entre tensão e deformação por vias de certas variáveis internas as quais podem mudar para novos valores de equilíbrio, através de processos cinéticos como a difusão.

\section{2. Funções Resposta Quase-Estáticas:}

Um experimento onde a aplicação de tensão ou deformação é mantida constante por algum período de tempo é chamado de quase-estático. Sob tais condições, os materiais anelásticos apresentam fenômenos como "creep", efeito pós-elástico e relaxação da tensão. 


\section{3. Funções Resposta Dinâmicas:}

Os experimentos quase-estáticos são usados para obter informações sobre o comportamento dos materiais após períodos de tempo de muitos segundos. Para informações sobre o comportamento do material, em tempos curtos, experimentos dinâmicos são mais apropriados. Nestes experimentos, uma tensão (ou deformação) a qual é periódica no tempo, é imposta ao sistema e a diferença de fase da deformação em relação à tensão é determinada. $O$ comportamento do sistema é melhor descrito com o auxílio do uso da notação complexa, onde a tensão será escrita como:

$$
\sigma=\sigma_{0} \exp (\mathrm{i} \omega t)
$$

onde: $\sigma_{0}$ é a amplitude da tensão e $\omega=2 \pi f$ é a freqüência angular de vibração.

A linearidade da relação tensão-deformação garante que a deformação é periódica com mesma freqüência, portanto, expressa na forma:

$$
\varepsilon=\varepsilon_{0} \exp [\mathrm{i}(\omega \mathrm{t}-\phi)]
$$

onde: $\varepsilon_{0}$ é a amplitude de deformação e $\phi$ é o ângulo com que a deformação atrasa-se em relação à tensão, chamado de ângulo de perda. 
Para o caso de elasticidade ideal $\phi=0$ e a razão $\varepsilon / \sigma$ é a flexibilidade elástica do material. Para o caso de anelasticidade, $\phi$ não é zero. Deste modo, a razão $\varepsilon / \sigma$ é uma quantidade complexa chamada de flexibilidade complexa, $\mathrm{J}^{*}(\omega)$, e deve ser escrita em função de $\omega$ :

$$
\mathrm{J} *(\omega) \equiv \frac{\varepsilon}{\sigma}=|\mathrm{J}|(\omega) \exp [-\mathrm{i} \phi(\omega)]
$$

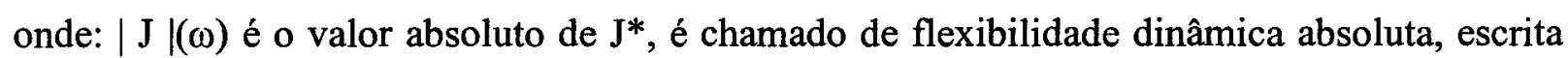
por:

$$
|\mathrm{J}|(\omega)=\varepsilon_{0} / \sigma_{0}
$$

Assim, pode-se substituir a eq. (5) pela forma:

$$
\varepsilon=\left(\varepsilon_{1}-i \varepsilon_{2}\right) \exp (i \omega t)
$$

onde: $\varepsilon_{1}$ é a amplitude da componente $\varepsilon$ em fase com a tensão e $\varepsilon_{2}$ é amplitude da componente de deformação $90^{\circ}$ fora da fase com a tensão.

Dividindo por $\sigma$, obtém-se:

$$
J *(\omega)=J_{1}(\omega)-i J_{2}(\omega)
$$


onde: $J_{1}(\omega)=\varepsilon_{1} / \sigma_{0}$ é a parte real de $J^{*}(\omega)$, chamada de alta flexibilidade e $J_{2}(\omega)=\varepsilon_{2} / \sigma_{0}$ é a parte imaginária de $\mathrm{J}^{*}(\omega)$, chamada de baixa flexibilidade.

A figura 2 mostra um digrama de fase entre $\mathrm{J}_{1}$ e $\mathrm{J}_{2}$. A partir deste diagrama, podemos obter as expressões para $|\mathrm{J}|$ e $\phi$ em relação a $\mathrm{J}_{1}$ e $\mathrm{J}_{2}$ :

$$
\begin{aligned}
& |\mathrm{J}|^{2}=\mathrm{J}_{1}{ }^{2}+\mathrm{J}_{2}{ }^{2} \\
& \tan \phi=\mathrm{J}_{2} / \mathrm{J}_{1}
\end{aligned}
$$

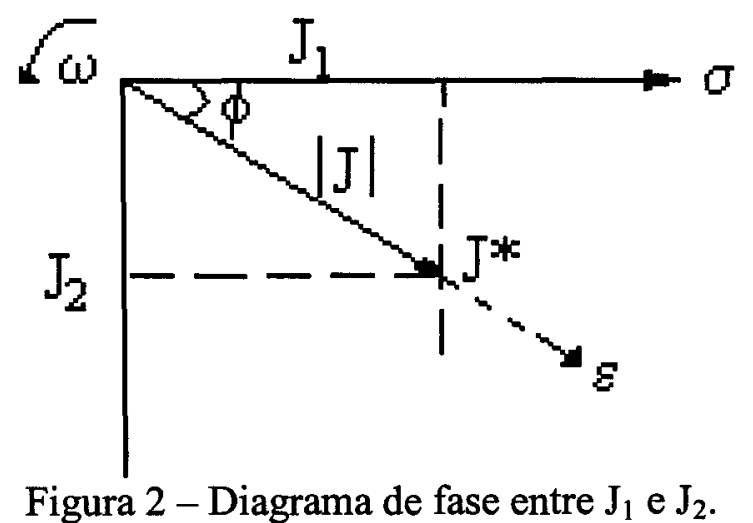

De modo similar ao da flexibilidade, considerando uma deformação periódica, define-se o módulo de elasticidade complexo $M^{*}(\omega)$, como:

$$
M^{*}(\omega) \equiv \sigma / \varepsilon=|M|(\omega) \exp [i \phi(\omega)]
$$

onde: | $\mathrm{M} \mid(\omega)$ é o valor absoluto $\mathrm{M}^{*}(\omega)$ é chamado de módulo de elasticidade dinâmico absoluto. 
Comparando as eq. (12) com (6), a flexibilidade complexa é recíproca do módulo de elasticidade complexo e que $|\mathrm{J}|(\omega)$ e $|\mathrm{M}|(\omega)$ também são, assim:

$$
\mathrm{M}^{*}(\omega)=\left[\mathrm{J}^{*}(\omega)\right]^{-1} \quad \text { e } \quad|\mathrm{J}|(\omega)=[|\mathrm{M}|(\omega)]^{-1}
$$

Podemos reescrever $M^{*}(\omega)$, substituindo pela forma:

$$
M^{*}(\omega)=M_{1}(\omega)+\mathrm{iM}_{2}(\omega)
$$

onde: $M_{1}(\omega)$ e $M_{2}(\omega)$ são, respectivamente, as partes reais e imaginárias de $M^{*}(\omega)$.

Comparando as equações (12) e (14), obtém-se:

$$
\begin{aligned}
& |\mathrm{M}|^{2}=\mathrm{M}_{1}^{2}+\mathrm{M}_{2}^{2} \\
& \tan \phi=\mathrm{M}_{2} / \mathrm{M}_{1}
\end{aligned}
$$

Comparando estes resultados com as eqs. (10) e (11) encontra-se $M_{2} / M_{1}=J_{2} / J_{1}$, assim:

$$
\mathrm{J}_{1}=\mathrm{M}_{1} /|\mathrm{M}|^{2}=\left[\mathrm{M}_{\mathrm{l}}\left(1+\tan ^{2} \phi\right)\right]^{-1}
$$

e

$$
\mathrm{J}_{2}=\mathrm{M}_{2} /|\mathrm{M}|^{2} \text { ou } \mathrm{M}_{2}=\mathrm{J}_{2} /|\mathrm{J}|^{2}
$$


Enquanto as quantidades complexas $\mathrm{J}^{*}(\omega)$ e $\mathrm{M}^{*}(\omega)$ são recíprocas, $\mathrm{J}_{1}$ não é recíproco de $\mathrm{M}_{1}$ e nem $\mathrm{J}_{2}$ é de $\mathrm{M}_{2}$.

Admitindo que $\phi^{2} \ll 1$, fazendo uma expansão em série de Taylor e desprezando termos maiores que $\phi^{2}$, obtemos $\tan \phi \approx \phi$. Usando esta aproximação, podemos concluir que:

$$
\mathrm{M}_{1}=|\mathrm{M}| \quad \text { e } \quad \mathrm{J}_{1}=|\mathrm{J}|
$$

$$
\mathrm{M}_{1}=\mathrm{J}_{1}^{-1}
$$

Assim as quantidades $M_{1}$ e $J_{1}$ são recíprocas para termos da ordem de $\phi^{2}$.

Para freqüências suficientemente baixas, a deformação será proporcional à tensão, com a flexibilidade relaxada proporcionalmente constante, então:

$$
\mathrm{J}^{*}(0)=1 / \mathrm{M}^{*}(0)=\mathrm{Jr}
$$

Para altas freqüências:

$$
\mathrm{J}^{*}(\infty)=1 / \mathrm{M}^{*}(\infty)=\mathrm{Ju}
$$


$\mathrm{O}$ significado das quantidades $\mathrm{J}_{1}$ e $\mathrm{J}_{2}$, "flexibilidade armazenada" e "flexibilidade perdida", respectivamente, é obtido calculando a energia armazenada e a energia dissipada em um ciclo de vibração. A energia por unidade de volume em qualquer fase do ciclo é $\int \sigma \mathrm{d} \varepsilon$, tomado os limites de integração com o início do ciclo e o ponto de interesse. A energia $\Delta \mathrm{W}$ dissipada no ciclo todo, por unidade de volume é dada por:

$$
\Delta \mathrm{W}=\oint \sigma \mathrm{d} \varepsilon=\pi \mathrm{J}_{2} \sigma_{0}^{2}
$$

A energia máxima $\mathrm{W}$, por unidade de volume é dada por:

$$
\mathrm{W}=\int_{\omega \tau=0}^{\pi / 2} \sigma \mathrm{d} \varepsilon=\frac{1}{2} \mathrm{~J}_{1} \sigma_{0}^{2}
$$

A razão entre a energia dissipada e a máxima armazenada é relacionada ao ângulo de perda $\phi$, por:

$$
\Delta \mathrm{W} / \mathrm{W}=2 \pi\left(\mathrm{J}_{2} / \mathrm{J}_{1}\right)=2 \pi \tan \phi
$$

Em razão de $\phi$ ser a média da perda de energia por ciclo, devido ao comportamento anelástico, esta quantidade $\phi$ é comumente conhecida como atrito interno do material.

Em geral um sistema ressonante deve ter dois elementos: o elemento elástico (que de fato deve ser anelástico) e a inércia. Para se medir o atrito interno é muito simples, uma 
amostra é posta a vibrar em seu estado natural, o que causa dissipação de energia na forma de calor devido ao atrito interno.

A situação é simplificada quando o sistema envolve um fio esticado por um peso, e posto a oscilar torsionalmente. Este é o caso do pêndulo de torção, no qual a deformação em qualquer ponto pode ser expressa em termos de um único parâmetro, o deslocamento angular da componente inercial. No caso do pêndulo de torção, o responsável pelo deslocamento é o torque associado a uma força externa aplicada.

\section{4. Vibrações Livres de um Sistema:}

O método mais usado para obter a resposta anelástica dinâmica envolve a medida do decaimento ou amortecimento das vibrações livres do sistema, o qual após a excitação é isolado de forças externas. A equação do movimento que descreve este caso é:

$$
\mathrm{m} \ddot{\mathrm{x}}+\mathrm{k}_{1}(1+\mathrm{i} \tan \phi) \mathrm{x}=0
$$

A solução que melhor descreve as vibrações livres de um sistema na presença de atrito interno é da forma:

$$
x=x_{0} \exp \left(i \omega^{*} t\right)
$$

onde: $\omega^{*}=\omega_{0}[1+(\mathrm{i} \delta / 2 \pi)]$ 
ou

$$
x=x_{0} \exp \left(-\delta f_{0} t\right) \exp \left(i \omega_{0} t\right) \equiv A(t) \exp \left(i \omega_{0} t\right)
$$

onde: $\mathrm{f}_{0}=\omega_{0} / 2 \pi$ é a freqüência de oscilação, $\delta$ é uma constante e $\mathrm{A}(\mathrm{t})$ é a amplitude.

Esta solução representa o decaimento exponencial das oscilações, se $\delta$ é pequeno. Quando esta solução é substituída na equação (26), e as partes real e imaginária são separadamente igualadas, obtém-se:

$$
\omega_{0}^{2}=\mathrm{k}_{1} / \mathrm{m}\left[1-\left(\delta^{2} / 4 \pi^{2}\right)\right]=\mathrm{k}_{1} / \mathrm{m}
$$

Enquanto

$$
\delta=\pi \phi
$$

A quantidade adimensional $\delta$, denominada decremento logarítmico, representa o logaritmo natural da razão das amplitudes $\left(A_{n}\right)$ em duas vibrações sucessivas:

$$
\delta=\frac{1}{N} \ln \left(\frac{A_{n}}{A_{n+1}}\right)
$$

O decremento logarítmico nos fornece uma medida do amortecimento das vibrações livres do sistema e em termos da eq. (30) é diretamente relacionado com a medida de atrito interno: 


$$
\mathrm{Q}^{-1}=\tan \phi \cong \phi=\left(\frac{\delta}{\pi}\right)=\frac{1}{\mathrm{~N} \pi} \ln \left(\frac{\mathrm{A}_{\mathrm{n}}}{\mathrm{A}_{\mathrm{n}+1}}\right)
$$

para pequenos valores de $\phi$.

\section{5. Modelos Mecânicos:}

Uma forma alternativa para se descrever o comportamento anelástico é em termos de um grupo de parâmetros os quais podem ser considerados atributos intrínsecos do material. $\mathrm{O}$ ponto inicial desta aproximação é relacionar tensão-deformação na forma de uma equação diferencial linear envolvendo tensão, deformação e suas dependências com o tempo.

A visualização do comportamento do material, governado por uma particular equação diferencial de tensão-deformação é auxiliado por um modelo mecânico apropriado. Esta equação diferencial capaz de representar a anelasticidade envolve três parâmetros independentes. Correspondentemente, o modelo equivalente é constituído de três elementos básicos (duas molas e um amortecedor). Um sólido anelástico padrão pode ser representado por este modelo.

\section{II.5.1. Equação Diferencial de Tensão-Deformação:}

A definição de anelasticidade envolve a necessidade de linearidade, ou seja, todas as equações diferenciais de tensão-deformação no caso da anelasticidade devem ser de primeira 
ordem. Assim, qualquer equação deve conter constantes independentes para descrever o comportamento anelástico de um sólido particular. A equação linear mais geral que contém coeficientes constantes, será da forma:

$$
a_{0} \sigma+a_{1} \sigma^{\prime}+a_{2} \sigma^{\prime \prime}+\ldots=b_{0} \varepsilon+b_{1} \varepsilon^{\prime}+b_{2} \varepsilon^{\prime \prime}+\ldots
$$

Para representar o caso específico de anelasticidade, necessitamos de uma única relação de equilíbrio entre tensão e deformação.

Quando os coeficientes $a_{0}$ e $b_{0}$ são diferentes de zero, tem-se o caso de corpo elástico ideal e o modelo mecânico apropriado é a mola convencional. A força sobre a mola representa a tensão, o deslocamento representa a deformação e a constante $\mathrm{k}$ da mola representa o módulo M. As principais características da mola são armazenar energia e reversibilidade, ou seja, retorna ao deslocamento zero quando a força é removida. Uma ou mais molas, portanto, constituem a parte essencial dos modelos mecânicos para representar o comportamento anelástico.

O segundo elemento, necessário para provocar atrito interno é um amortecedor Newtoniano, que consiste de um pistão movendo-se em um líquido com viscosidade ideal. $\mathrm{O}$ amortecedor fará com que a velocidade de movimento seja proporcional à aplicação da força. Em termos de tensão e deformação, tem-se $\sigma=\eta \varepsilon$, onde $\eta$ é a viscosidade do amortecedor.

Nos modelos formados, os elementos mecânicos são combinados em série ou paralelo. Na combinação em série de dois elementos, a tensão $\sigma_{1}$ e $\sigma_{2}$ são iguais enquanto que as deformações $\varepsilon_{1}$ e $\varepsilon_{2}$ são somadas, isto é: 


$$
\varepsilon=\varepsilon_{1}+\varepsilon_{2}, \quad \sigma=\sigma_{1}=\sigma_{2}
$$

Similarmente, para a combinação em paralelo dos elementos:

$$
\varepsilon=\varepsilon_{1}=\varepsilon_{2}, \quad \sigma=\sigma_{1}+\sigma_{2}
$$

Quando a combinação é constituída de uma mola e um amortecedor em paralelo, temos o chamado modelo de Voigt; e quando a combinação é constituída de uma mola e um amortecedor em série, temos o chamado modelo de Maxwell, conforme mostra a figura 3.

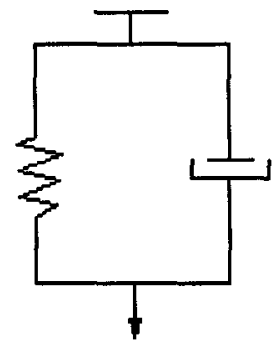

Modelo de Voigt

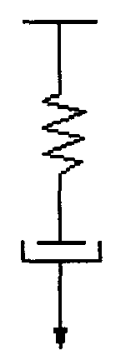

Modelo de Maxwell

Figura 3 - Modelos de Voigt e Maxwell para representar um sólido anelástico.

\section{II.5.2. Modelo de Voigt:}

No modelo de Voigt é conveniente descrever a mola contendo flexibilidade constante $\mathrm{J}$, enquanto que para simplificação dimensional é mais conveniente escrever a viscosidade $\eta$ do amortecedor como $\tau / J$. Deste modo tem-se dois parâmetros independente J e $\tau$, porém a 
constante $\tau$ tem dimensão de tempo. Neste modelo, quando a tensão $\sigma_{0}$ é aplicada em um tempo $\mathrm{t}=0$, o amortecedor não se deformará instantaneamente e esta tensão será toda sustentada pelo amortecedor em $\mathrm{t}=0$. Com o decorrer do tempo o amortecedor se deformará até $\mathrm{t} \rightarrow \infty$, ou o valor de equilíbrio, passando a mola sustentar toda tensão, pois estará deformada, tentando voltar ao seu estado normal. Quando a tensão é retirada, a mola instantaneamente exercerá uma força tentando voltar ao seu estado natural, sendo freada ou amortecida pelo amortecedor. No sentido de apresentar resultados mais quantitativos pode-se usar $\varepsilon_{1}=\mathrm{J} \sigma_{1}$ para a mola, e $\varepsilon_{2}^{\prime}=\mathrm{J} \sigma_{2} / \tau$ para o amortecedor. Usando o resultado da equação (46), elimina-se $\varepsilon_{1}, \varepsilon_{2}, \sigma_{1}$ e $\sigma_{2}$. Desta forma:

$$
\mathrm{J} \sigma=\varepsilon+\varepsilon^{\prime} \tau
$$

\section{II.5.3. Modelo de Maxwell:}

No modelo de Maxwell é conveniente representar a mola com módulo $\mathrm{M}$ e a viscosidade do amortecedor por $\eta=M \tau$. Neste caso quando uma tensão é aplicada no sistema, a mola sofrerá uma deformação instantânea, enquanto a deformação do amortecedor se dará de forma mais lenta até que ele se distenda por completo, ao contrário do primeiro modelo. Assim que a tensão é retirada a mola volta ao seu estado natural rapidamente, ao passo que o amortecedor não retornará ao seu estado inicial, continuará deformado. Com o auxílio da equação (34), tem-se que $\sigma_{1}=M \varepsilon_{1}$ e $\sigma_{2}=M \tau \varepsilon_{2}$, podendo ser rescrita na forma:

$$
\tau \sigma^{\prime}+\sigma=\tau M \varepsilon^{\prime}
$$




\section{II.5.4. O Modelo dos Três Parâmetros:}

Este modelo consiste em uma unidade de Voigt e uma mola acoplada em série, ou seja, terá duas molas e um amortecedor, sendo dispostos de forma que fique uma mola e o amortecedor combinados em paralelo (unidade de Voigt), e a outra mola acoplada em série com esta unidade, como pode ser visto na figura 4. Quando é aplicada uma tensão neste sistema, a mola que está acoplada em série com a unidade Voigt imediatamente se deforma, enquanto que na unidade de Voigt a deformação se dará de forma mais lenta devido à ação do amortecedor, até que a tensão seja totalmente transferida para a mola desta unidade. Assim que a tensão é retirada, a mola que está em série imediatamente retornará ao seu estado inicial e na unidade de Voigt, a mola fará com que a unidade volte ao seu estado inicial sendo amortecida pelo amortecedor.

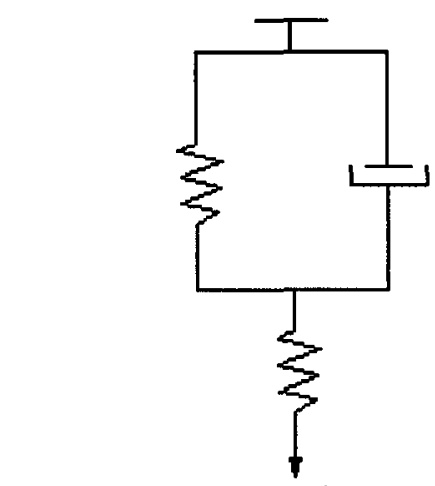

Figura 4 - Modelo dos Três Parâmetros.

\section{6. Propriedades Dinâmicas de um Sólido Anelástico Padrão:}

Para obter funções respostas dinâmicas $J_{1}$ e $J_{2}$ correspondentes à tensão periódica, partimos da definição de uma tensão e deformação que variem periodicamente com o tempo, 
dadas pelas equações (4) e (5). Relembrando que $J_{1}=\varepsilon_{1} / \sigma_{0}$ e $J_{2}=\varepsilon_{2} / \sigma_{0}$ e igualando separadamente as partes imaginária e real, obtêm-se as equações:

$$
\mathrm{Jr}=\mathrm{J}_{1}+\omega \tau_{\sigma} \mathrm{J}_{2}, \quad \omega \tau_{\sigma} \mathrm{Ju}=\omega \tau_{\sigma} \mathrm{J}_{1}-\mathrm{J}_{2}
$$

Quando estas equações são resolvidas para $\mathrm{J}_{1}$ e $\mathrm{J}_{2}$ obtemos:

$$
\begin{aligned}
& \mathrm{J}_{1}(\omega)=\mathrm{Ju}+\frac{\delta \mathrm{J}}{\left(1+\omega^{2} \tau_{\sigma}{ }^{2}\right)} \\
& \mathrm{J}_{2}(\omega)=\delta \mathrm{J} \frac{\omega \tau_{\sigma}}{\left(1+\omega^{2} \tau_{\sigma}{ }^{2}\right)}
\end{aligned}
$$

As equações (39) e (40) são chamadas equações de Debye.

A figura 5 mostra as curvas de $J_{1}$ e $J_{2}$ como função do logaritmo de $\omega \tau_{\sigma}$ mostrando uma comparação entre estas duas quantidades. 


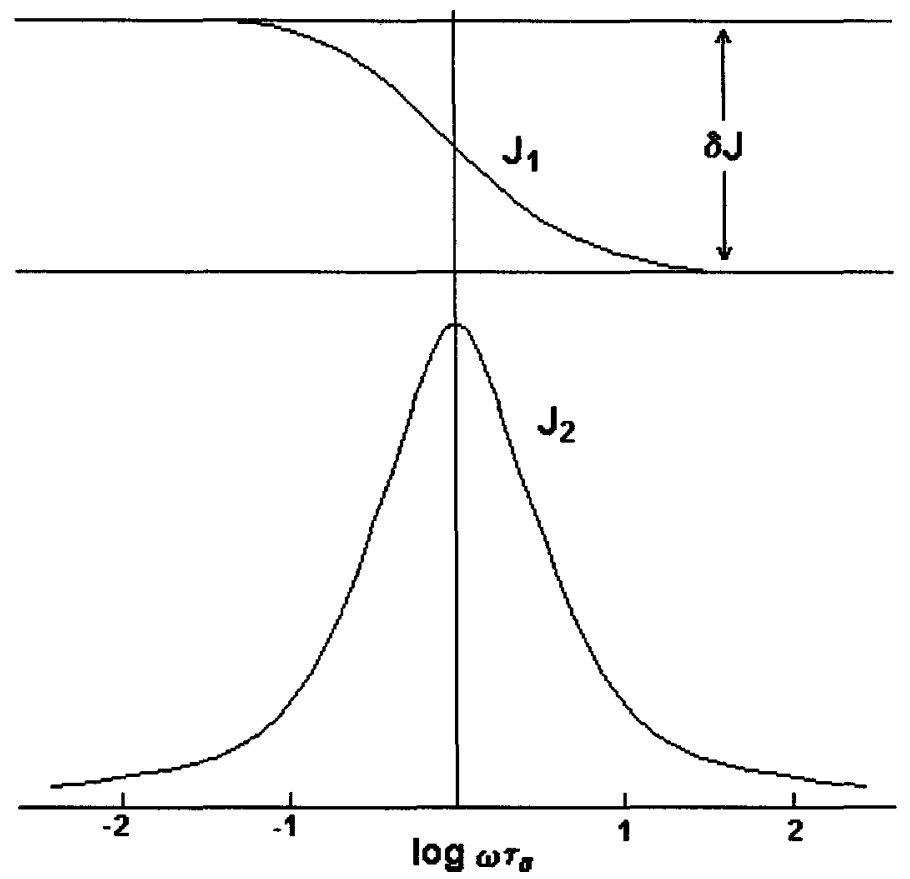

Figura 5 - Comparação entre $\mathrm{J}_{1}$ e $\mathrm{J}_{2}$ como função do logaritmo de $\omega \tau_{\sigma}$ para um sólido anelástico padrão.

O atrito interno e flexibilidade dinâmica absoluta $|\mathrm{J}|(\omega)$, podem ser descritos a partir das equações de Debye ${ }^{26}$. Expressões para estas duas grandezas são obtidas das equações (39) e (40) com o auxílio das relações $\tan \phi=\mathrm{J}_{2} / \mathrm{J}_{1}$ e $|\mathrm{J}|(\omega)=\left[\mathrm{J}_{1}{ }^{2}+\mathrm{J}_{2}{ }^{2}\right]^{1 / 2}$. Portanto, para um sólido anelástico ideal:

$$
\begin{aligned}
& \tan \phi=\frac{\mathrm{J}_{2}}{\mathrm{~J}_{1}}=\delta \mathrm{J} \frac{\omega \tau_{\sigma}}{\mathrm{Jr}+\mathrm{Ju} \omega^{2} \tau_{\sigma}^{2}} \\
& |\mathrm{~J}|(\omega)=\left[\mathrm{J}_{1}{ }^{2}+\mathrm{J}_{2}{ }^{2}\right]^{1 / 2}=\left(\frac{\mathrm{Jr}^{2}+\mathrm{Ju}^{2} \omega^{2} \tau_{\sigma}^{2}}{1+\omega^{2} \tau_{\sigma}^{2}}\right)^{1 / 2}
\end{aligned}
$$

No caso de um sólido anelástico padrão, $\phi(\omega)$ pode ser expresso sem qualquer aproximação através da intensidade de relaxação. Isto é feito rearranjando a expressão (41), substituindo $\tau_{\sigma}$ por $\tau$ ' o qual é definido como a média geométrica de $\tau_{\sigma}$ e $\tau_{\varepsilon}$, isto é: 


$$
\tau^{\prime} \equiv\left(\tau_{\sigma} \tau_{\varepsilon}\right)^{1 / 2}=\tau_{\sigma}(\mathrm{Ju} / \mathrm{Jr})^{1 / 2}=\tau_{\sigma} /(1+\Delta)^{1 / 2}=\tau_{\varepsilon}(1+\Delta)^{1 / 2}
$$

Portanto:

$$
\mathrm{Q}^{-1}=\tan \phi=\frac{\delta \mathrm{J}}{(\mathrm{Ju} \mathrm{Jr})^{1 / 2}} \frac{\omega \tau^{\prime}}{1+\omega^{2} \tau^{\prime 2}}=\frac{\Delta}{(1+\Delta)^{1 / 2}} \frac{\omega \tau^{\prime}}{1+\omega^{2} \tau^{\prime 2}}
$$

onde $\Delta=\delta \mathrm{J} / \mathrm{Ju}$ é cohecido como intensidade de relaxação. Para pequenos valores de intensidade de relaxação $\tau_{\sigma}$ e $\tau_{\varepsilon}$, são praticamente iguais de modo que:

$$
\mathrm{Q}^{-1}=\Delta \frac{\omega \tau}{1+(\omega \tau)^{2}}
$$

Os gráficos apresentados na figura 5 mostram as curvas das equações de Debye obtidas variando-se a freqüência, o que do ponto de vista experimental é muito complicado de se obter, pois é necessária uma variação muito grande da freqüência para obter o pico de Debye. Por isso, é mais prático e mais usual obter as curvas mantendo fixa a frequêencia e variando a temperatura e por se tratar de processos termicamente ativados é válida a Lei de Arrhenius:

$$
\tau=\tau_{0} \exp (\mathrm{E} / \mathrm{kT})
$$

onde: $\tau_{0}$ é o tempo de relaxação fundamental, $\mathrm{E}$ é a energia de ativação, $\mathrm{k}$ é constante de Boltzmann e $\mathrm{T}$ é a temperatura absoluta. 
Portanto, é possivel tratar as equações de Debye como função da temperatura substituindo a equação (46) nas equações (39) e (40) obtendo, para o atrito interno, a seguinte expressão:

$$
\mathrm{Q}^{-1}=\frac{\Delta}{2} \operatorname{sech}\left(\frac{\mathrm{E}}{\mathrm{k}}\left(\frac{1}{\mathrm{~T}_{\mathrm{m}}}-\frac{1}{\mathrm{~T}}\right)\right)
$$

Para reorientação induzida por tensão, $\Delta$ deve ser proporcional ao inverso da temperatura ${ }^{26}$ :

$$
\Delta \propto \frac{1}{\mathrm{~T}}
$$

Em uma boa aproximação, a constante de proporcionalidade pode ser substituída pela altura do pico, $\mathrm{Q}_{\mathrm{m}}^{-1}$ e a temperatura correspondente, $\mathrm{T}_{\mathrm{m}}$, de modo que obtemos a expressão $^{26,27}$ :

$$
\Delta=\frac{\mathrm{C}}{\mathrm{T}}=\frac{2 \mathrm{Q}_{\mathrm{m}}^{-1} \mathrm{~T}_{\mathrm{m}}}{\mathrm{T}}
$$

Substituindo a equação (49) na (47) obtemos:

$$
Q^{-1}=\frac{Q_{m}^{-1} T_{m}}{T} \operatorname{sech}\left(\frac{E}{k}\left(\frac{1}{T_{m}}-\frac{1}{T}\right)\right)
$$




\section{CAPÍTULO III - REAÇÃO METAL-GÁS}

Neste capítulo, são apresentados os aspectos mais relevantes dos mecanismos de reação metal-gás, fazendo uma abordagem geral destes mecanismos, dando um enfoque nos processos de gaseificação e desgaseificação.

\section{1. Aspectos Gerais da Reação Metal-Gás}

A presença de uma atmosfera gasosa é inevitável em qualquer processamento de um metal, desde a elaboração até sua utilização na forma de um produto final. A interação do metal com estes elementos gasosos é responsável por uma série de mudanças nas propriedades fisicas destes metais ${ }^{2,29}$. 
Os gases podem agir na superfície de um metal através de reações de oxidação, sulfetação, cloração, etc., ou podem dissolver-se no metal formando soluções sólidas ou líquidas, participando de reações químicas ou precipitando novas fases.

Em condições moderadas de pressão e temperatura, pode-se obter o equilíbrio entre uma fase gasosa, composta de um gás diatômico com moléculas de $\mathrm{A}_{2}$ e átomos $\mathrm{A}$, dissolvidos em um metal sólido ou líquido. Esta situação pode ser descrita por uma equação de reação do tipo' ${ }^{1}$

$$
\frac{1}{2} A_{2}(g) \Leftrightarrow A \quad(e m M e)
$$

onde: A representa $\mathrm{H}, \mathrm{N}$ ou $\mathrm{O}$ e $\mathrm{Me}$ o metal. A notação (em $\mathrm{Me}$ ) significa os átomos $\mathrm{A}$ dissolvidos no metal; (g) simboliza o estado gasoso.

A constante de equilíbrio $\mathrm{K}_{\mathrm{p}}$ para esta reação de dissolução é dada por:

$$
\mathrm{K}_{\mathrm{p}}=\frac{a_{\mathrm{A}}}{\sqrt{\mathrm{P}_{\mathrm{A}_{2}}}}=\exp \left(-\frac{\Delta \mathrm{G}^{0}}{\mathrm{RT}}\right)
$$

onde: $a_{\mathrm{A}}$ é a atividade química dos átomos gasosos dissolvidos,

$\mathrm{PA}_{2}$ é a pressão parcial do gás, $\Delta \mathrm{G}^{0}$ é a variação da energia de Gibbs.

Se um estado padrão henriano for escolhido para a atividade de A dissolvido e a solução for diluída, a concentração do gás é dada por ${ }^{1,2}$ : 


$$
X_{\mathrm{A}}=\sqrt{\mathrm{P}_{\mathrm{A}_{2}}} \mathrm{~K}(\mathrm{~T})
$$

onde: $\mathrm{K}(\mathrm{T})$ representa a constante de Sieverts, que depende da temperatura.

Utilizando a Segunda Lei da Termodinâmica, temos:

$$
X_{\mathrm{A}}=\sqrt{\mathrm{P}_{\mathrm{A}_{2}}} \cdot \exp \left(-\frac{\Delta \mathrm{H}^{0}-\mathrm{T} \Delta \mathrm{S}^{0}}{\mathrm{RT}}\right)
$$

onde: $\Delta S^{0}$ é a entropia da reação,

$\Delta \mathrm{H}^{0}$ é a entalpia da reação,

$\mathrm{R}$ é a constante dos gases.

\section{2. Mecanismo Gaseificação com Oxigênio e Nitrogênio}

O mecanismo de gaseificação com oxigênio e nitrogênio para a maioria dos metais refratários é o mesmo e sob certas condições de equilíbrio a reação é descrita pela equação $(51)^{2}$.

De um modo geral existem quatro etapas envolvidas nos processos de gaseificação com gases diatômicos: 
1. Transporte das moléculas diatômicas na fase gasosa para a superfície do metal, onde acontece uma adsorção física.

2. Dissociação das moléculas do gás na superfície do metal ocorrendo a chamada adsorção química.

3. Os átomos do gás penetram através da superficie do metal, superando a barreira de potencial da superfície.

4. Difusão dos átomos na rede cristalina.

A figura 6 mostra um diagrama das etapas do processo de gaseificação e desgaseificação com oxigênio e com nitrogênio. $O$ processo de gaseificação é o mesmo para os dois tipos de gases e segue as etapas descritas acima.

O processo de remoção de nitrogênio segue as mesmas etapas da gaseificação mas no sentido inverso. Já a remoção de oxigênio é diferente, pois sua eliminação acontece na forma de evaporação de óxidos voláteis que se formam na superfície do metal. Na figura 5 (a) são as etapas 5) e 6).

\section{3. Difusão}

Raramente um metal em sua forma pura é utilizado na prática. Usualmente uma mistura de dois ou mais elementos é produzida para obter as propriedades físicas e químicas desejadas $^{30}$, propriedades estas que podem ser alteradas pela introdução ou remoção de elementos gasosos nestes metais. 


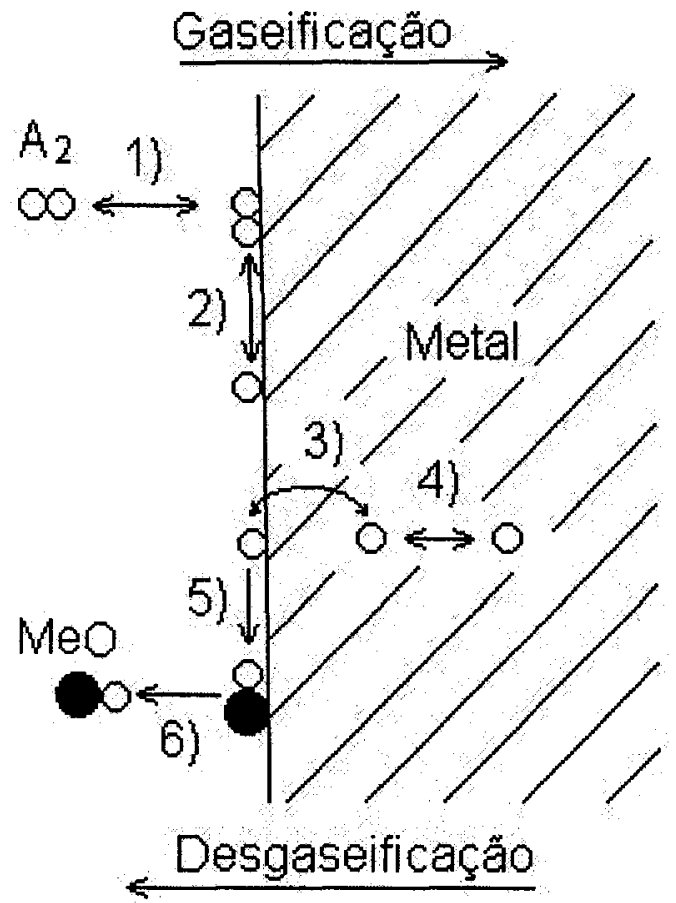

(a)

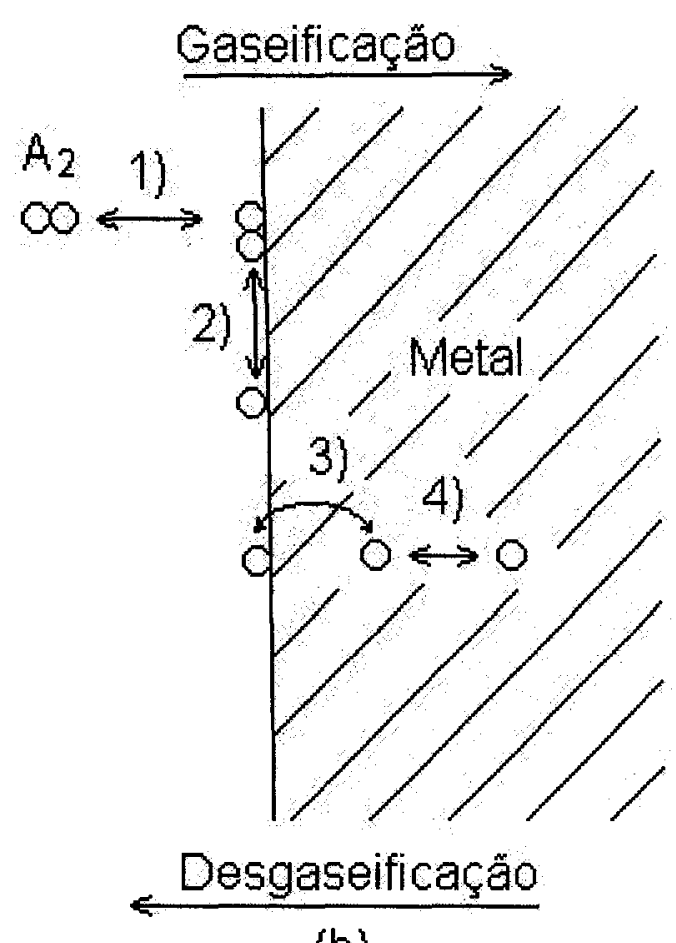

(b)

Figura 6 - Etapas do processo de gaseificação e desgaseificação: a) reação metal-oxigênio; b) reação metal-nitrogênio.

Difusão pode ser definida como sendo o mecanismo pelo qual matéria é transportada através de matéria ${ }^{31,32}$. Do ponto de vista macroscópico o coeficiente de difusão (D) do soluto é o coeficiente de proporcionalidade entre o fluxo (J) do soluto e o gradiente de concentração $\left(\frac{d C}{d x}\right)$ do mesmo, ou seja:

$$
J=-D \frac{d C}{d x}
$$

A equação (55) é denominada primeira de Lei de Fick (unidimensional), que relaciona o fluxo de soluto com o gradiente de concentração do mesmo, porém na aplicação da difusão aos processos técnicos é importante determinar a velocidade ou tempo destes processos, o que pode ser estabelecido resolvendo a segunda Lei de Fick: 


$$
\frac{d C}{d x}=D \frac{d^{2} C}{d x^{2}}
$$

A solução desta equação depende das condições de contorno para uma situação particular. Uma solução é ${ }^{33}$ :

$$
\frac{c_{s}-c_{x}}{c_{s}-c_{0}}=\operatorname{erf}\left(\frac{x}{2 \sqrt{D t}}\right)
$$

onde: $c_{s}$ é a concentração de átomos na superfície do material,

$\mathrm{c}_{0}$ é a concentração inicial de átomos no material,

$c_{\mathrm{x}}$ é a concentração de átomos localizados a $\mathbf{x}$ abaixo da superfície após um tempo t, erf é a função erro.

Para se atingir uma distribuição homogênea de concentração numa dada peça em forma de placa, cilindro ou esfera, a solução da segunda Lei de Fick para a difusão leva a valores de tempo $t$, descritos aproximadamente por $^{1,29,34}$ :

$$
\mathrm{t} \approx \frac{\mathrm{L}^{2}}{\mathrm{D}}
$$

Onde: L é o raio do cilindro ou esfera, ou ainda a meia espessura do placa.

A equação (58) relaciona o fator geométrico com o coeficiente de difusão, estimando o tempo necessário para o processo de difusão. 


\section{CAPÍTULO IV - PARTE EXPERIMENTAL}

Neste capítulo, são descritas as técnicas e procedimentos utilizadas para a caracterização das amostras bem como a técnica de medida do atrito interno utilizando o pêndulo de torção.

As amostras utilizadas neste trabalho constituem policristais da liga de $\mathrm{Nb}-\mathrm{Ta}$ com aproximadamente $8,9 \%$ em peso de tântalo, produzidas pela Faculdade de Engenharia Química de Lorena (FAENQUIL). As amostras foram produzidas por fusão em feixe eletrônico de cavacos de nióbio e tântalo de alta pureza, logo após feito um forjamento rotativo obtendo um fio cilíndrico ${ }^{25}$. 


\section{1. Densidade}

O método utilizado para se medir a densidade da amostra foi o Princípio de Arquimedes, que decorre do fato que todo corpo sólido quando imerso parcial ou totalmente em um líquido, recebe deste líquido um empuxo cujo módulo é igual ao peso do líquido deslocado pelo corpo ${ }^{35,36}$.

O peso de um corpo qualquer é:

$$
\mathrm{P}=\mathrm{mg}
$$

onde: $\mathrm{m}$ é massa do corpo no ar e g é aceleração da gravidade.

Quando o corpo é imerso no líquido a resultante das forças agindo no corpo será dado pela seguinte expressão:

$$
P=P_{\text {Liq }}+E
$$

Com

$$
\begin{aligned}
& \mathrm{P}_{\mathrm{Liq}}=\mathrm{m}_{\text {liq }} \mathrm{g} \\
& \mathrm{E}=\mathrm{g} \rho_{\text {Liq }} \mathrm{V} \\
& \mathrm{V}=\frac{\mathrm{m}}{\rho_{o b j}}
\end{aligned}
$$

onde: $\mathrm{P}_{\text {Liq }}$ é o peso do corpo imerso no líquido;

$\mathrm{m}_{\text {liq }}$ é a massa do corpo imerso no líquido; 
$\mathrm{E}_{\mathrm{p}}$ é o empuxo, $\rho_{\mathrm{Liq}}$ é a densidade do líquido;

V é o volume de líquido deslocado;

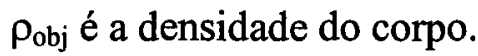

Assim, substituindo as equações (59), (61), (62) e (63), na equação (60) e rescrevendo-a, obtemos:

$$
\rho_{o b j}=\frac{\mathrm{m}}{\left(\mathrm{m}-\mathrm{m}_{\mathrm{liq}}\right)} \rho_{L i q}
$$

Essa equação nos fornece a densidade de um corpo sólido utilizando a massa do objeto medida no ar e imerso em um líquido e a densidade deste líquido.

Para efetuar as medidas de densidade foram utilizados uma balança analítica modelo Explorer da Ohaus Corporation e o seu "Kit" de determinação de densidade.

As medidas de densidade foram efetuadas seguindo os seguintes procedimentos: primeiro mede-se a massa do corpo no ar e após mede-se, com o auxílio de um béquer contendo água destilada e o "Kit" de medida de densidade, a massa do corpo imerso na água. Este procedimento é repetido várias vezes visando minimizar os erros. A densidade da amostra é obtida através da equação (64). 


\section{2. Difração de Raios $X$}

Os raios X foram descobertos em 1895 pelo físico alemão Roentgen e o nome se deve à sua natureza desconhecida naquele tempo. Diferente da luz visível, estes raios são invisíveis, mas viajam em linha reta e afetam filmes fotográficos do mesmo modo que outros tipos de radiação ${ }^{37}$.

Conhecemos hoje que os raios X são radiações eletromagnéticas de mesma natureza que a luz, mas com comprimento de onda muito curto da ordem de angstron ( $\AA$ ). Os raios X utilizados na difração têm comprimento de onda de aproximadamente $0,5-2,5 \AA$, portanto, os raios X ocupam a região entre os raios gama e ultravioleta.

Os raios $\mathrm{X}$ têm grande uso na vida moderna. Além do seu emprego nas radiografias, seu poder de penetração é muito útil também na verificação da qualidade e localização de defeitos estruturais em peças e materiais, no estudo da estrutura cristalina da matéria, inclusive a do DNA, na indústria e em quase todos os campos da ciência e da tecnologia.

Uma das técnicas mais utilizadas no estudo da estrutura de materiais é a difração de raios $\mathrm{X}(\mathrm{DRX})$. No difratômetro a intensidade do feixe difratado é medida diretamente por um contador eletrônico. Existem muitos tipos de contadores, mas todos convertem raios X que entram como ondas ou pulsos de corrente elétrica no circuito conectado ao contador. Este circuito conta o número pulsos de corrente por unidade de tempo, e este número é diretamente proporcional à intensidade do feixe de raios $\mathrm{X}$ entrando no contador ${ }^{37}$. 
Um difratômetro é projetado semelhante à câmara de Debye - Scherrer, exceto por um contador móvel substituindo o filme. A figura 7 mostra um diagrama esquemático do difratômetro de raios $X$.

Bragg (1913), Foi quem primeiro mostrou que o processo de espalhamento o qual conduz a difração pode igualmente ser visualizado como se os raios $\mathrm{X}$ estivessem refletindo em planos imaginários definidos pelos índices de Miller.

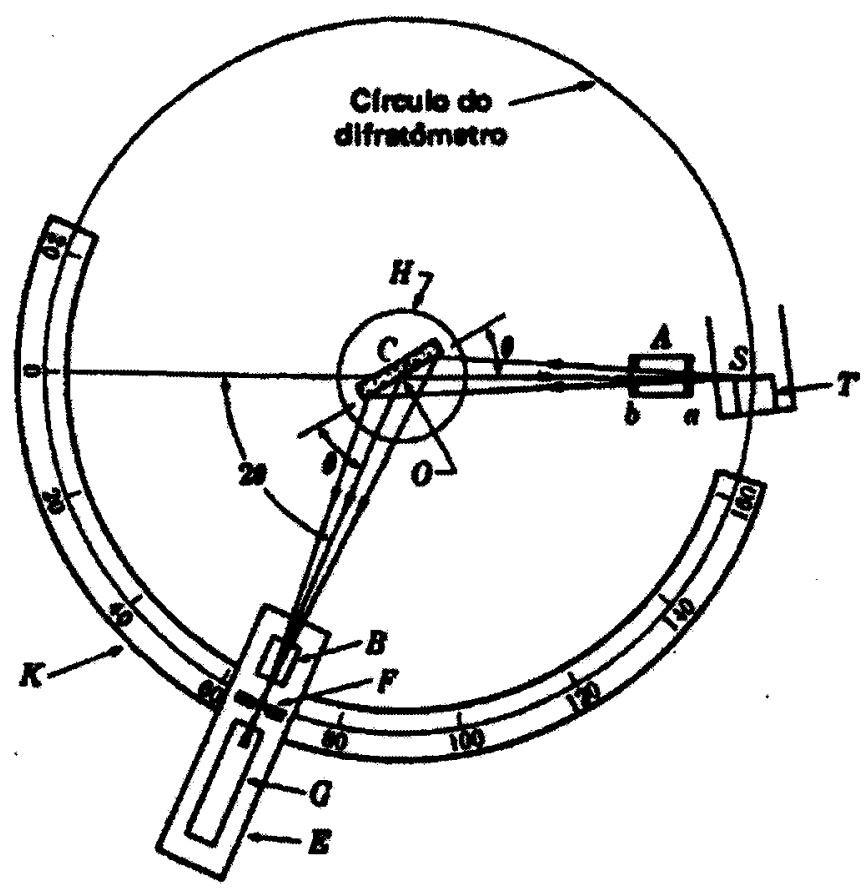

Figura 7 - Diagrama esquemático do difratômetro de raios $\mathrm{X}$.

A radiação utilizada tanto na câmara de Debye-Scherrer quanto no difratômetro é essencialmente monocromática, e o detector de raios $\mathrm{X}$ está localizado em uma circunferência centrada na amostra. A amostra é colocada em $\mathrm{C}$ sobre um suporte $\mathrm{H}$, o qual pode rotacionar em torno do eixo $\mathrm{O}$ perpendicular ao plano da figura, como mostra a figura 7 . Os raios $\mathrm{X}$ divergem da fonte que está em $\mathrm{S}$ e são difratados pela amostra para formar um feixe convergente difratado que é focado na fenda $F$ e então entra no contador $G$. A e B são fendas 
especiais que colimam os feixes incidente e difratado. A fonte e o contador podem se mover sobre o círculo do difratômetro onde existe uma escala graduada $\mathrm{K}$.

A figura 8 mostra os raios $\mathrm{X}$ chocando-se contra um grupo de planos atômicos com índices (hkl), com ângulo $\theta$ entre o feixe incidente e os planos. A distância entre os planos é $\mathrm{d}_{\mathrm{hkl}}$ e considerando que os átomos localizados nos planos agem com fonte de espalhamento, a distância $d_{h k l}$ é o espaçamento interatômico. Olhando somente para os feixes 1 e 2 nota-se que o feixe 2 tem que viajar uma distância $A B C$ a mais que o feixe 1 . Se os feixes iniciam em fase, então a distância $\mathrm{ABC}$ fará com que o feixe 2 esteja desalinhado com 1 após a reflexão. Uma interferência construtiva ocorrerá quando as duas ondas refletirem em fase, ou quando $\mathrm{ABC}=1 \lambda$ ou $2 \lambda$ ou $3 \lambda$, ou de forma mais geral ${ }^{37}$.

$$
\mathrm{n} \lambda=\mathrm{ABC}
$$

onde: n é um número inteiro positivo,

$\lambda$ é o comprimento de onda.

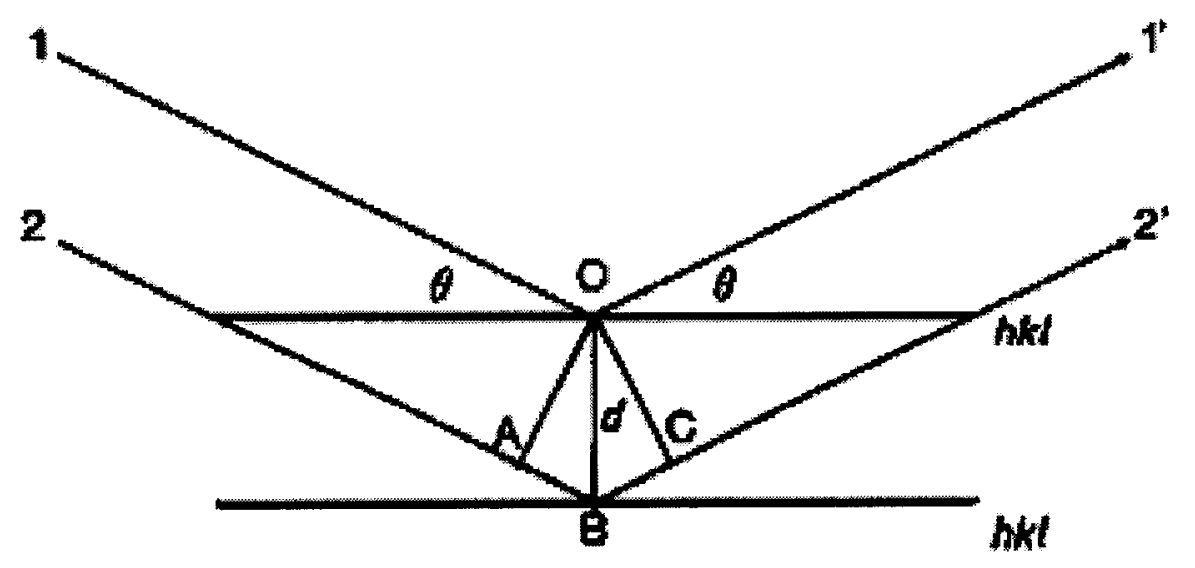

Figura 8 - Difração de raios X nos planos cristalinos. 
Pela figura 8 nota-se que $A B=d \sin \theta$, ou $A B C=2 d \sin \theta$, assim a condição para a difração ocorrer é:

$$
\mathrm{n} \lambda=2 \mathrm{~d} \sin \theta
$$

Essa equação relaciona a distância entre os grupos de planos em um cristal e o ângulo com o qual estes planos difratam os raios $\mathrm{X}$ de um comprimento de onda particular. Usualmente é mais conveniente dividir ambos os lado da equação por $\mathrm{n}$ e definir $\mathrm{d} / \mathrm{n}$ como $\mathrm{d}_{\mathrm{hkl}}$, assim a equação de Bragg fica da forma:

$$
\lambda=2 \mathrm{~d}_{\mathrm{hkl}} \sin \theta
$$

A Lei de Bragg nos permite conhecendo $\lambda$ e medindo $\theta$ calcular $\mathrm{d}_{\mathrm{hkl}}$ e descobrir as dimensões da cela unitária. A relação entre o parâmetro de rede $(a)$ do sistema cúbico e a distância interplanar é dada pela seguinte expressão ${ }^{37,38}$ :

$$
\mathrm{d}_{\mathrm{hkl}}=\frac{a}{\sqrt{\mathrm{h}^{2}+\mathrm{k}^{2}+1^{2}}}
$$

Os difratogramas de raios $\mathrm{X}$ apresentados nesta dissertação foram efetuados em um difratômetro Rigaku D/max-2100PC controlado por um microcomputador e os dados coletados automaticamente. A radiação utilizada foi a $\mathrm{K}_{\alpha}$ do cobre com comprimento de onda $\lambda=1,544 \AA^{37}$. 


\section{3. Tratamentos Térmicos}

As regras de tratamento térmico na engenharia moderna não podem ser superestimadas. As mudanças nas propriedades dos metais devido ao tratamento térmico são extremamente significantes ${ }^{39}$.

A proposta de qualquer processo de tratamento térmico é produzir a mudança desejável na estrutura do metal pelo aquecimento a uma temperatura especificada e por um subseqüente resfriamento ${ }^{39}$.

Os principais fatores que agem no tratamento térmico são temperatura e tempo, de modo que esse processo pode ser representado em coordenadas temperatura e tempo (T- t).

As condições do tratamento térmico são caracterizadas pelos seguintes parâmetros: temperatura de aquecimento $\mathrm{T}_{\max }$, isto é, a temperatura máxima no qual o metal é aquecido, tempo de permanência na temperatura de aquecimento $t_{h}$, velocidade de aquecimento $\mathrm{v}_{\mathrm{h}} \mathrm{e}$ velocidade de resfriamento $\mathrm{v}_{\mathrm{c}}$.

Para mudar as propriedades de uma liga é essencial que o tratamento térmico produza certas mudanças na sua estrutura resultando das transformações de fase. Se o metal está em um estado estruturalmente instável, o aquecimento pode aumentar a mobilidade dos átomos e o metal aproximará de um estado de equilíbrio no qual o tratamento térmico será possivel sem transformações de fase. 
Existem vários tipos de tratamentos térmicos, dentre os quais quatro são principais:

- Recozimento de primeira ordem, que é o tratamento que consiste no aquecimento de um metal que está em um estado instável devido a um tratamento anterior, trabalhado a frio, por exemplo. Este tratamento muda o metal para um estado de maior estabilidade.

- Recozimento de segunda ordem, que é o tratamento no qual o metal é aquecido acima da temperatura de transformação de fase e então resfriado lentamente para obter um estado estruturalmente estável. Neste tratamento há uma recristalização.

- Têmpera, que é um tratamento no qual o metal é aquecido acima da temperatura de transformação de fase e então resfriado rapidamente obtendo um estado estruturalmente instável.

- Revenimento, que é o tratamento térmico no qual o metal endurecido é aquecido a uma temperatura abaixo da temperatura de transformação de fase para obter um metal com um estado estrutural mais estável.

A figura 9 mostra um diagrama esquemático do sistema de tratamento térmico e dopagem de amostra que foi utilizado para a realização das dopagens com oxigênio e recozimento das amostras utilizadas neste trabalho.

A preparação do sistema para a realização dos tratamentos é simples, a amostra é colocada em um aparador que está localizado na extremidade do posicionador magnético através da câmara de colocação de amostra que é então fechada e onde é feito vácuo com a 
bomba turbomolecular até que o sensor $S_{1}$ atinja $10^{-5}$ Torr, mantendo as válvulas $V_{1}$ e $V_{3}$ fechadas. Após alcançado o vácuo fecha-se $V_{2}$ e abre-se $V_{3}$ e $V_{4}$ para a passagem da amostra que é levada para dentro do tubo de quartzo pelo posicionador magnético, assim que a amostra é posicionada, volta-se o posicionador para a posição inicial e fecha-se $\mathrm{V}_{3}$ e abre-se $\mathrm{V}_{1}$ para que seja feito vácuo com a bomba turbomolecular dentro do tubo de quartzo até que os sensores $S_{1}$ e $S_{2}$ estejam marcando uma pressão da ordem de $10^{-7}$ Torr.

Logo depois dessa preparação e tendo os sensores $S_{1}$ e $S_{2}$ alcançado um vácuo da ordem de $10^{-7}$ Torr é ligada bomba iônica para que o seja feito ultra-alto vácuo no sistema, de modo que $S_{3}$ atinja $10^{-9}$ Torr. Assim que o sistema alcance essa ordem de pressão é ligado o Analisador de Gases Residuais (RGA), para que seja feita uma análise da atmosfera dentro do tubo. Em seguida é levado o forno para o aquecimento, que nos permite estabelecer a taxa de aquecimento, temperatura máxima e tempo de permanência nessa temperatura, bem como a taxa de resfriamento para o caso do tratamento térmico. Durante o processo de queima é feita a análise de gases com o RGA, a fim de determinar qualitativamente quais elementos poderiam ter saído da amostra.

Para a dopagem de amostras o procedimento é um pouco diferente, é determinada a taxa de aquecimento, a temperatura máxima e o tempo de permanência, porém quando atingida a temperatura máxima $\mathrm{V}_{4}$ é fechada e a bomba iônica e o RGA são desligados e então é introduzido o gás (oxigênio ou nitrogênio), com uma pressão parcial controlada pelo sensor $\mathrm{S}_{4}$ que foi "zerado" antes de introduzir o gás. Depois de decorrido o tempo de permanência na temperatura máxima o sistema é resfriado a uma taxa determinada. 


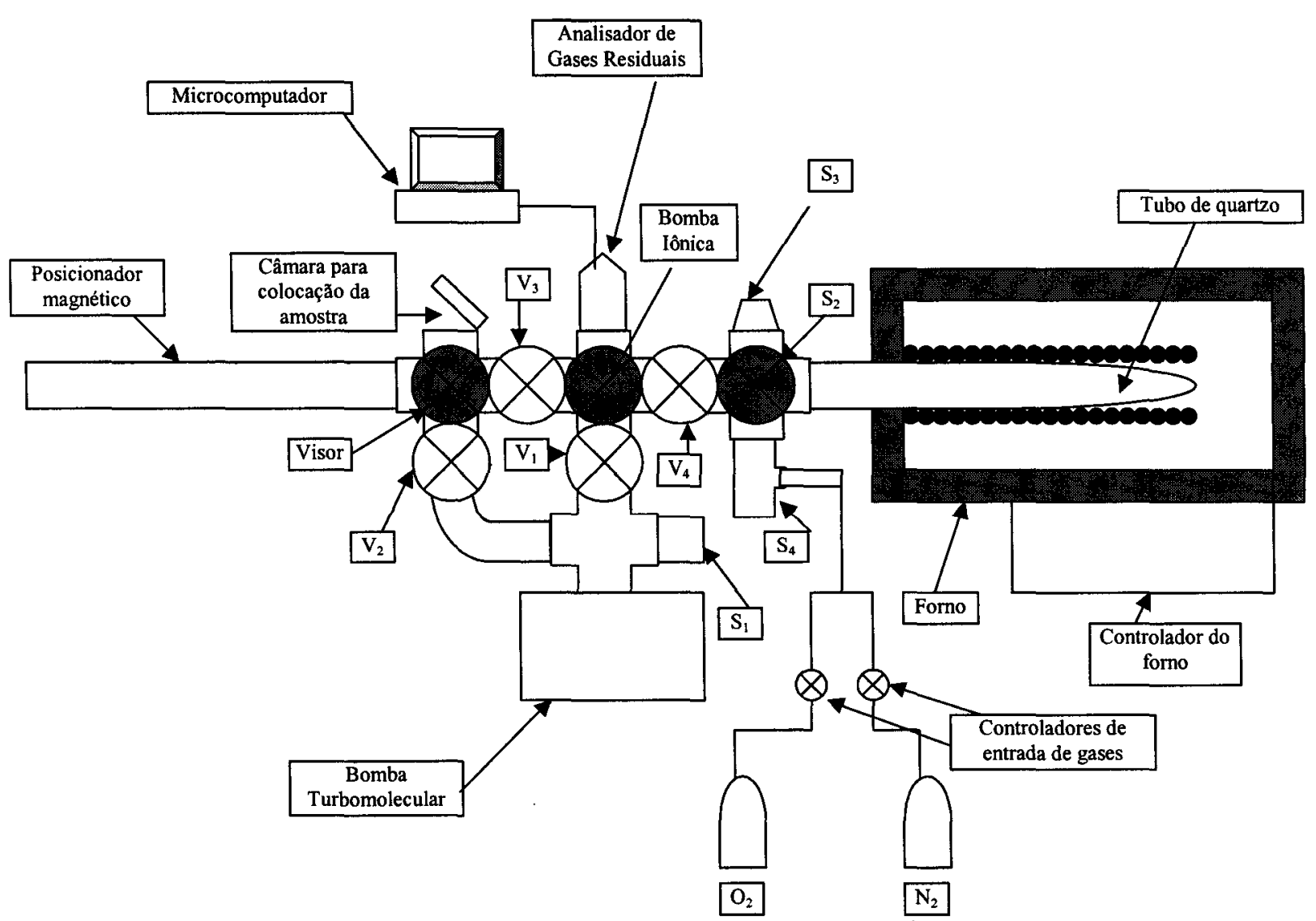

Figura 9 - Diagrama esquemático do sistema de tratamentos térmicos e dopagem de amostra.

\section{4. Atrito Interno}

Para se realizar as medidas de atrito interno, a técnica utilizada foi a de baixa frequiência, isto é, a técnica do Pêndulo de Torção. A figura 10 mostra um diagrama de corte do pêndulo.

Para melhor explicar o sistema, este foi dividido em quatro partes:

- Sistema Criogênico: consiste num criostato construído em aço inoxidável, contendo em seu interior um reservatório para nitrogênio líquido com capacidade para cinco litros. 
- Pêndulo de Torção: constitui na principal ferramenta de medida de atrito interno. É constituído pelo suporte da amostra, barra de conexão, barra de inércia e contrapeso.

- Acionamento e Coleta de Dados: foram colocados dois eletroímãs, um em cada lado da barra de inércia, os quais servem para dar o torque inicial ao pêndulo. Esses eletroímãs são acionados através de uma fonte externa. A coleta de dados é feita através de uma interface acionada por um computador. Esta interface está conectada a dois fotosensores que são acionados pelo feixe do laser que é refletido por um espelho colocado na haste do pêndulo. Esta interface possibilita fazer, rapidamente, medidas do tempo e freqüência de cada oscilação.

- Sistema de aquecimento: é constituído de um forno de resistência, sendo alimentado por uma tensão alternada e com a corrente elétrica sendo controlada por um transformador de tensão variável. A temperatura na amostra é medida com auxílio de um termopar ligado a um multímetro digital.

Para se efetuar as medidas, a amostra é colocada na parte inferior do pêndulo, dentro do sistema criogênico, presa por dois mandris. Na parte superior do pêndulo, os eletroímãs localizados na barra de inércia, presa à haste central do pêndulo, são acionados pela fonte externa, tirando o sistema de seu estado de equilíbrio, pondo-o a oscilar.

Para evitar que a amostra seja contaminada, as medidas são efetuadas em vácuo melhor que $10^{-5}$ Torr. Este vácuo é obtido através de um sistema de bombeamento composto por uma bomba mecânica e uma bomba difusora. 
A temperatura é medida por um termopar de cobre-constantan com referência no gelo. Para variar a temperatura da amostra, utilizamos um forno de resistência cuja potência é ajustada através de um transformador regulável. As temperaturas usadas estão na faixa de 300 e $700 \mathrm{~K}$, porém, com o auxílio da câmara criogênica pode-se fazer medidas num intervalo de temperatura compreendida entre 100 e $700 \mathrm{~K}$.

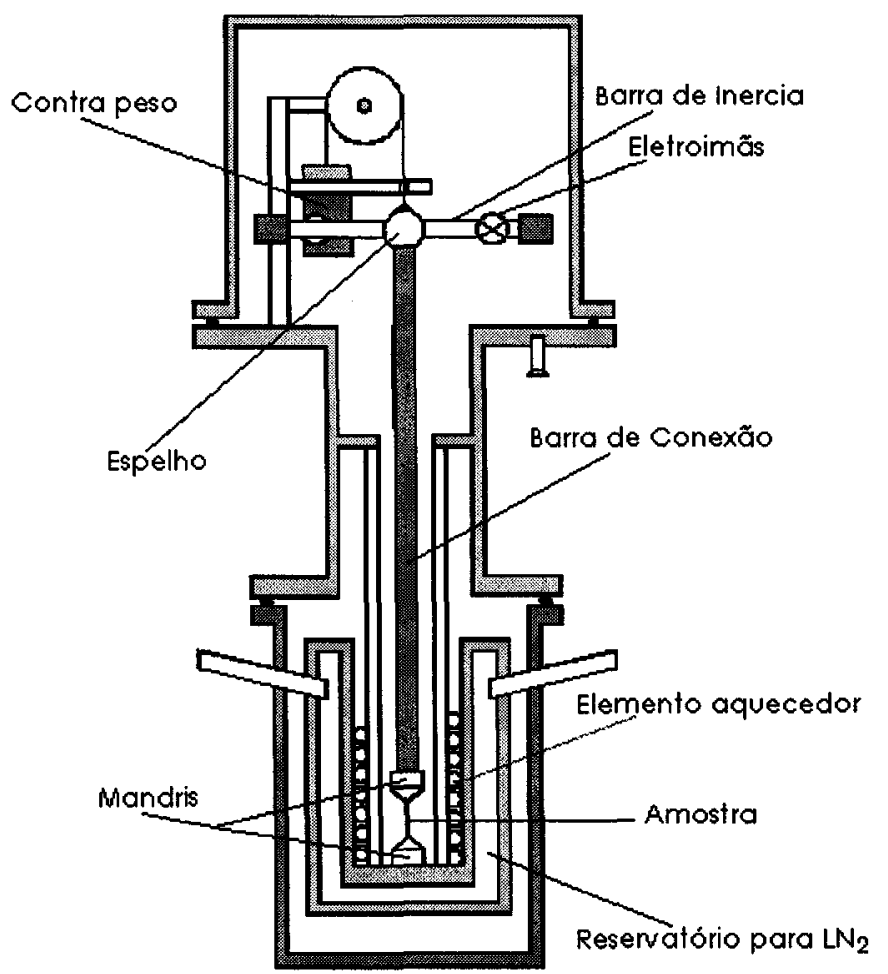

Figura 10 - Diagrama de corte do Pêndulo de Torção.

O princípio utilizado para medir o decremento logarítmico foi o método das velocidades.

Um oscilador harmônico simples com amortecimento é descrito por ${ }^{40}$ :

$$
\frac{\mathrm{d}^{2} \mathrm{x}}{\mathrm{dt}^{2}}+2 \mathrm{k} \frac{\mathrm{dx}}{\mathrm{dt}}+\omega_{0} \mathrm{x}=0
$$


onde: $\mathrm{k}$ representa $\mathrm{o}$ amortecimento, $\omega_{0}=2 \pi \mathrm{f}$; $\mathrm{f}$ é a freqüência de natural de oscilação sem amortecimento.

Quando $\mathrm{x}=0$ a $\mathrm{t}=0$ a solução da equação (69) será:

$$
x=A e^{-k t} \sin \omega t
$$

onde: $\omega=\omega_{0}\left(1-\frac{\mathrm{k}^{2}}{\omega_{0}^{2}}\right)^{\frac{1}{2}}$

O decremento logarítmico é dado por:

$$
\delta=\mathrm{k} \Gamma=\pi \mathrm{Q}^{-1}
$$

onde: $\Gamma$ é o período.

$\mathrm{O}$ atrito interno $\left(\mathrm{Q}^{-1}\right)$ normalmente é determinado tomando o número de oscilações (N) para a amplitude decair de $\mathrm{x}_{1}$ para $\mathrm{x}_{2}$. Assim:

$$
\delta=\frac{1}{\mathrm{~N}} \ln \left(\frac{\mathrm{x}_{1}}{\mathrm{x}_{2}}\right)
$$

O decremento logarítmico, $\delta$, também pode ser obtido da medida de velocidade a deslocamento zero ao invés de deslocamento a velocidade zero. Em $\mathrm{x}=0, \mathrm{v}=\dot{\mathrm{x}}=\omega \mathrm{A} \mathrm{e}^{-\mathrm{kt}}$. 
Medindo $v_{0}$ a $t=0$ e $v_{n}$ a $t=n \tau$, teremos:

$$
\delta=\frac{1}{\mathrm{n}} \ln \left(\frac{\mathrm{v}_{0}}{\mathrm{v}_{\mathrm{n}}}\right)
$$

Do ponto de vista experimental tem-se dois fotosensores posicionados ao longo de uma linha horizontal separados por uma distância s, então se os tempos para atravessar a distância 0 a $s_{1}$ são $t_{0}$ e $t_{n}$, então utilizando a velocidade média sobre esta distância, a equação (73) torna-se:

$$
\delta=\frac{1}{\mathrm{n}} \ln \left(\frac{\mathrm{t}_{\mathrm{n}}}{\mathrm{t}_{0}}\right)
$$

para a qual uma boa aproximação quando temos um $\delta$ pequeno é:

$$
\delta=\frac{1}{\mathrm{n}} \frac{\mathrm{t}_{\mathrm{n}}-\mathrm{t}_{0}}{\frac{\left(\mathrm{t}_{\mathrm{n}}+\mathrm{t}_{0}\right)}{2}}=\frac{1}{\mathrm{n}} \frac{\Delta \mathrm{t}}{\overline{\mathrm{t}}}
$$

estando dentro de $1 \%$ para valores de $t_{n} / t_{0}$ acima de 1,5 . Esta é uma condição que sempre é satisfeita na prática.

A condição sob a qual a velocidade média entre $\mathrm{x}=0$ e $\mathrm{x}=\mathrm{s}_{1}$ pode ser usada ao invés da velocidade instantânea a $x=0$ é obtida retornando para a equação (70) a qual nos leva a: 


$$
\delta=\frac{1}{\mathrm{n}} \ln \left(\frac{\operatorname{sen} \omega \mathrm{t}_{\mathrm{n}}}{\operatorname{sen} \omega \mathrm{t}_{0}}\right)
$$

Expandindo em termos de $\Delta \mathrm{t}$ e $\overline{\mathrm{t}}$,

$$
\delta=\frac{1}{\mathrm{n}} \frac{\Delta \mathrm{t}}{\overline{\mathrm{t}}}\left(1-\frac{\omega^{2}}{3} \overline{\mathrm{t}}^{-2}+\ldots\right)
$$

Isto raramente causará mais que $3 \%$ de erro, e se necessário pode ser conferido visto que os valores de todas as quantidades envolvidas são conhecidos.

Condições similares são aplicadas para atravessar a distância $-\mathbf{s}_{2}$ para 0 , então se agora $t_{0}, t_{n}, \Delta t$ e $\bar{t}$ são aplicados para a distância total $-s_{2}$ a $s_{1}$, então $\delta$ é dado por:

$$
\delta=\frac{1}{\mathrm{n}} \frac{\Delta \mathrm{t}}{\overline{\mathrm{t}}}
$$

Assim um alinhamento exato de modo que $\mathrm{s}_{1}=\mathrm{s}_{2}$ não é necessário.

\section{5. Caracterização das Amostras}

As amostras analisadas constituíram policristais da liga $\mathrm{Nb}$ - $\mathrm{Ta}$ de forma cilindrica com aproximadamente 2,74 mm de diâmetro, produzida pelo Departamento de Engenharia de 
Materiais da Faculdade de Engenharia Química de Lorena, com composição nominal de 8,9\% em peso de tântalo.

Para efetuarmos uma caracterização completa da amostra foram realizadas algumas análises no Centro de Caracterização e Desenvolvimento de Materiais (CCDM) na Universidade Federal de São Carlos (UFSCar). Foram obtidas medidas de composição química e teor de oxigênio e nitrogênio.

A Tabela 1 apresenta a composição química da amostra $\mathrm{Nb}-8,9 \%$ p.Ta que foi determinada por emissão atômica com plasma, em um equipamento modelo VISTA da Varian. Essa tabela mostra que existe uma diferença entre a composição nominal e a experimental em torno de $8,4 \%$ e que a amostra possuiu algumas impurezas, porém em quantidades muito pequenas, provavelmente provenientes do processo de fabricação.

\begin{tabular}{c|c} 
Tabela 1 Composição química da amostra Nb-8,9\%p.Ta. \\
\hline Elemento & Quantidade (\%p.) \\
\hline $\mathrm{Al}$ & 0,06 \\
$\mathrm{Ta}$ & 8,15 \\
$\mathrm{Si}$ & $<0,01$ \\
$\mathrm{Cu}$ & 1,35 \\
$\mathrm{~Pb}$ & 0,53 \\
$\mathrm{Nb}$ & Balanço \\
\hline
\end{tabular}

Foram realizadas medidas de densidade na amostra da maneira como recebida, efetuadas conforme descrito na seção IV. 1. A Tabela 2 mostra os dados referentes às medidas de massa, bem como o valor densidade da amostra calculada através da equação (64). 
Tabela 2 - Medidas de massa e densidade da amostra.

\begin{tabular}{c|c|c|c}
\hline \hline Amostra & $\mathbf{m} \mathbf{( g )}$ & $\mathbf{m}_{\mathbf{L i q}}(\mathbf{g})$ & $\rho\left(\mathrm{g} / \mathbf{c m}^{\mathbf{3}}\right)$ \\
\hline \multirow{3}{*}{$\mathrm{Nb}-8,9 \%$ p.Ta } & 4,2529 & 3,7715 & 8,8124 \\
& 4,2525 & 3,7853 & 9,0793 \\
& 4,2529 & 3,7859 & 9,0841 \\
& 4,2527 & 3,7843 & 9,0565 \\
\hline média & $(\mathbf{4 , 2 5 2 8} \pm \mathbf{0 , 0 0 0 2})$ & $\mathbf{( 3 , 7 8 2} \pm \mathbf{0 , 0 0 7})$ & $\mathbf{( 9 , 0 \pm 0 , 1 )}$ \\
\hline
\end{tabular}

Foram realizadas medidas de difração de raios $\mathrm{X}$ na amostra como recebida para determinar o parâmetro de rede e observar qual a influência dos sucessivos tratamentos térmicos e dopagens neste parâmetro. A figura 11 mostra o difratograma de raios $\mathrm{X}$ obtido para a amostra como recebida.

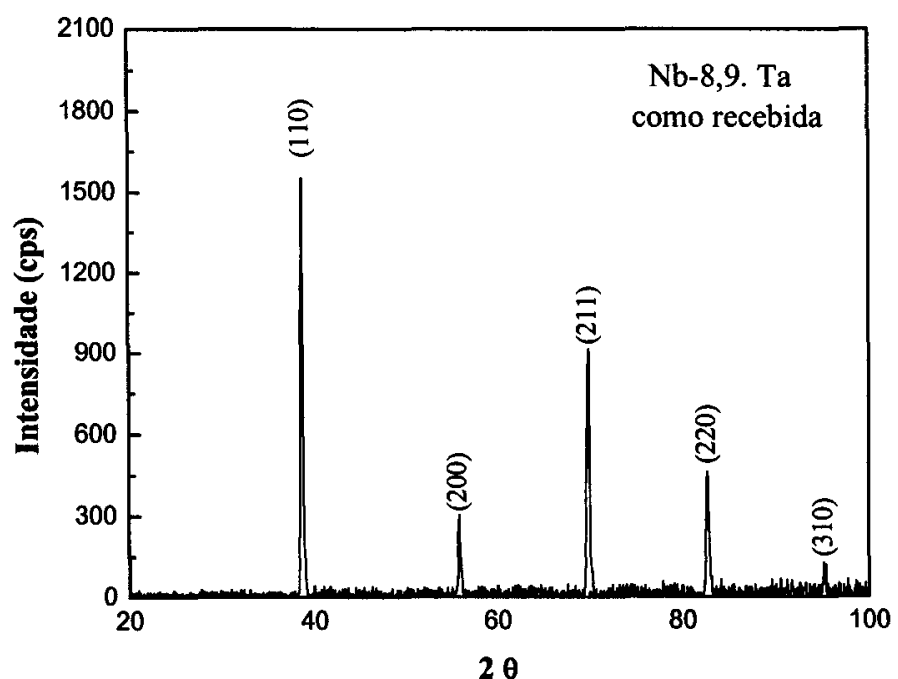

Figura 11 - Difratograma de raios $\mathrm{X}$ obtido para amostra da liga $\mathrm{Nb}-8,9 \%$ p.Ta (como recebida).

O parâmetro de rede da amostra pode ser calculado com base nos dados fornecidos pelo difratograma de raios X e a equação (67). Os dados e o parâmetro de rede calculado são apresentados na Tabela 3 . 
Tabela 3 - Parâmetro de rede da amostra como recebida.

\begin{tabular}{c|c|c|c|c|c|c}
\hline \multicolumn{6}{c}{ Nb-8,9\%p.Ta (como recebida) } \\
\hline $\mathbf{h}$ & $\mathbf{k}$ & $\mathbf{l}$ & $\mathbf{2 \theta}\left({ }^{\circ}\right)$ & $\boldsymbol{\theta}\left({ }^{\circ}\right)$ & $\mathbf{d}_{\text {hkl }}(\mathbf{\AA})$ & $\mathbf{A ~ ( \AA )}$ \\
\hline 1 & 1 & 0 & 38,740 & 19,370 & 2,328 & 3,292 \\
2 & 0 & 0 & 55,840 & 27,920 & 1,649 & 3,297 \\
2 & \multirow{2}{*}{1} & 1 & 69,880 & 34,940 & 1,348 & 3,302 \\
2 & 2 & 0 & 82,720 & 41,360 & 1,168 & 3,304 \\
3 & 1 & 0 & 95,120 & 47,560 & 1,046 & 3,308 \\
\hline
\end{tabular}

A amostra será, posteriormente, dopada com oxigênio e para analisarmos a influência da quantidade destes intersticiais na liga, foi efetuada análise química para se obter os teores de oxigênio e de nitrogênio da amostra como recebida.

Foram enviados para o CCDM quatro pedaços retirados das extremidades da amostra para se obter os teores de oxigênio e nitrogênio, este procedimento foi repetido após cada tratamento térmico. A Tabela 4 apresenta os resultados das análises dos teores de oxigênio e nitrogênio.

Tabela 4 - Teores de oxigênio e nitrogênio na amostra Nb-8,9\%p.Ta.

\begin{tabular}{c|c}
\hline \hline Elemento & Teor $(\% \mathrm{p})$. \\
\hline Oxigênio & $(0,0150 \pm 0,0003)$ \\
Nitrogênio & $(0,0030 \pm 0,0004)$ \\
\hline
\end{tabular}

Durante o processo de fabricação, a amostra foi trabalhada a frio para tomar a forma de fio com o diâmetro de $2,7 \mathrm{~mm}$, podendo, assim, conter tensões internas proveniente deste processo de fabricação. 
Com o objetivo de eliminar as tensões internas a amostra passou por um tratamento térmico de recozimento na amostra. Antes disso, a amostra foi submetida a um processo de limpeza utilizando uma solução de ácido fluorídrico, ácido nítrico e água, na proporção 2:2:1. Após essa limpeza a amostra foi colocada no tubo de quartzo no qual foi feito vácuo da ordem de $10^{-9}$ Torr.

Antes de iniciarmos o aquecimento foi efetuada uma análise de atmosfera dentro do tubo de quartzo para identificarmos que elementos estavam presentes nesta atmosfera. Estes dados foram obtidos pelo RGA e são apresentados na figura 12.

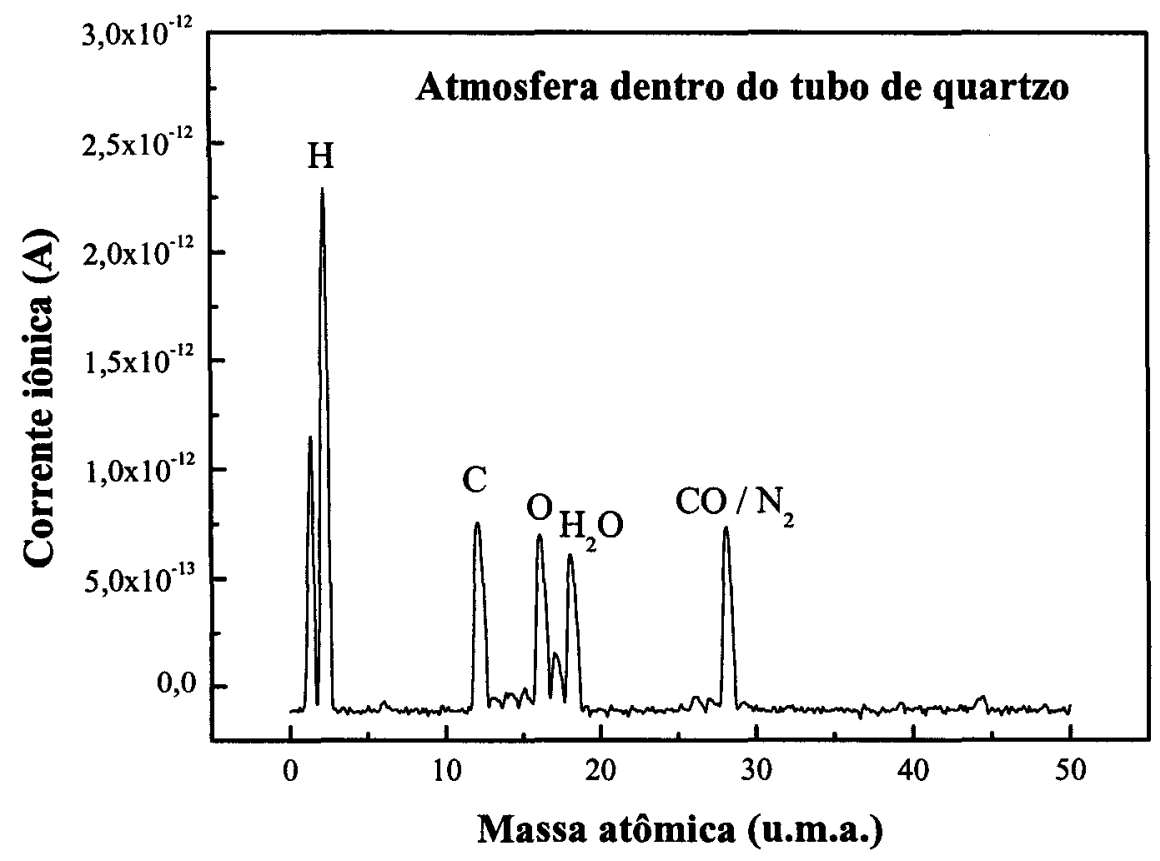

Figura 12 - Análise de atmosfera dentro do tubo de quartzo, para o tratamento térmico .

Após a análise da atmosfera dentro do tubo, o forno foi ligado para iniciar o tratamento térmico da amostra, que ocorreu da seguinte forma: a amostra foi aquecida até a 
$\mathrm{T}_{\max }=1000^{\circ} \mathrm{C}$ com aquecimento $\mathrm{v}_{\mathrm{h}}=10^{\circ} \mathrm{C} / \mathrm{min}$, com $\mathrm{t}_{\mathrm{h}}=180$ minutos $(3$ horas), após decorrido esse tempo a amostra foi resfriada com $v_{c}=10^{\circ} \mathrm{C} / \mathrm{min}$.

Durante o processo de tratamento térmico o ambiente atmosférico dentro do tubo de quartzo foi acompanhado pelo RGA, que detectou a variação da concentração de alguns elementos, o que é mostrado figura 13.

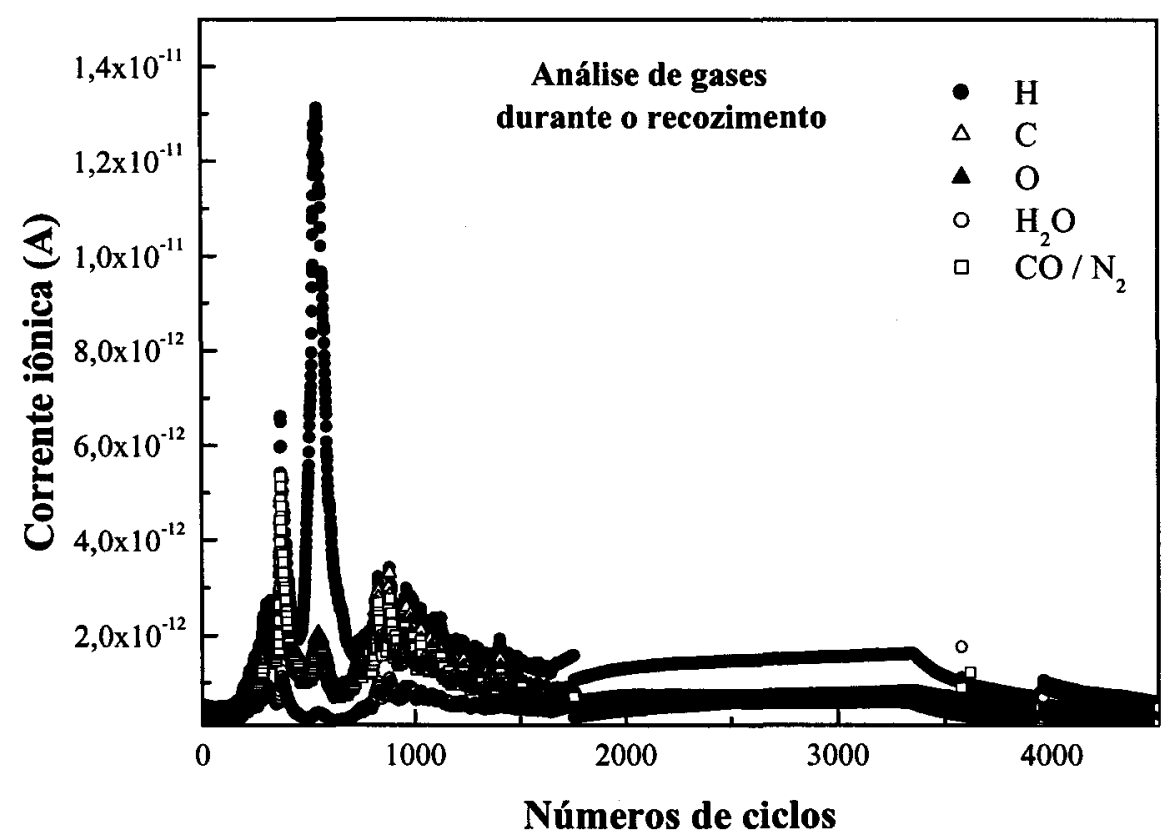

Figura 13 - Análise de gases fefetuado pelo RGA durante o processo de recozimento.

A figura 13 mostra que o elemento que teve uma maior variação de concentração foi o hidrogênio. Esse hidrogênio pode ser proveniente da limpeza que é feita com ácido e água e estar na superfície da amostra e com o aquecimento evaporou.

Após o tratamento térmico de recozimento, uma parte da amostra foi encaminhada ao CCDM para realizar análise química para determinar o teor de oxigênio e nitrogênio. A análise do teor de oxigênio e nitrogênio é apresentada na Tabela 5 . 
Tabela 5 - Teores de oxigênio e nitrogênio na amostra $\mathrm{Nb}-8,9 \% \mathrm{p}$.Ta, após o tratamento térmico.

\begin{tabular}{c|c}
\hline \hline Elemento & Teor (\%p.) \\
\hline Oxigênio & $(0,0189 \pm 0,0003)$ \\
Nitrogênio & $(0,0124 \pm 0,0004)$ \\
\hline
\end{tabular}

O difratograma de raios $\mathrm{X}$ após o tratamento térmico é mostrado na figura 14 e os dados fornecidos pelo equipamento e o cálculo do parâmetro de rede é mostrado na tabela 6 .

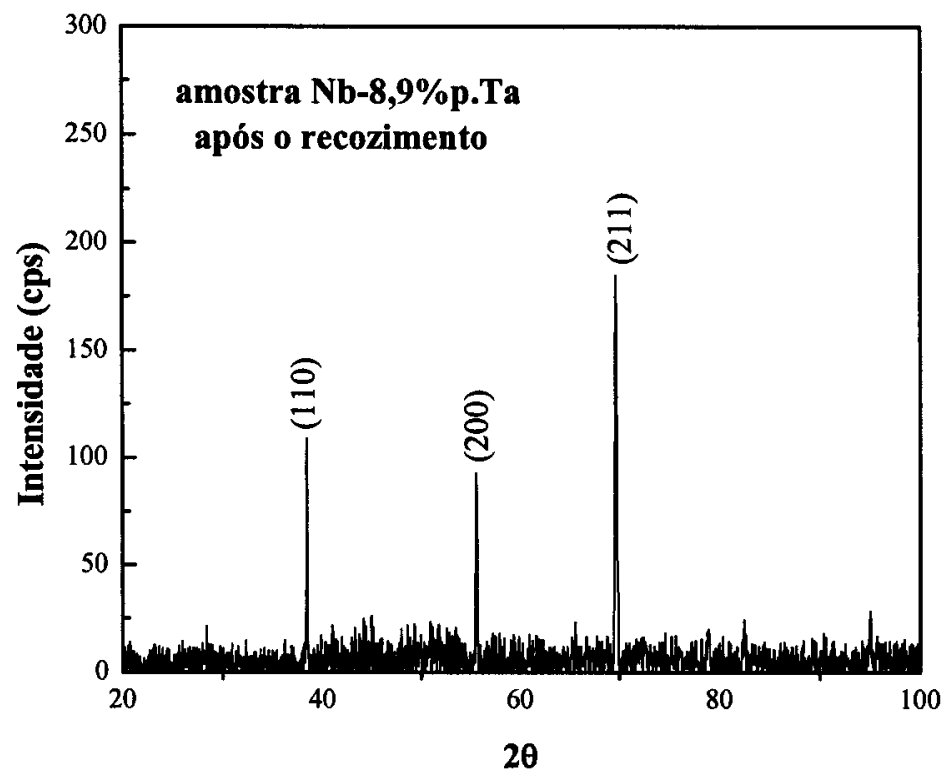

Figura 14 - Difratograma de raios X para amostra da liga obtido após o tratamento térmico de recozimento.

Tabela 6 - Parâmetro de rede da amostra após o recozimento.

\begin{tabular}{c|c|c|c|c|c|c}
\hline \multicolumn{6}{c}{ Nb-8,9\%p.Ta (após recozimento ) } \\
\hline $\mathbf{H}$ & $\mathbf{k}$ & $\mathbf{l}$ & $2 \theta\left({ }^{\circ}\right)$ & $\boldsymbol{\theta}\left({ }^{\circ}\right)$ & $\mathbf{d}_{\text {hkl }}(\AA)$ & $\mathbf{a}(\AA)$ \\
\hline 1 & 1 & 0 & 38,460 & 19,230 & 2,344 & 3,315 \\
2 & 0 & 0 & 55,580 & 27,790 & 1,656 & 3,312 \\
2 & \multirow{2}{*}{1} & 1 & 69,680 & 34,840 & 1,351 & 3,310 \\
\hline
\end{tabular}


Os resultados mostram que após o recozimento houve uma variação na concentração dos elementos intersticiais, principalmente na concentração de nitrogênio. É possível observar pelo difratograma da amostra que houve um aumento no parâmetro de rede da amostra, isso porque os elementos intersticiais distorcem a rede causando esse aumento.

Após o tratamento de recozimento, iniciamos os processos de dopagem da amostra com oxigênio. $\mathrm{O}$ procedimento de dopagem é semelhante ao recozimento. A diferença está na temperatura máxima, no tempo de permanência nessa temperatura e o resfriamento que é feito com água.

A primeira dopagem da amostra se deu da seguinte forma: a amostra foi colocada dentro do tubo de quartzo, seguindo os mesmos procedimentos descritos para o processo de recozimento, porém agora a amostra foi aquecida até a temperatura máxima de $800^{\circ} \mathrm{C}$, após alcançar essa temperatura foi introduzido oxigênio com uma pressão parcial de $2,0 \times 10^{-5}$ Torr e mantido por um tempo de 30 minutos. Ao final deste tempo a amostra foi resfriada em água até temperatura ambiente.

As figuras 15 e 16 mostram, respectivamente, a análise de atmosfera do tubo de quartzo antes do aquecimento e a análise do ambiente atmosférico durante o aquecimento para a primeira dopagem com oxigênio. 


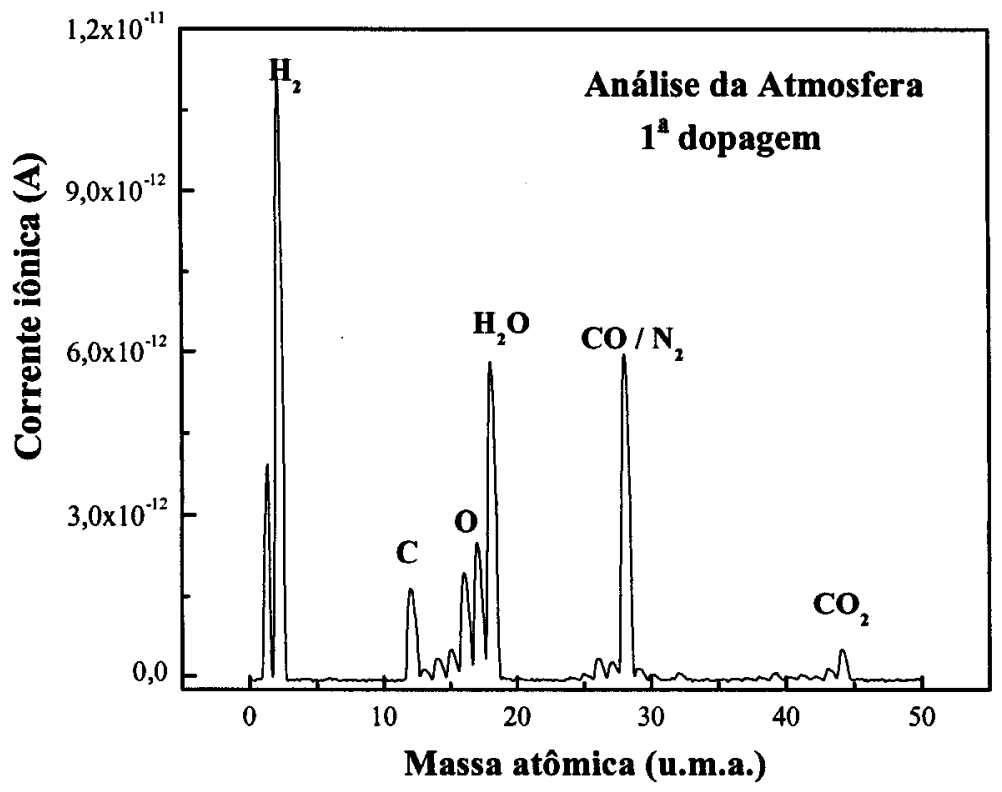

Figura 15 - Análise da atmosfera do tubo de quartzo antes do aquecimento para a primeira dopagem.

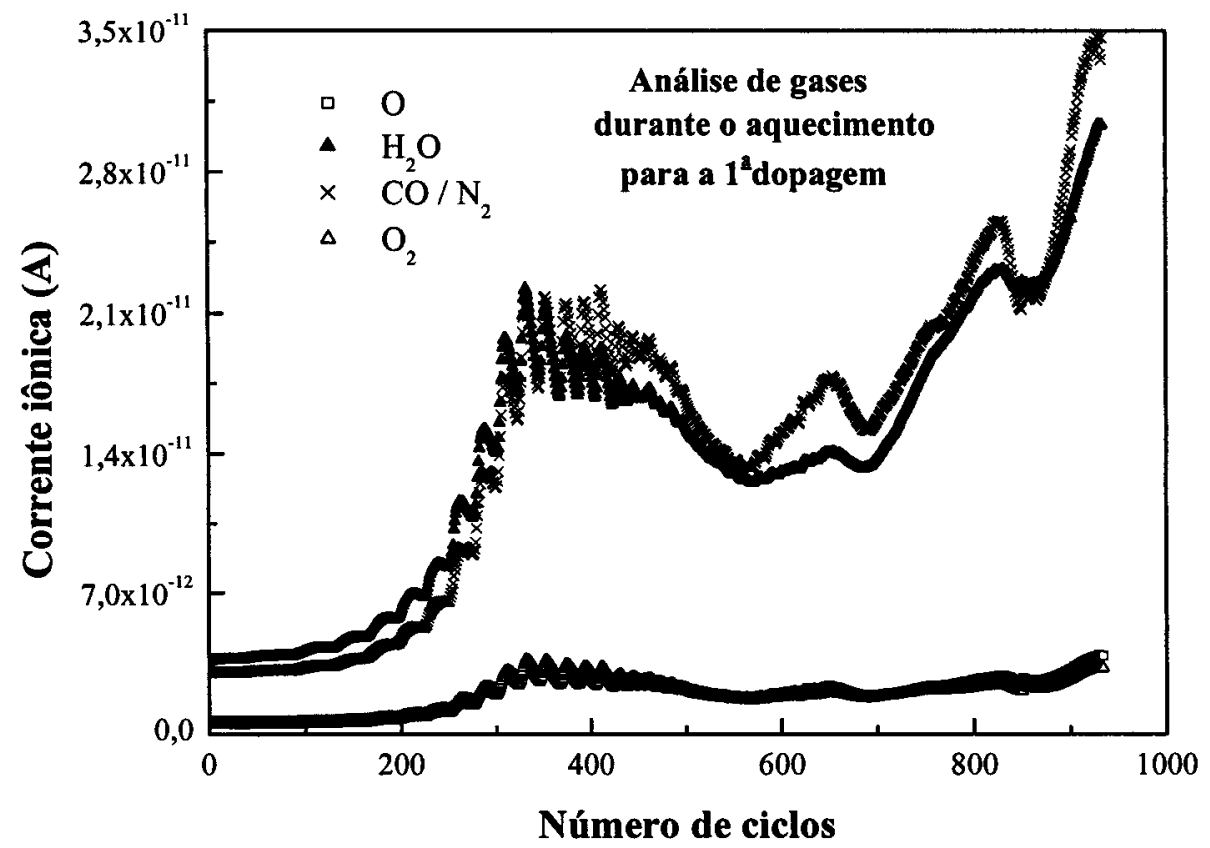

Figura 16 - Análise de gases durante o aquecimento para a primeira dopagem com oxigênio. 
Observamos pela figura 16 que houve uma maior variação da concentração de água, que poderia estar presente na superficie da amostra após o processo de limpeza e evaporado durante o aquecimento.

Após a dopagem foi novamente efetuada análise química para determinar o teor de oxigênio e nitrogênio e difração de raios X. Os dados da análise química são apresentados na Tabela 7. A figura 17 mostra o difratograma de raios $\mathrm{X}$ para amostra dopada. Os dados deste difratograma bem como o parâmetro de rede calculado são listados na Tabela 8.

Tabela 7 - Teores de oxigênio e nitrogênio na amostra Nb-8,9\%p.Ta, após a primeira dopagem.

\begin{tabular}{c|c}
\hline \hline Elemento & Teor $(\% \mathrm{p})$. \\
\hline Oxigênio & $(0,051 \pm 0,003)$ \\
Nitrogênio & $(0,011 \pm 0,002)$ \\
\hline
\end{tabular}

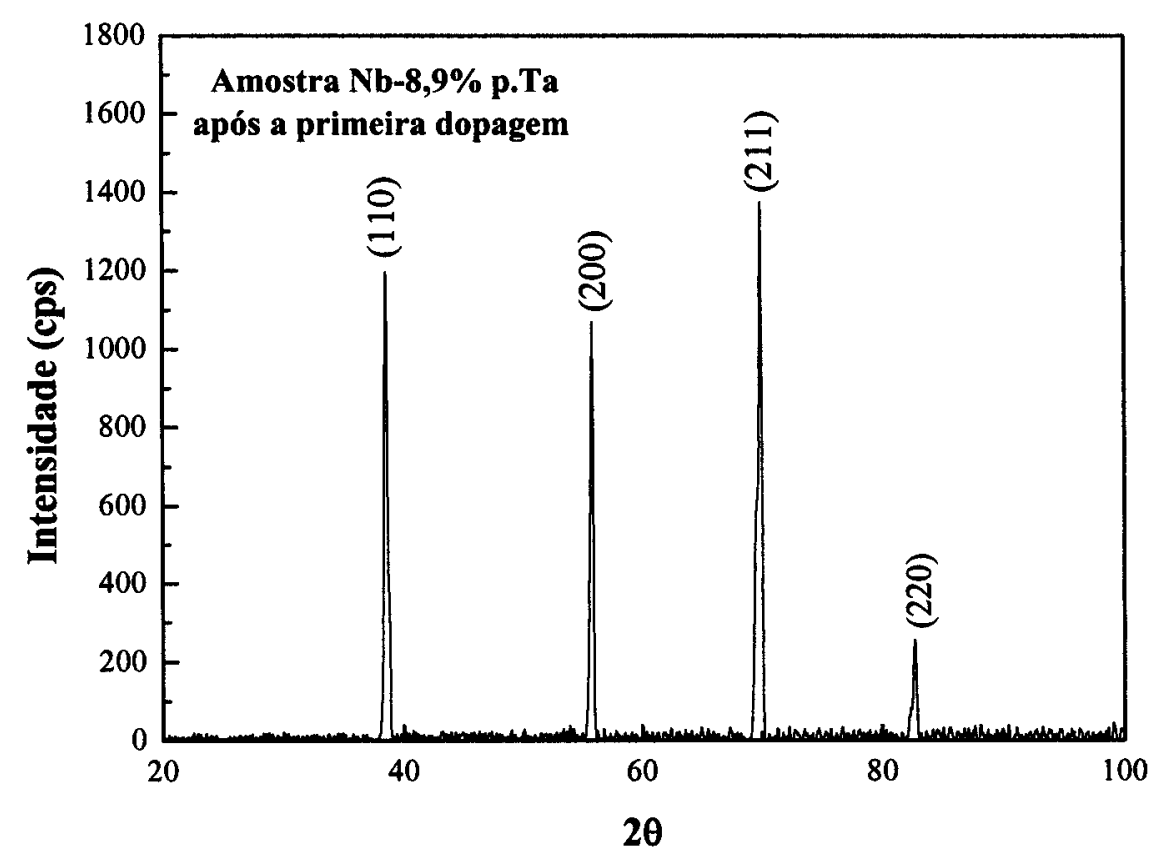

Figura 17 - Difratograma de raios $\mathrm{X}$ para amostra da liga obtido após a primeira dopagem. 
Tabela 8 - Parâmetro de rede da amostra após a primeira dopagem.

\begin{tabular}{c|c|c|c|c|c|c}
\hline \hline \multicolumn{6}{c}{ Nb-8,9\%p.Ta ( 1 ${ }^{\mathbf{a}}$ dopagem ) } \\
\hline $\mathbf{H}$ & $\mathbf{k}$ & $\mathbf{l}$ & $\mathbf{2 \theta}\left({ }^{\circ}\right)$ & $\boldsymbol{\theta}\left({ }^{\circ}\right)$ & $\mathbf{d}_{\mathbf{h k l}}(\mathbf{\AA})$ & $\mathbf{a}(\mathbf{\AA})$ \\
\hline 1 & 1 & 0 & 38,540 & 19,270 & 2,339 & 3,308 \\
2 & 0 & 0 & 55,840 & 27,920 & 1,649 & 3,297 \\
2 & 1 & 1 & 69,940 & 34,970 & 1,347 & 3,299 \\
2 & 2 & 0 & 82,680 & 41,340 & 1,169 & 3,306 \\
\hline
\end{tabular}

Podemos observar pelos dados apresentados que houve um aumento na concentração de oxigênio enquanto que a concentração de nitrogênio praticamente não se alterou, sendo esse nosso objetivo, dopar a amostra apenas com oxigênio. Os elementos intersticiais distorcem a rede cristalina causando um aumento no parâmetro de rede, o que foi confirmado pelos dados de raios $\mathrm{X}$.

A segunda dopagem com oxigênio seguiu os mesmos procedimentos da dopagem anterior, com os mesmos parâmetros de $T_{\max }, v_{h}, t$ e $v_{c}$, porém a pressão parcial de oxigênio foi um pouco maior, $6,7 \times 10^{-5}$ Torr, já que a intenção era aumentar a concentração deste intersticial.

A figura 18 mostra os dados obtidos pelo RGA da análise de atmosfera dentro do tubo antes do aquecimento e a figura 19 mostra a análise do ambiente atmosférico durante o aquecimento para a segunda dopagem.

Podemos ver por estas figuras que a maior variação na concentração foi de $\mathrm{CO} / \mathrm{N}_{2}$ que podem ser resíduos superficiais provenientes do processo de limpeza que é feito com ácido e água. 


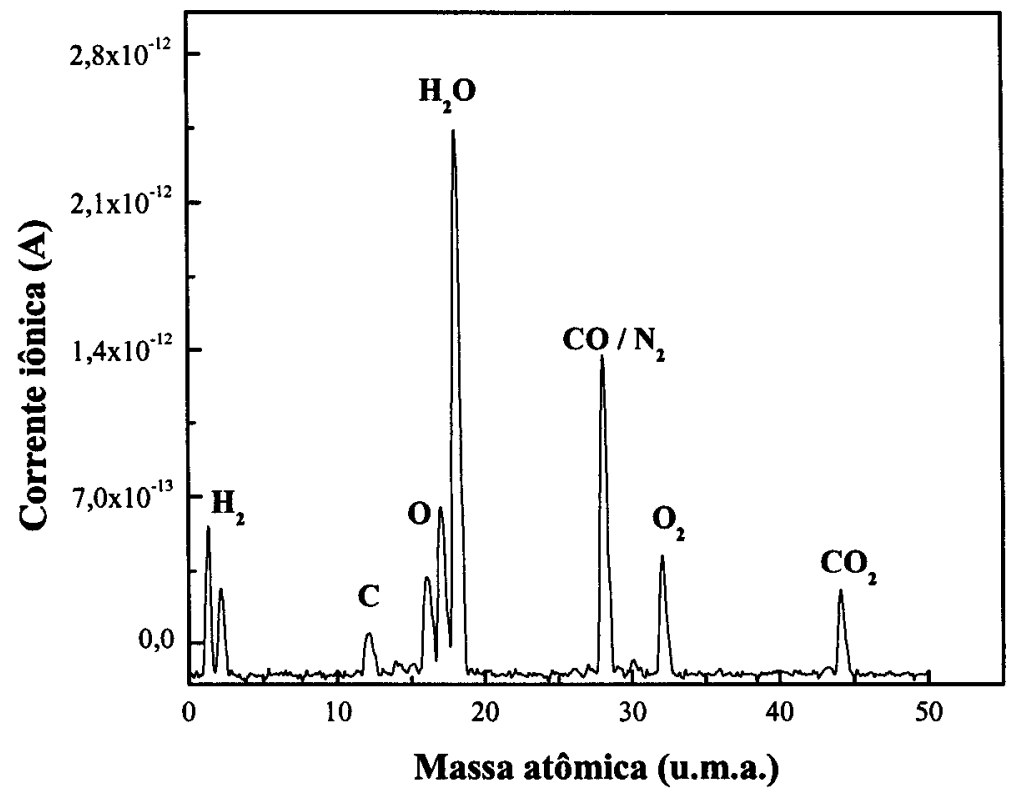

Figura 18 - Análise da atmosfera do tubo de quartzo antes do aquecimento para a segunda dopagem.

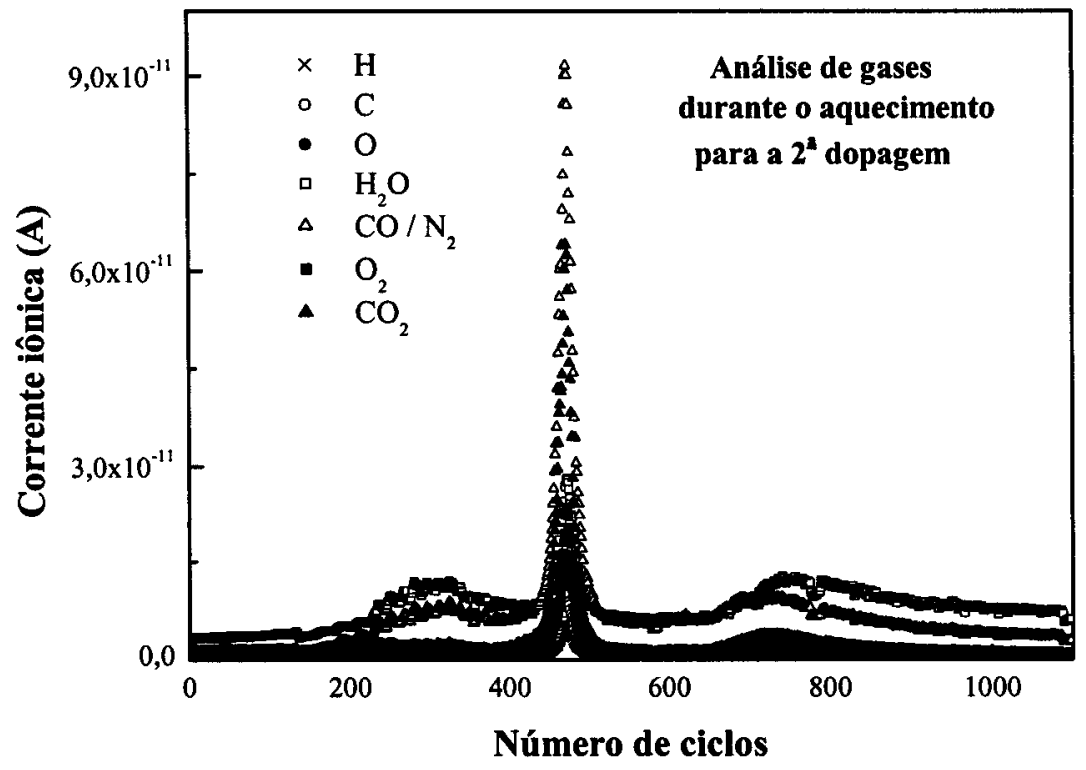

Figura 19 - Análise de gases durante o aquecimento para a segunda dopagem com oxigênio.

Após a dopagem foi efetuada análise do teor de oxigênio e nitrogênio e difração de raios $\mathrm{X}$. Os resultados referentes a essas análises são apresentados nas Tabelas 9 e 10 e na figura 20. 
Tabela 9 - Teores de oxigênio e nitrogênio na amostra Nb-8,9\%p.Ta, após a segunda dopagem.

\begin{tabular}{c|c}
\hline \hline Elemento & Teor $(\%$ p.) \\
\hline Oxigênio & $(0,09 \pm 0,01)$ \\
Nitrogênio & $(0,013 \pm 0,002)$ \\
\hline
\end{tabular}

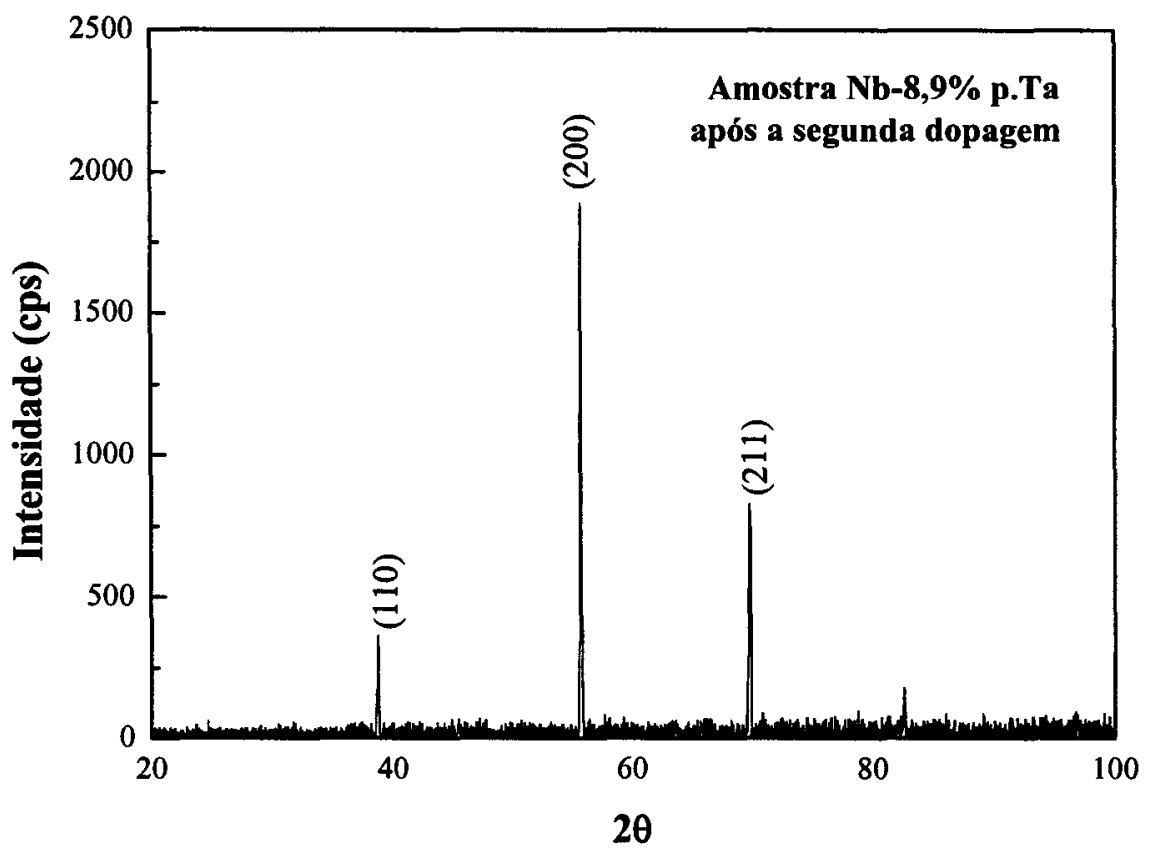

Figura 20 - Difratograma de raios X para amostra da liga obtido após a segunda dopagem.

Tabela 10 - Parâmetro de rede da amostra após a segunda dopagem.

\begin{tabular}{c|c|c|c|c|c|c}
\hline \multicolumn{6}{c}{ Nb-8,9\%p.Ta ( $\mathbf{2}^{\mathbf{a}}$ Dopagem ) } \\
\hline $\mathbf{H}$ & $\mathbf{k}$ & $\mathbf{I}$ & $\mathbf{2 \theta}\left({ }^{\circ}\right)$ & $\boldsymbol{\theta}\left({ }^{\circ}\right)$ & $\mathbf{d}_{\mathbf{h k l}}(\boldsymbol{\AA})$ & $\mathbf{a}(\AA)$ \\
\hline 1 & 1 & 0 & 38,640 & 19,320 & 2,333 & 3,300 \\
2 & 0 & 0 & 55,740 & 27,870 & 1,651 & 3,303 \\
2 & 1 & 1 & 69,820 & 34,910 & 1,349 & 3,304 \\
2 & 2 & 0 & 82,620 & 41,310 & 1,169 & 3,308 \\
\hline \multicolumn{7}{|c|}{}
\end{tabular}


Os dados mostram que a concentração de elementos intersticiais está aumentando gradualmente e que quanto maior a quantidade de elementos intersticiais maior é a distorção da rede, o que é comprovado pelo difratograma de raios $\mathrm{X}$, visto que o parâmetro de rede é um pouco maior.

De modo similar às dopagens anteriores, foi efetuada a terceira dopagem, a única diferença está na pressão parcial de oxigênio, que neste caso foi de $1,5 \times 10^{-4}$ Torr. Nesta terceira dopagem também foi feito um acompanhamento atmosférico, via RGA, antes do aquecimento e durante o aquecimento. A figura 21 mostra a análise de atmosfera antes do aquecimento e a figura 22 durante o aquecimento.

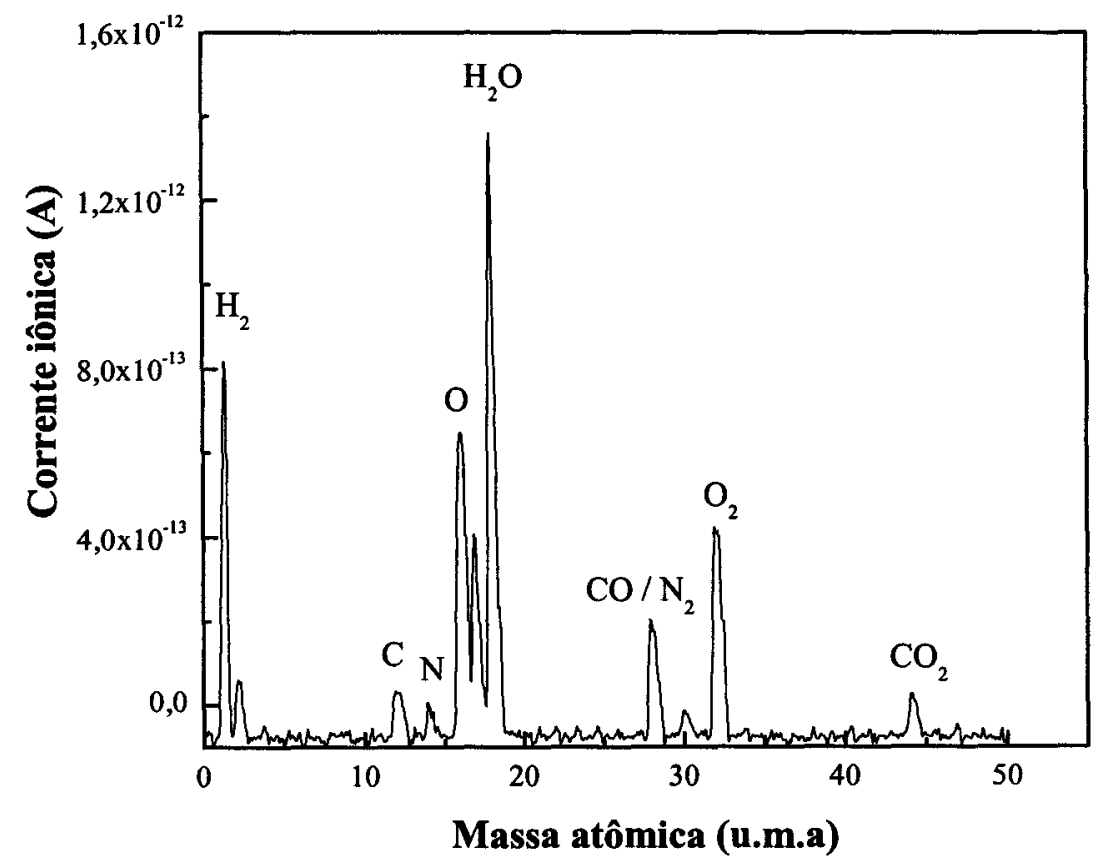

Figura 21 - Análise da atmosfera do tubo de quartzo antes do aquecimento para a terceira dopagem. 


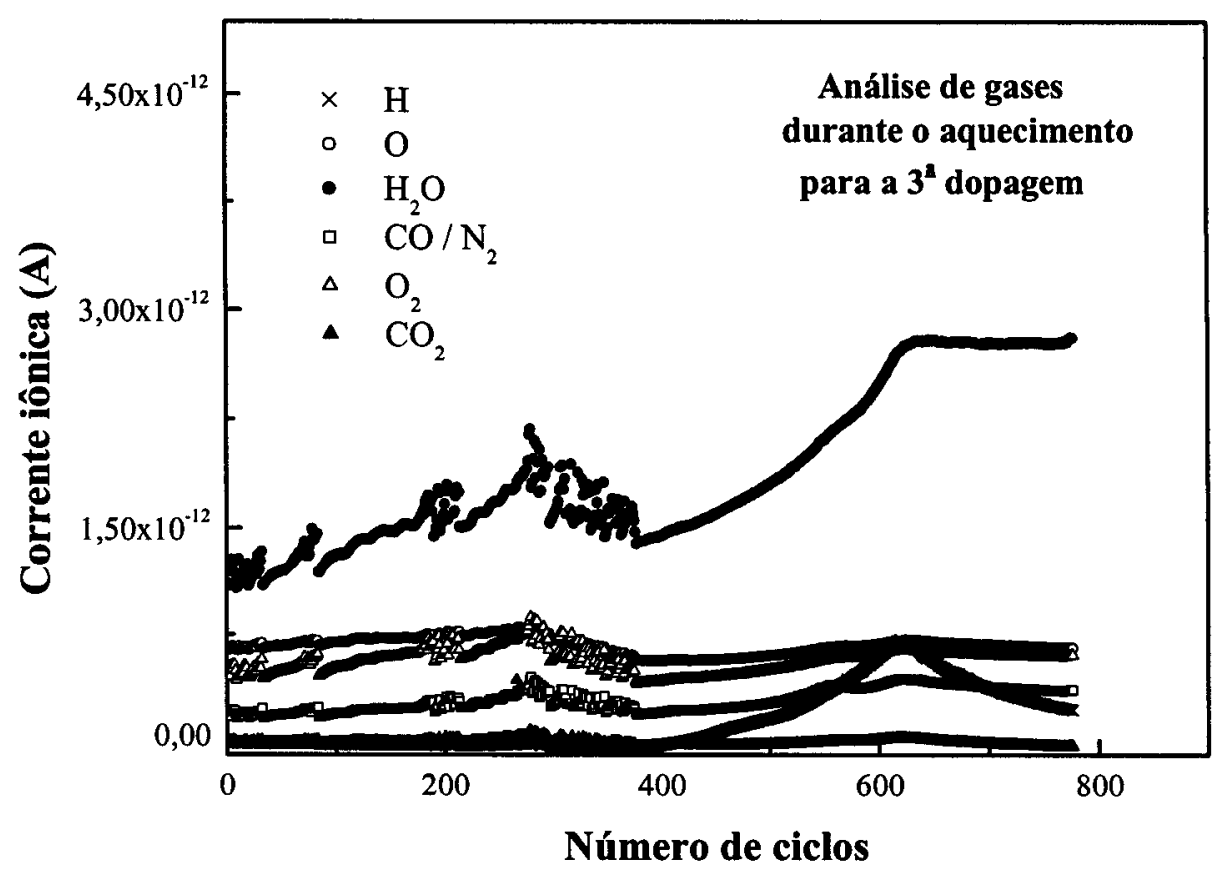

Figura 22 - Análise de gases durante o aquecimento para a terceira dopagem com oxigênio.

Pode-se observar pela figura 22 que houve uma maior variação de água que pode ser proveniente da limpeza da amostra e ter ficado na superfície da amostra e evaporado no aquecimento.

Novamente foram realizadas análises de teor de oxigênio e nitrogênio e difração de raios $\mathrm{X}$, estando os resultados apresentados nas Tabelas 11 e 12 e na figura 23 .

Tabela 11 - Teores de oxigênio e nitrogênio na amostra Nb-8,9\%p.Ta, após a terceira dopagem.

\begin{tabular}{c|c}
\hline \hline Elemento & Teor (\%p.) \\
\hline Oxigênio & $(0,103 \pm 0,007)$ \\
Nitrogênio & $(0,014 \pm 0,002)$ \\
\hline
\end{tabular}




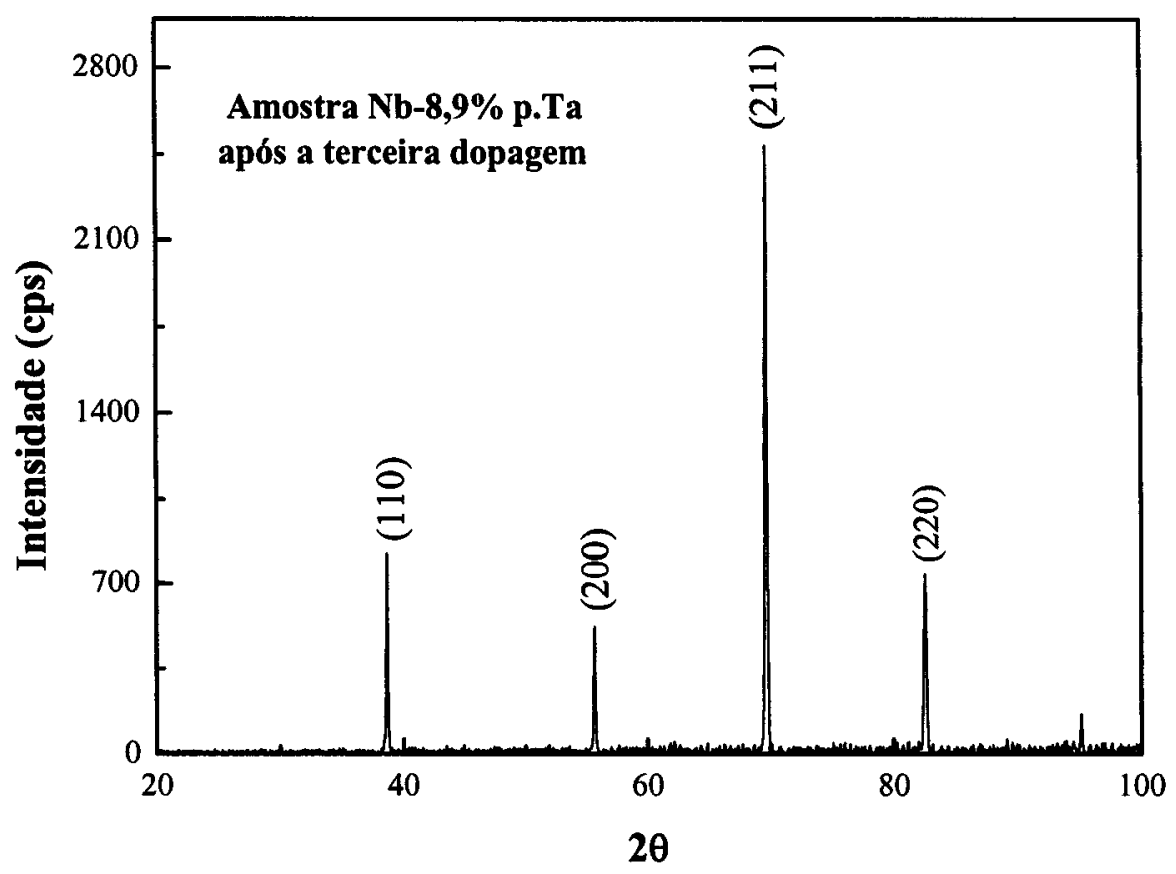

Figura 23 - Difratograma de raios X para amostra da liga obtido após a terceira dopagem.

Tabela 12 - Parâmetro de rede da amostra após a terceira dopagem.

\begin{tabular}{|c|c|c|c|c|c|c|}
\hline \multicolumn{7}{|c|}{ Nb-8,9\%p.Ta ( $3^{\circ}$ Dopagem ) } \\
\hline $\mathbf{H}$ & $\mathbf{k}$ & $\mathbf{l}$ & $2 \theta\left({ }^{\circ}\right)$ & $\theta\left({ }^{\circ}\right)$ & $\mathbf{d}_{\text {hkl }}(\AA)$ & $\mathbf{a}(\AA)$ \\
\hline 1 & 1 & 0 & 38,660 & 19,330 & 2,332 & 3,298 \\
\hline 2 & 0 & 0 & 55,660 & 27,830 & 1,654 & 3,307 \\
\hline 2 & 1 & 1 & 69,700 & 34,850 & 1,351 & 3,309 \\
\hline 2 & 2 & 0 & 82,540 & 41,270 & 1,170 & 3,310 \\
\hline & & & & & média & $(3,306 \pm 0,004)$ \\
\hline
\end{tabular}

Percebe-se pela análise do teor de oxigênio e nitrogênio que somente a concentração de oxigênio está aumentando, o que era nosso objetivo, dopar a amostra apenas com oxigênio. $E$ estes intersticiais fazem com que a rede cristalina fique um pouco maior, já que ocupam locais intersticiais, esta variação é comprovada com as medidas de difração de raios X. 
A quarta dopagem também teve procedimento similar aos tratamentos anteriores, porém foi utilizada uma pressão parcial de $6,7 \times 10^{-4}$ Torr. Esta dopagem também teve o ambiente atmosférico antes e durante o aquecimento acompanhado via RGA. A figura 24 mostra o ambiente atmosférico antes do aquecimento e a figura 25 durante o aquecimento.

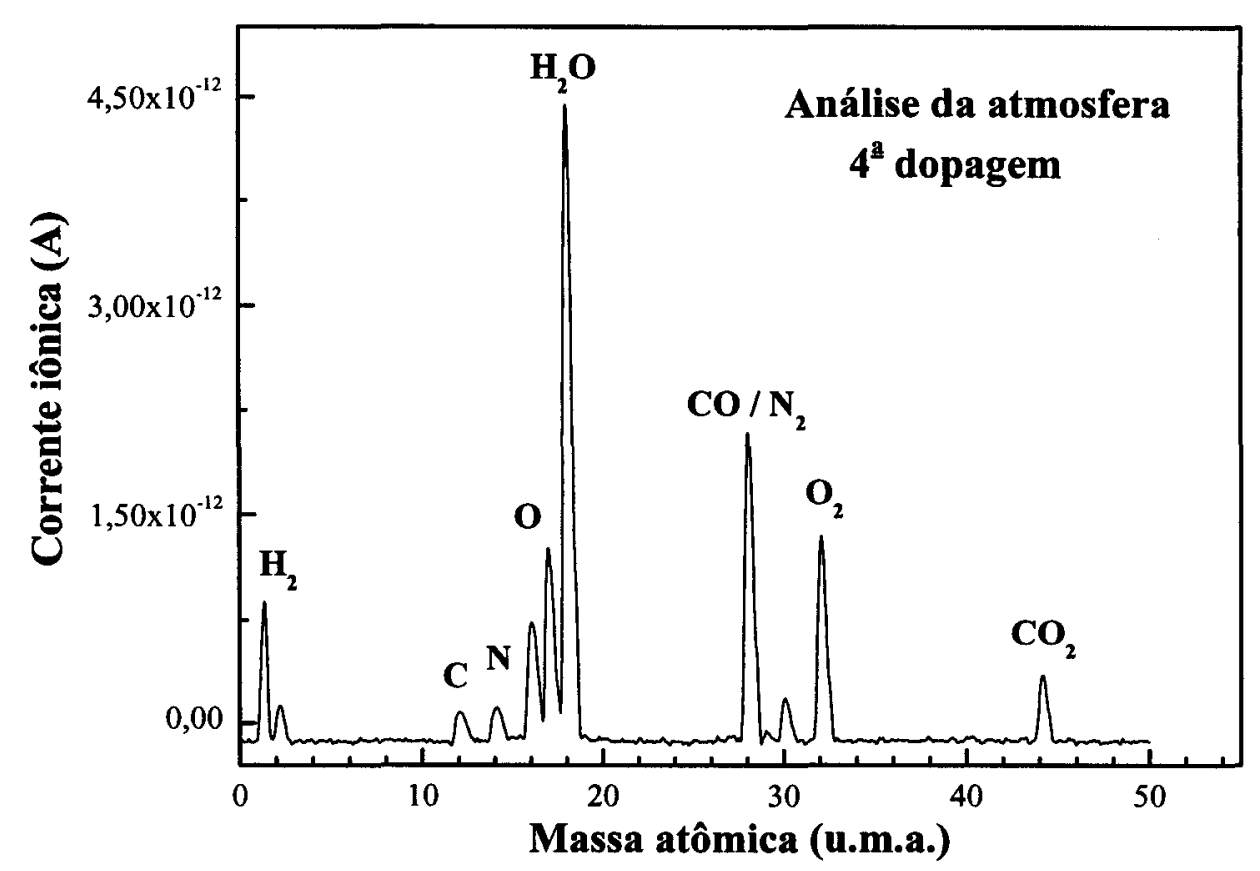

Figura 24 - Análise da atmosfera do tubo de quartzo antes do aquecimento para a quarta dopagem.

Vemos pela figura 25 que a maior variação na concentração foi de água que pode ser proveniente da superficie da amostra, já que antes de ser colocada no sistema foi submetida a um processo de limpeza e durante o aquecimento evaporou. 


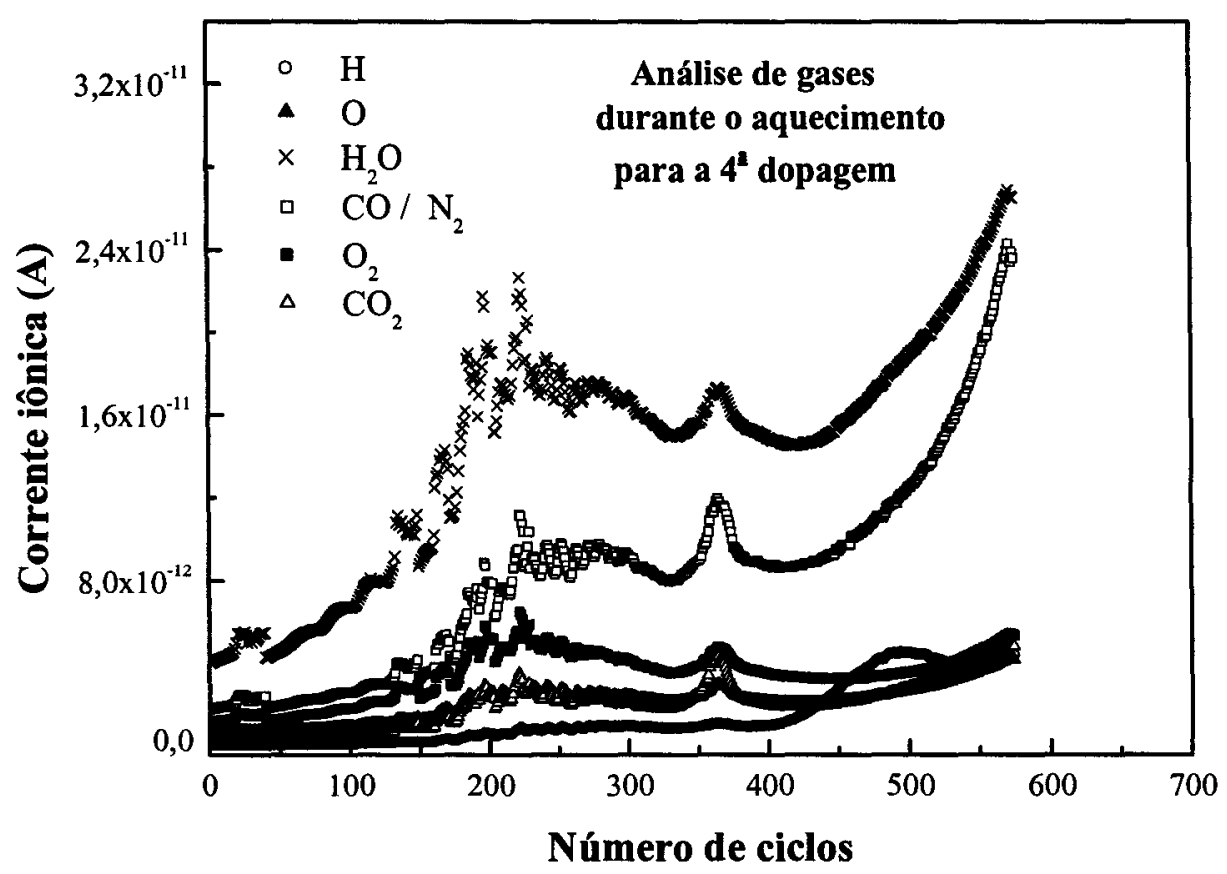

Figura 25 - Análise de gases durante o aquecimento para a quarta dopagem com oxigênio.

Após a dopagem foram efetuadas análises do teor de oxigênio e nitrogênio e difração de raios X, o resultado destas análises é apresentado nas Tabelas 13 e 14 e na figura 26.

Tabela 13 - Teores de oxigênio e nitrogênio na amostra $\mathrm{Nb}-8,9 \%$ p.Ta, após a quarta dopagem.

\begin{tabular}{c|c}
\hline \hline Elemento & Teor (\%p.) \\
\hline Oxigênio & $(0,14 \pm 0,01)$ \\
Nitrogênio & $(0,0145 \pm 0,0003)$ \\
\hline
\end{tabular}




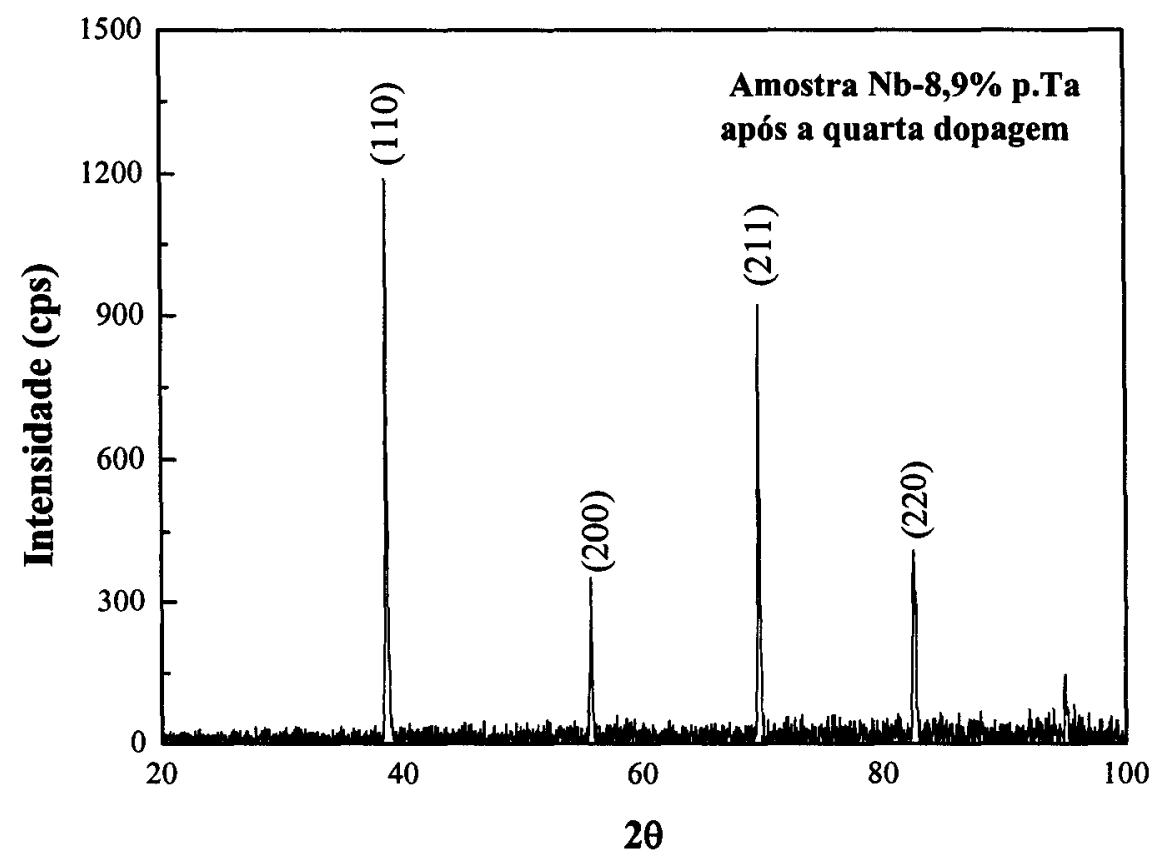

Figura 26 - Difratograma de raios X para amostra da liga obtido após a quarta dopagem.

Tabela 14 - Parâmetro de rede da amostra após a quarta dopagem.

\begin{tabular}{|c|c|c|c|c|c|c|}
\hline \multicolumn{7}{|c|}{ Nb-8,9\%p.Ta ( $4^{\circ}$ Dopagem ) } \\
\hline $\mathbf{H}$ & $\mathbf{k}$ & $\mathbf{1}$ & $2 \theta\left(^{\circ}\right)$ & $\theta\left({ }^{0}\right)$ & $\mathbf{d}_{\text {hkl }}(\AA)$ & $\mathbf{a}(\AA)$ \\
\hline 1 & 1 & 0 & 38,600 & 19,300 & 2,336 & 3,303 \\
\hline 2 & 0 & 0 & 55,700 & 27,850 & 1,653 & 3,305 \\
\hline 2 & 1 & 1 & 69,720 & 34,860 & 1,351 & 3,308 \\
\hline 2 & 2 & 0 & 82,500 & 41,250 & 1,171 & 3,312 \\
\hline 3 & 1 & 0 & 95,020 & 47,510 & 1,047 & 3,311 \\
\hline & & & & & média & $(3,308 \pm 0,003)$ \\
\hline
\end{tabular}

Os dados mostram que a concentração de oxigênio praticamente dobrou, em relação à concentração inicial. Essa quantidade de intersticiais distorce a rede fazendo com que esta se torne um pouco maior, distorção que é comprovada pelo difratograma de raios $\mathrm{X}$. 
Com os dados de concentração de oxigênio e as medidas do parâmetro de rede podemos verificar como se relaciona o parâmetro de rede com a concentração de intersticiais, esta relação é mostrada no gráfico da figura 27.

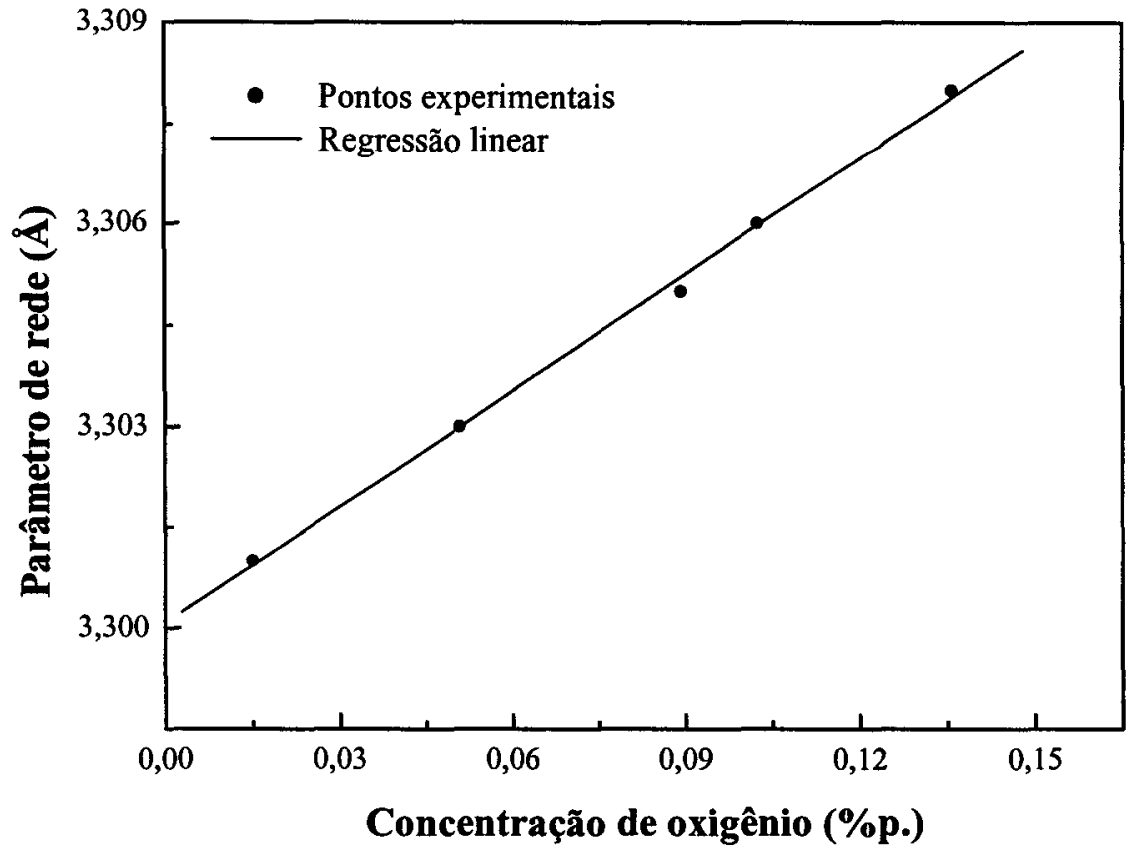

Figura 27 - Relação entre o parâmetro de rede e a concentração de oxigênio.

Pode-se observar pelo gráfico acima que o parâmetro de rede está relacionado com a concentração de oxigênio de forma linear (equação 79), já que este elemento entra em posições intersticiais causando uma distorção na rede e quanto maior a concentração maior será a distorção e consequentemente maior o parâmetro de rede.

$$
a=3,300+0,058 c
$$

onde: $a_{0}$ é o parâmetro de rede e $c$ a concentração de oxigênio (\% p.). 


\section{CAPÍTULO V - RESULTADOS E DISCUSSÕES}

Neste capítulo serão apresentados os resultados das medidas de atrito interno na liga $\mathrm{Nb}-8,9 \%$ p.Ta contendo várias concentrações de elementos intersticiais.

As medidas de atrito interno das amostras da liga $\mathrm{Nb}-8,9 \%$ p.Ta foram obtidas utilizando o pêndulo de torção descrito na seção IV. 4, operando com frequêencia de oscilação entre 1 a $30 \mathrm{~Hz}$, intervalo de temperatura compreendido entre 300 e $700 \mathrm{~K}$, taxa de aquecimento de $1 \mathrm{~K} /$ min e vácuo da ordem de $10^{-5}$ Torr.

As figuras de 28 a 30 mostram os espectros de atrito interno com função da temperatura (espectro anelástico) para amostra da liga $\mathrm{Nb}-8.9 \%$ p.Ta da maneira como recebida, medidos com diferentes freqüências. 


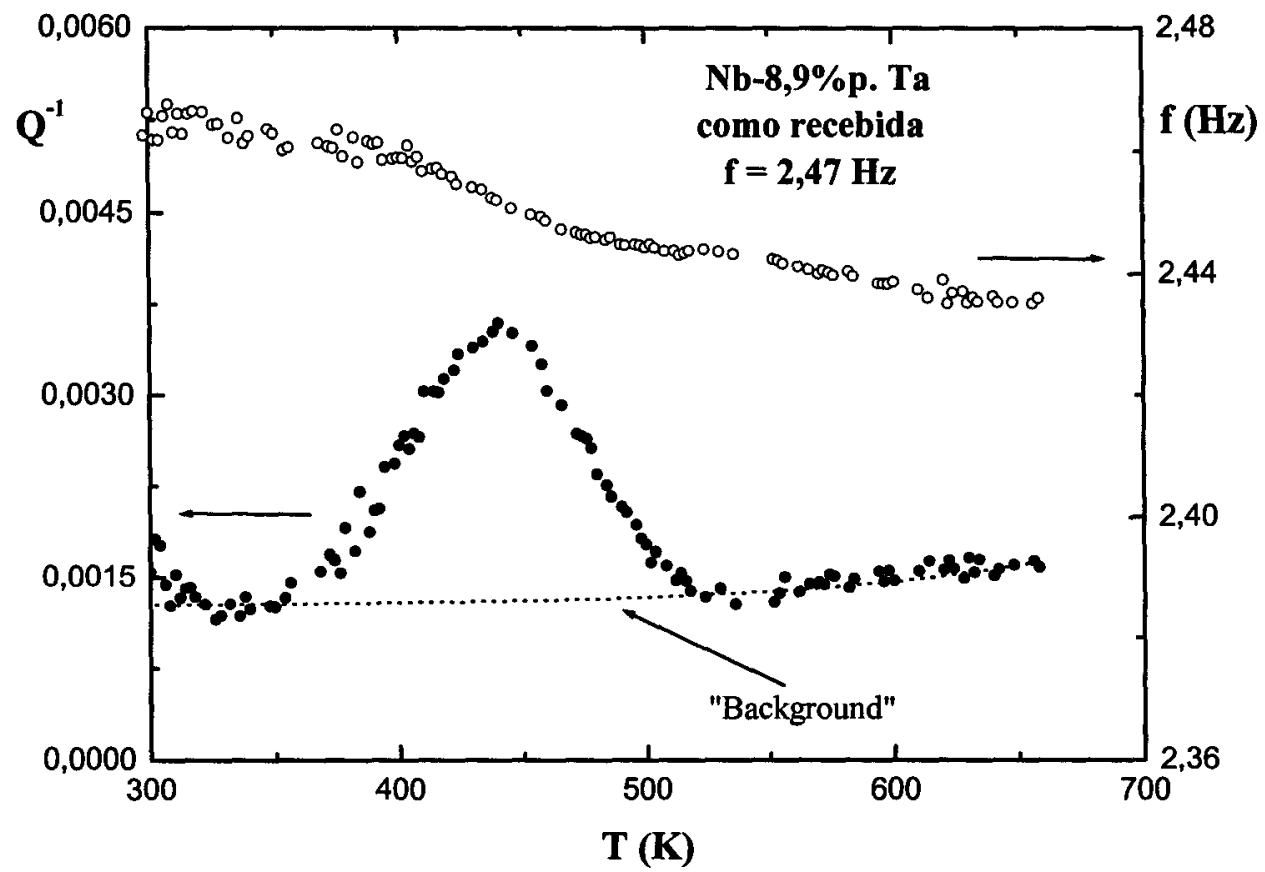

Figura 28 - Espectro de atrito interno como função da temperatura para amostra da liga $\mathrm{Nb}$ $8,9 \%$ p.Ta medido com freqüência de $2,47 \mathrm{~Hz}$, da maneira como recebida.

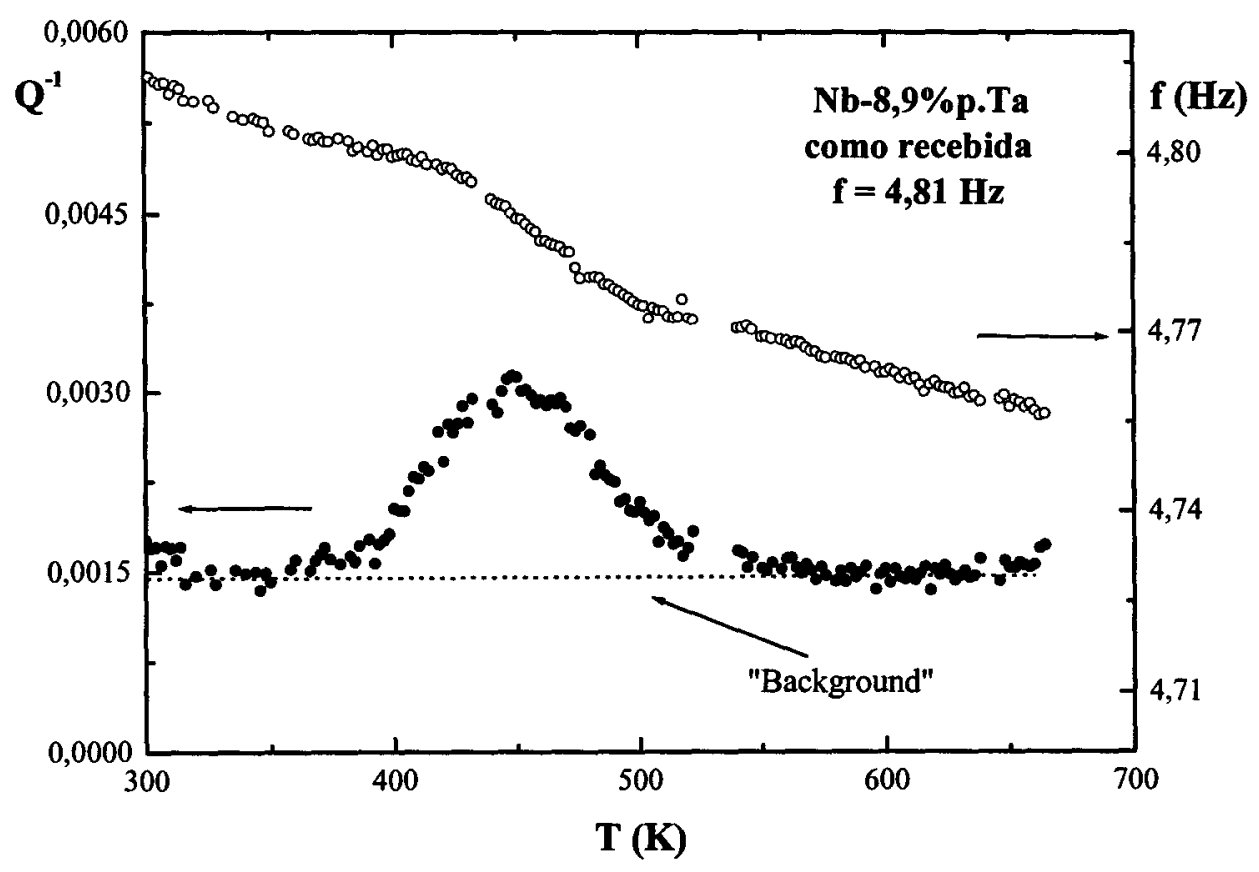

Figura 29 - Espectro de atrito interno como função da temperatura para amostra da liga $\mathrm{Nb}$ $8,9 \%$ p.Ta medido com freqüência de $4,81 \mathrm{~Hz}$, da maneira como recebida. 


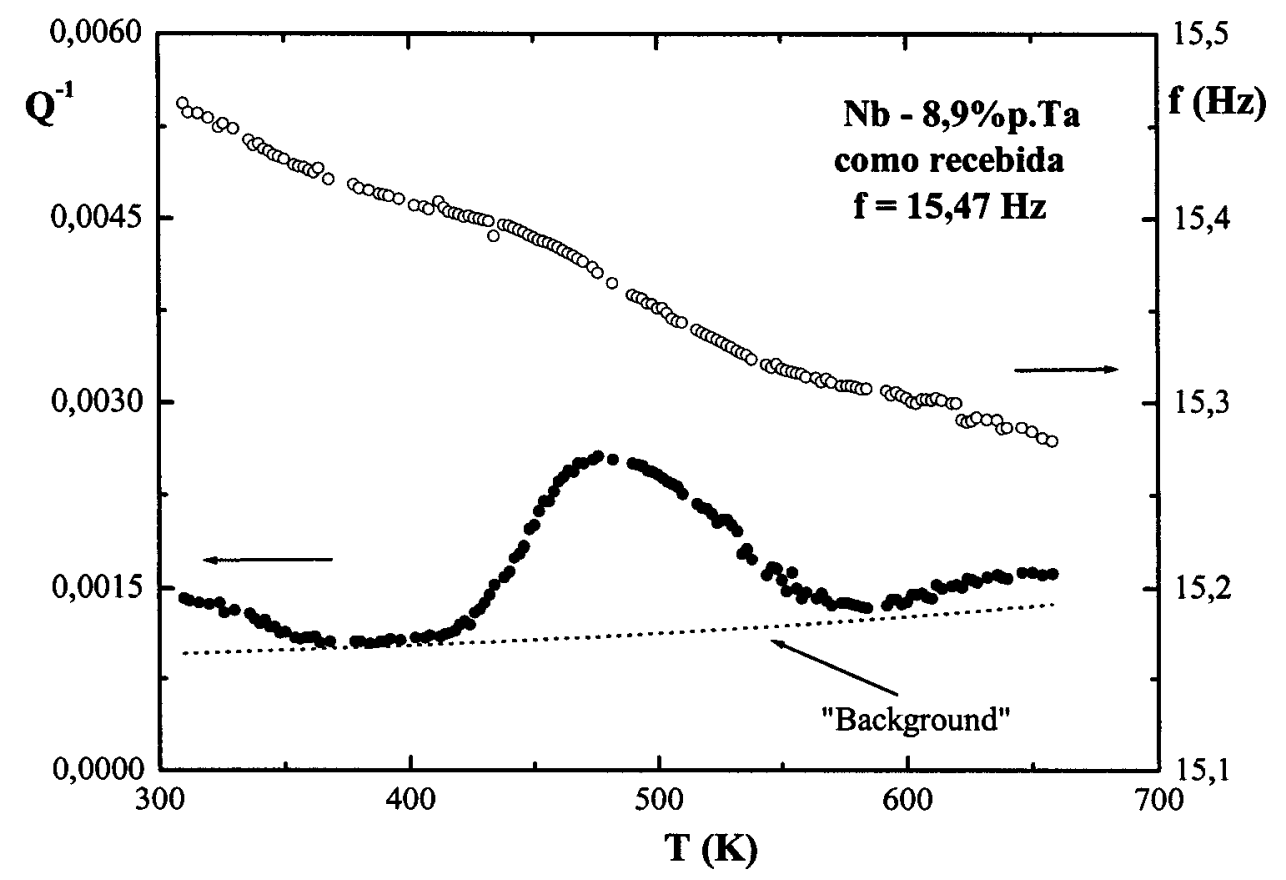

Figura 30 - Espectro de atrito interno como função da temperatura para amostra da liga $\mathrm{Nb}$ $8,9 \%$ p.Ta medido com freqüência de $15,47 \mathrm{~Hz}$, da maneira como recebida.

Em metais CCC, defeitos pontuais como átomos de solutos intersticiais estão preferencialmente posicionados em sítios octaedrais, causando deformação local da rede cristalina com simetria tetragonal.

$\mathrm{Na}$ ausência de tensão os átomos intersticiais estão distribuídos aleatoriamente nos sítios com eixos tetragonais. Quando uma tensão mecânica externa é aplicada ocorre uma reorientação dos átomos intersticiais para diferentes sítios equivalentes ${ }^{6,14,18}$.

A reorientação dos átomos para diferentes sítios é dependente do tempo, ou seja, estes processos causam uma mudança com o tempo da configuração de equilíbrio dos defeitos para um novo e único estado de equilíbrio, quando uma oscilação mecânica é aplicada. 
Quando esta tensão é removida a mudança é revertida e com o tempo o estado de equilíbrio original é restaurado ${ }^{6}$.

A dissipação de energia gerada durante a reorientação dos intersticiais, chamada atrito interno, alcança um valor máximo em uma temperatura distinta (dependendo da freqüência), conhecido como máximo de Snoek, ou pico de Snoek.

Pode-se observar pelos espectros anelásticos apresentados, a existência de uma estrutura de relaxação caracterizada pelo pico no espectro de atrito interno e o degrau na curva de freqüência, que são comportamentos característicos de processos de relaxação tipo Snoek (pico de Snoek) $^{7,15,41}$.

As estruturas de relaxação do tipo Snoek, são atribuídos à reorientação induzida por tensão de átomos intersticiais em torno de átomos da matriz metálica $22,23,42,43$.

A figura 31 mostra os espectros anelásticos apresentados anteriormente com o “background" extraído, onde é possível observar que existe um deslocamento da estrutura de relaxação para a região de maior temperatura à medida que se trabalhou com freqüências mais elevadas. 


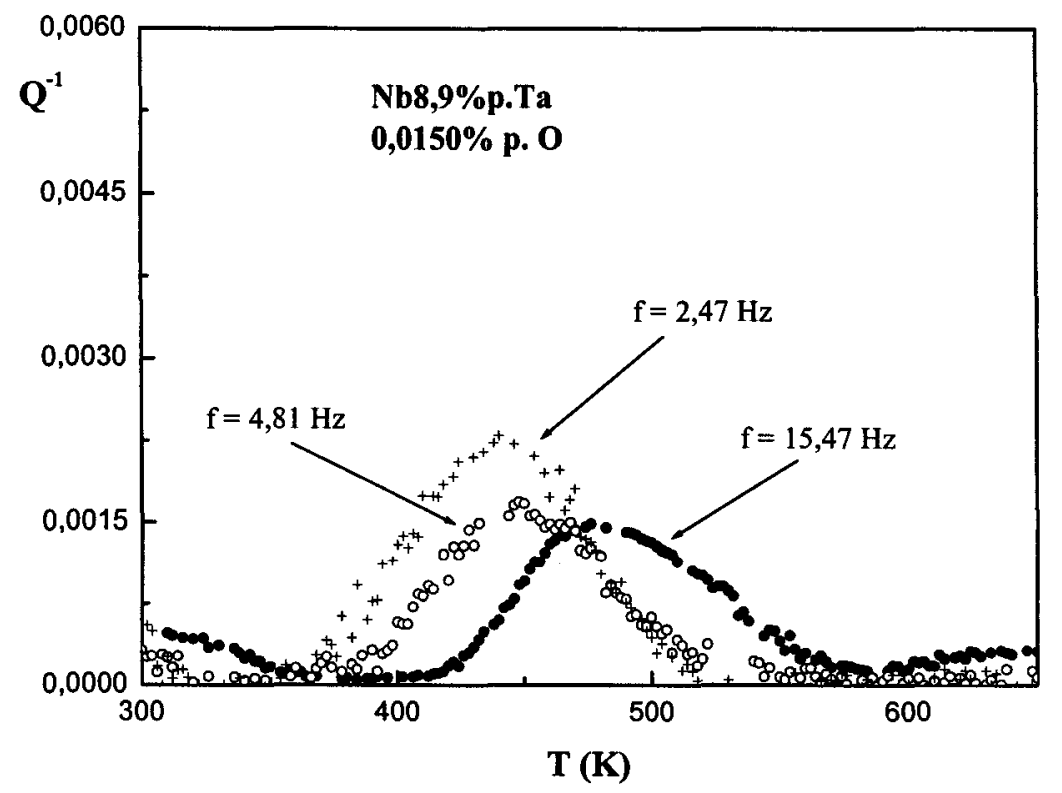

Figura 31 - Espectros anelásticos com "background" extraído para amostra da liga Nb8,9\%p.Ta medidos com diferentes freqüências, da maneira como recebida.

Esse deslocamento mostra que a estrutura de relaxação é termicamente ativada. Assim, é válida a Lei de Arrhenius, equação (46), que pode ser trabalhada da seguinte forma $^{7,44}$ :

$$
\omega \tau=\omega \tau_{0} \exp \left(\frac{\mathrm{E}}{\mathrm{kT}}\right)
$$

A condição básica para a ocorrência do pico de relaxação é que $\omega \tau=1$. Assim, aplicando essa condição e rearranjando a equação (80) temos:

$$
\ln f=-\ln \pi \tau_{0}-\frac{E}{k T_{p}}
$$


Deste modo medindo-se a temperatura e a freqüência nas proximidades do pico e fazendo um gráfico do logaritmo da freqüência em função do inverso da temperatura é possível obter os parâmetros necessários para calcular a energia de ativação ${ }^{45}$ e a frequiência de saltos $\tau_{0}^{-1}$, admitindo que o pico observado no espectro anelástico seja devido a um único processo de relaxação.

Com os dados obtidos através dos espectros anelásticos foi feito um gráfico do logaritmo da frequiência em função do inverso da temperatura do pico, sendo o resultado apresentado na figura 32 .

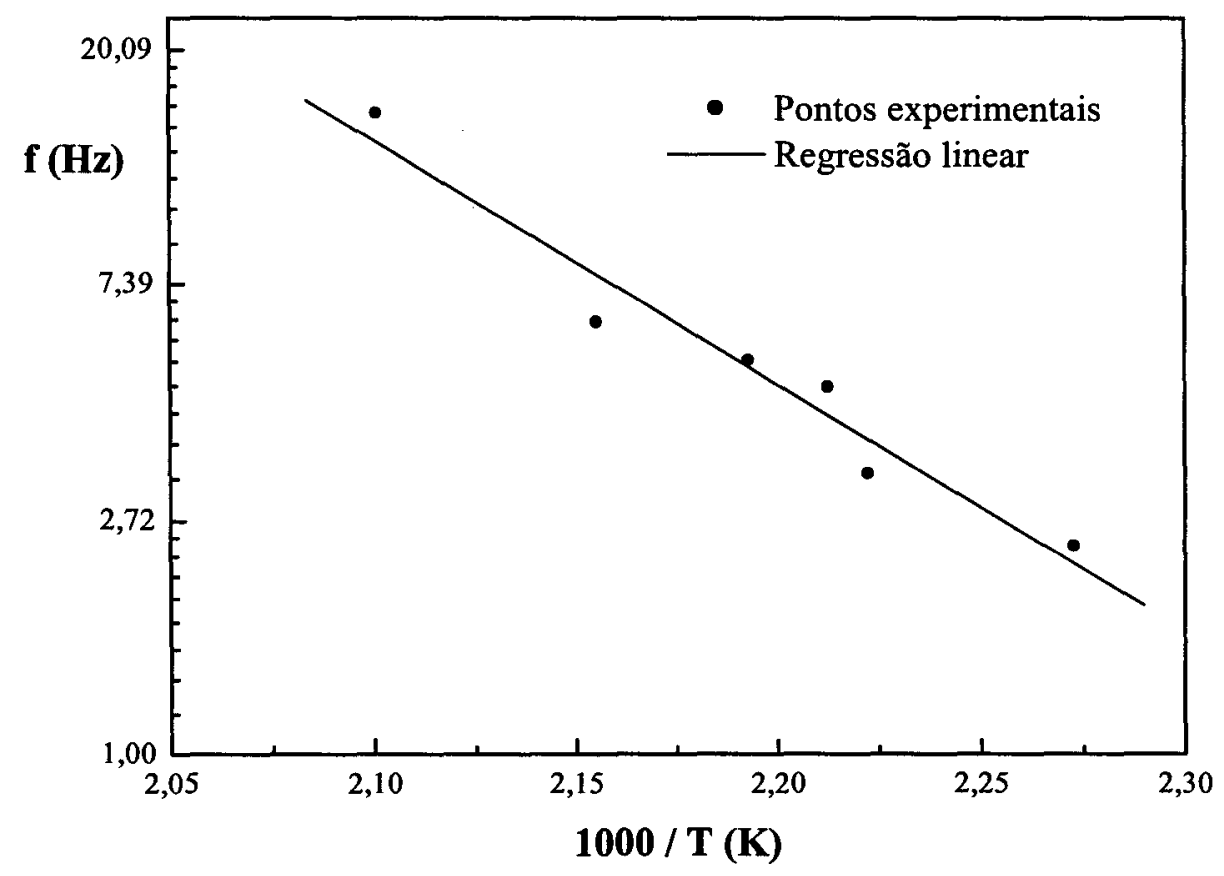

Figura 32 - Gráfico do logaritmo da freqüência em função do inverso da temperatura para a amostra da liga $\mathrm{Nb}-8,9 \%$ p.Ta.

A figura 32 mostra que os pontos experimentais estão em boa concordância com a Lei de Arrhenius, pois apresentam uma linearidade muito boa. Utilizando o programa de análise do Microcal Origin ${ }^{\circledR}$ foi possivel fazer uma regressão linear da curva experimental e 
obter os parâmetros necessários para calcular a energia de ativação do processo de relaxação e a frequiência de saltos. Os valores obtidos foram:

$$
\begin{aligned}
& E=(0,9 \pm 0,1) \mathrm{eV} \\
& \tau_{0}^{-1}=(1,30 \pm 0,05) \times 10^{11} \mathrm{~s}^{-1}
\end{aligned}
$$

Os valores obtidos acima apresentam uma discrepância com o que é encontrado na literatura. A Tabela 15 apresenta os valores de energia de ativação para alguns processos de relaxação, encontrados na literatura.

Tabela 15 - Energia de ativação dos processos de relaxação encontrada na literatura.

\begin{tabular}{c|c|c}
\hline \hline Processo & E (eV) & Ref. \\
\hline $\mathrm{Ta}-\mathrm{O}$ & 1,10 & $6,7,19,42$ \\
$\mathrm{Nb}-\mathrm{O}$ & 1,15 & $6,7,19,42$ \\
$\mathrm{Nb}-\mathrm{O}-\mathrm{O}$ & 1,22 & 6,19 \\
$\mathrm{Nb}-\mathrm{N}$ & 1,52 & 6,19 \\
\hline
\end{tabular}

Os valores de energia de ativação obtidos através da Lei de Arrhenius, bem como a assimetria do pico no espectro anelástico, sugerem que a estrutura de relaxação observada não seja devido a um processo de relaxação simples, mas sim uma composição de mais processos de relaxação ${ }^{46-49}$, sendo os dados experimentais obtidos uma somatória destes processos.

Assim, quando estão presentes mais de um processo de relaxação é necessário decompor o espectro anelástico em seus picos constituintes. Com o auxílio do programa Peak Fitting do Origin $\otimes$ foi possível fazer essa decomposição usando a equação de Debye (50), obtendo os parâmetros de relaxação para cada processo. 
As figuras 33 a 35 mostram as curvas experimentais obtidas para a amostra da liga $\mathrm{Nb}-8,9 \%$ p.Ta medida da maneira como recebida, decompostas em seus processos de relaxação constituintes. Foram identificados três processos, o primeiro atribuído à reorientação induzida por tensão de átomos de oxigênio em torno de átomos de tântalo, processo $\mathrm{Ta}-\mathrm{O}$; o segundo, atribuído à reorientação induzida por tensão de átomos de oxigênio em torno de átomos de nióbio, processo $\mathrm{Nb}-\mathrm{O}$ e o terceiro, atribuído à reorientação de átomos de nitrogênio em torno de átomos de nióbio, processo $\mathrm{Nb}-\mathrm{N}$.

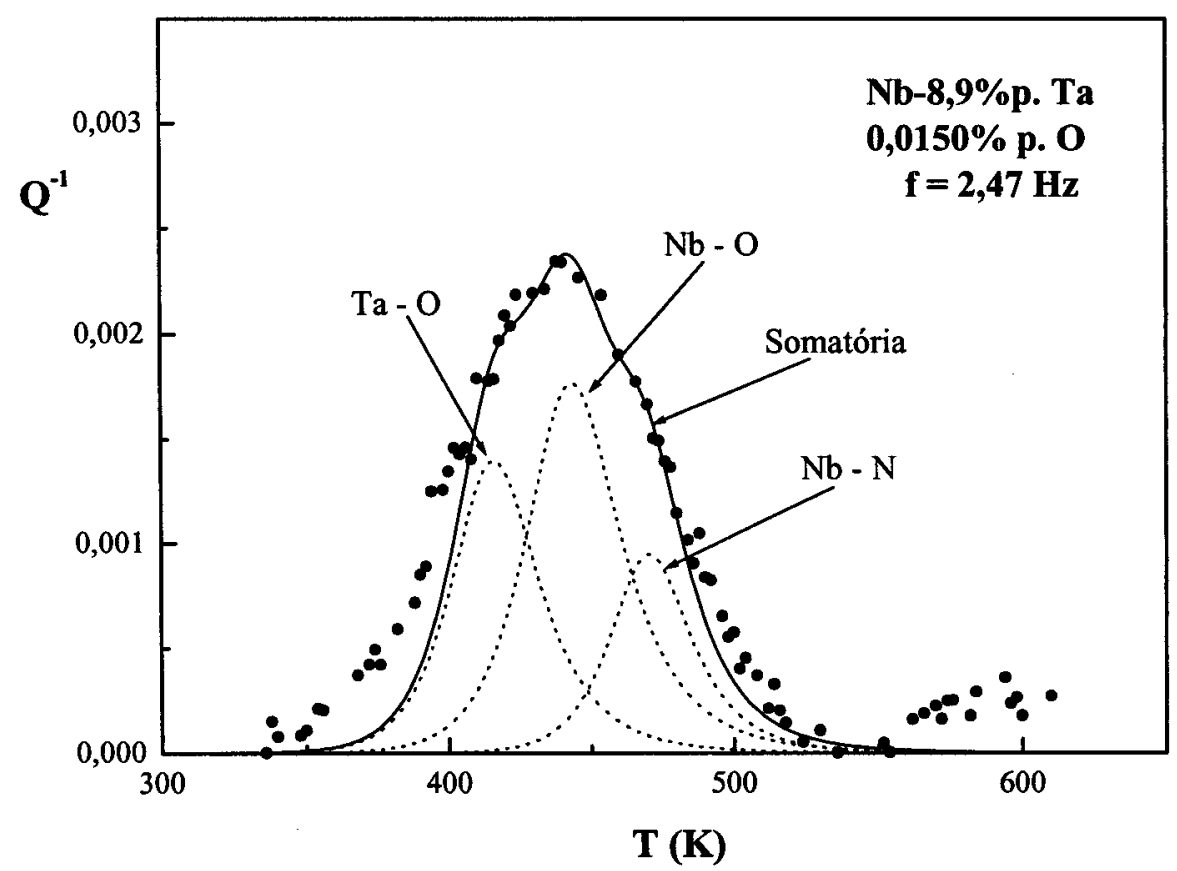

Figura 33 - Análise do espectro anelástico com "background" extraído para a amostra da liga $\mathrm{Nb}-8,9 \%$ p.Ta medido com freqüência de oscilação de $2,47 \mathrm{~Hz}$, da maneira como recebida, decomposto em seus processos de relaxação constituintes. 


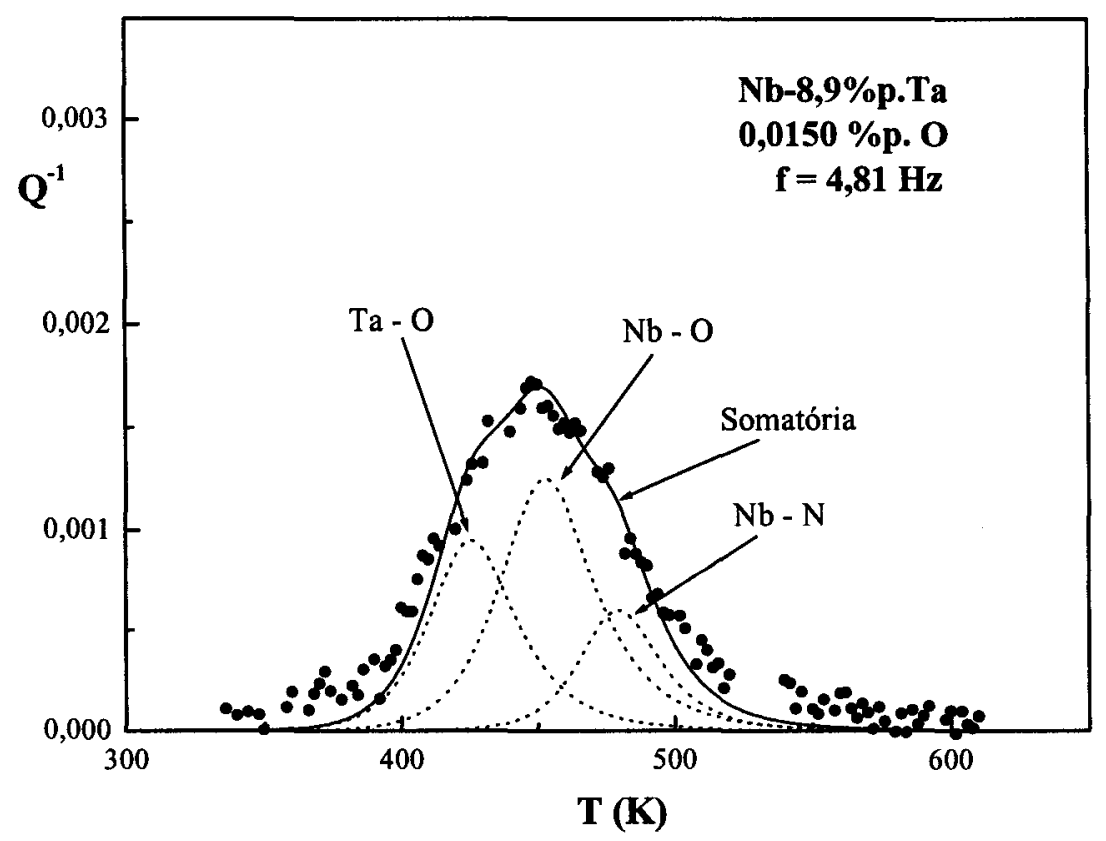

Figura 34 - Análise do espectro anelástico com "background" extraído para a amostra da liga $\mathrm{Nb}-8,9 \%$ p.Ta medido com freqüência de oscilação de $4,81 \mathrm{~Hz}$, da maneira como recebida, decomposto em seus processos de relaxação constituintes.

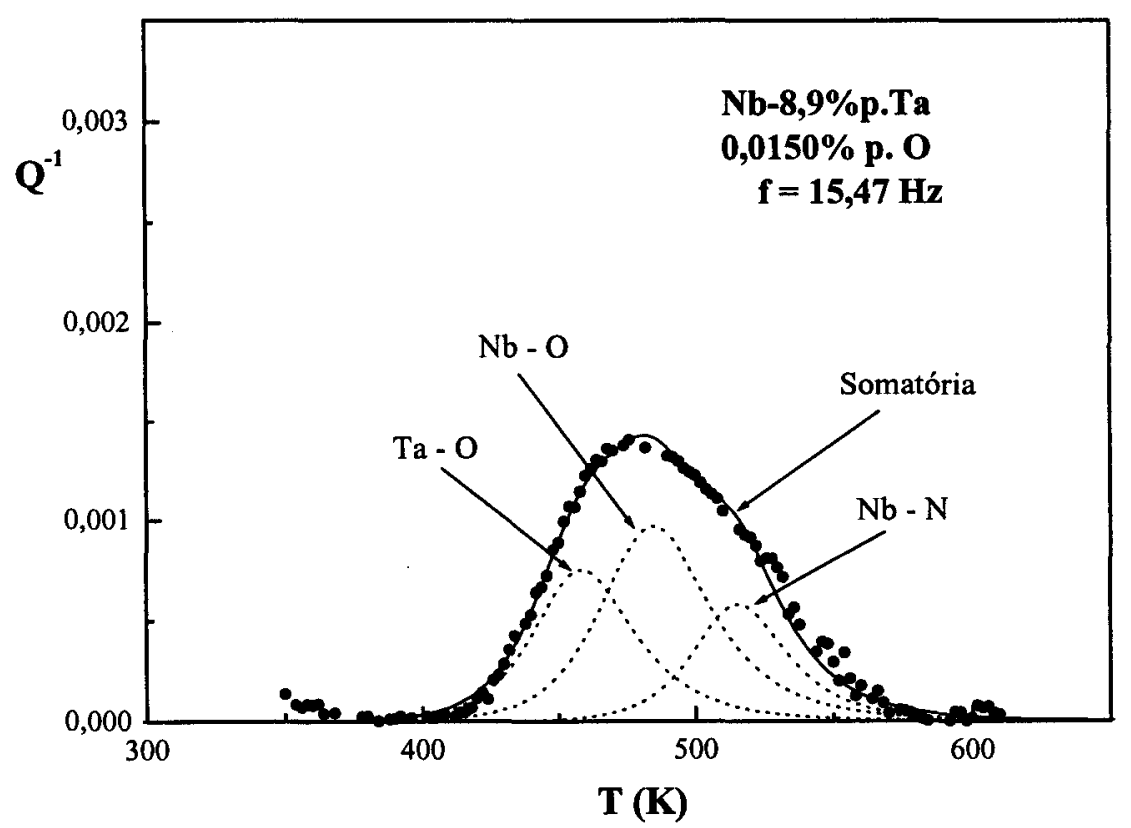

Figura 35 - Análise do espectro anelástico com "background" extraído para a amostra da liga $\mathrm{Nb}-8,9 \%$ p.Ta medido com freqüência de oscilação de $15,47 \mathrm{~Hz}$, da maneira como recebida, decomposto em seus processos de relaxação constituintes. 
Observa-se pelos espectros analisados que a superposição dos três processos propostos ajusta-se muito bem à curva experimental. $\mathrm{O}$ processo com maior intensidade é o $\mathrm{Nb}-\mathrm{O}$, devido ao fato da base desta liga ser nióbio. O processo que tem intensidade menor é o $\mathrm{Nb}-\mathrm{N}$, pois a concentração de nitrogênio é bem menor que de oxigênio. Os parâmetros de relaxação são listados na Tabela 16.

Tabela 16 - Parâmetros de relaxação (amostra como recebida).

\begin{tabular}{c|c|c|c|c}
\hline \hline Processo & $\mathbf{f}(\mathbf{H z})$ & $\mathbf{Q}_{\mathbf{p}}^{-1}$ & $\mathbf{T}_{\mathbf{p}}(\mathbf{K})$ & $\mathbf{E}(\mathbf{e V})$ \\
\hline \multirow{3}{*}{$\mathrm{Ta}-\mathrm{O}$} & 2,47 & 0,0013 & 415 & 1,10 \\
& 4,81 & 0,0010 & 425 & 1,10 \\
& 15,47 & 0,0007 & 459 & 1,10 \\
\hline \multirow{3}{*}{$\mathrm{Nb}-\mathrm{O}$} & 2,47 & 0,0018 & 442 & 1,15 \\
& 4,81 & 0,0013 & 453 & 1,15 \\
& 15,47 & 0,0009 & 485 & 1,15 \\
\hline \multirow{3}{*}{$\mathrm{Nb}-\mathrm{N}$} & 2,47 & 0,0008 & 469 & 1,52 \\
& 4,81 & 0,0006 & 479 & 1,52 \\
& 15,47 & 0,0006 & 516 & 1,52 \\
\hline
\end{tabular}

Após as análises iniciais efetuadas na amostra como recebida, esta passou por um tratamento térmico de recozimento para alívio de tensões internas. Em seguida foram obtidos os espectros anelásticos para a amostra, o que é apresentado nas figuras 36 a 38 . 


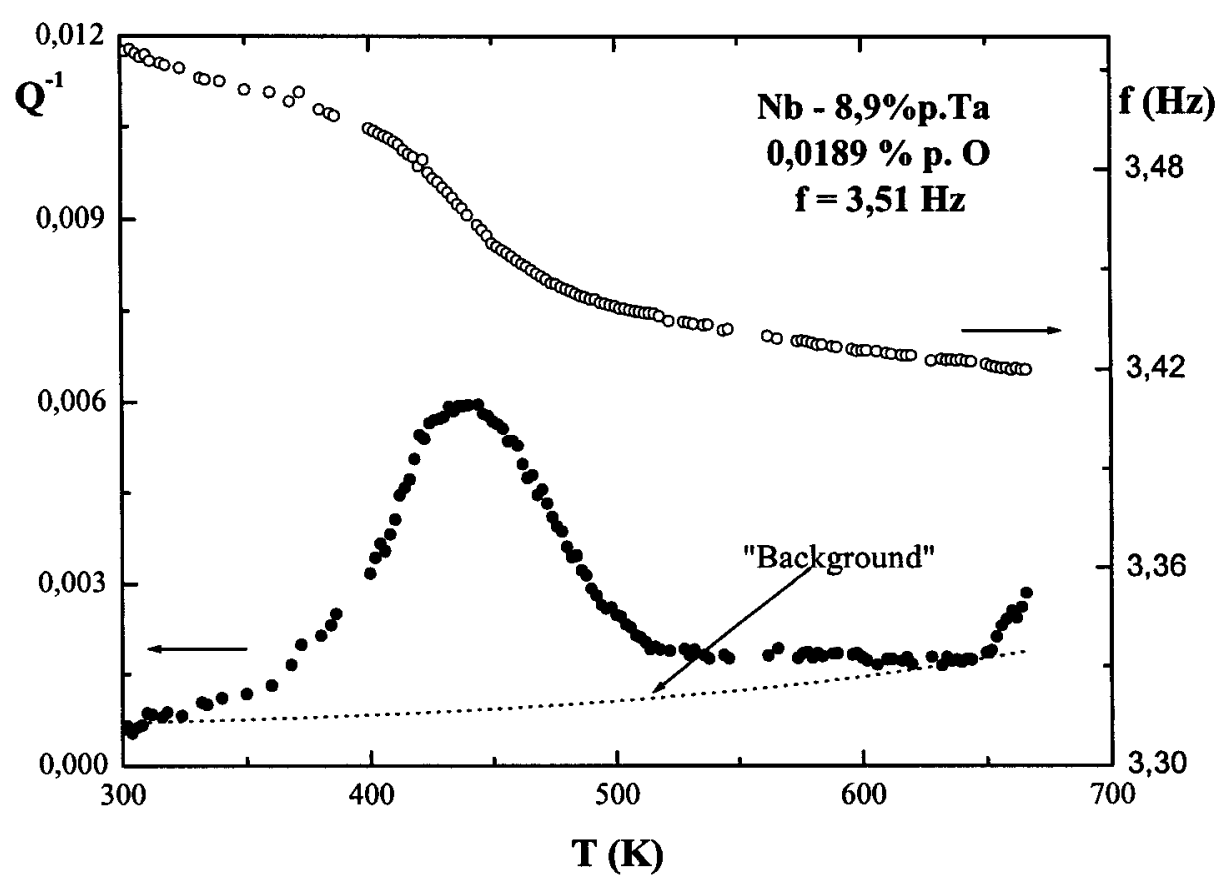

Figura 36 - Espectro de atrito interno como função da temperatura para amostra da liga Nb$8,9 \%$ p.Ta medido com freqüência de $3,51 \mathrm{~Hz}$, após o recozimento.

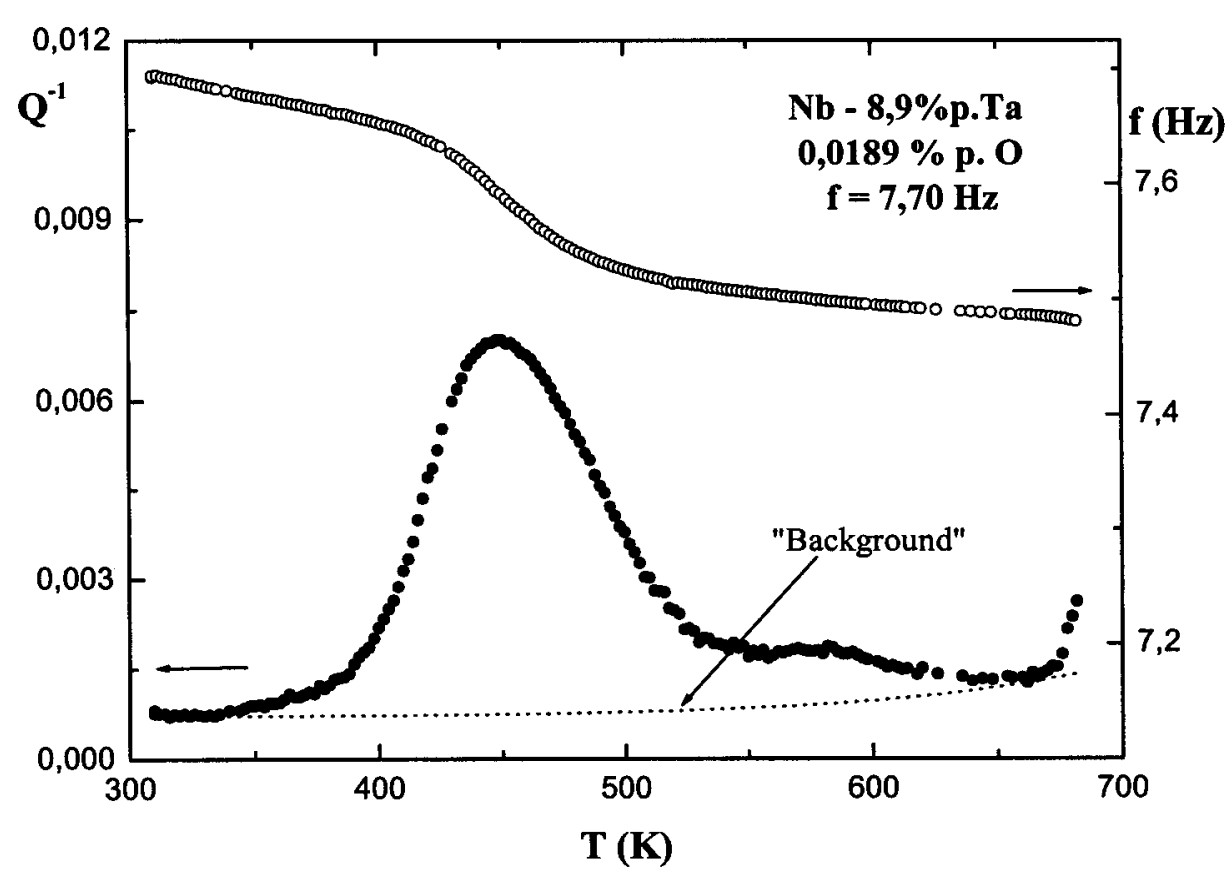

Figura 37 - Espectro de atrito interno como função da temperatura para amostra da liga Nb8,9\%p.Ta medido com frequiência de $7,70 \mathrm{~Hz}$, após o recozimento. 


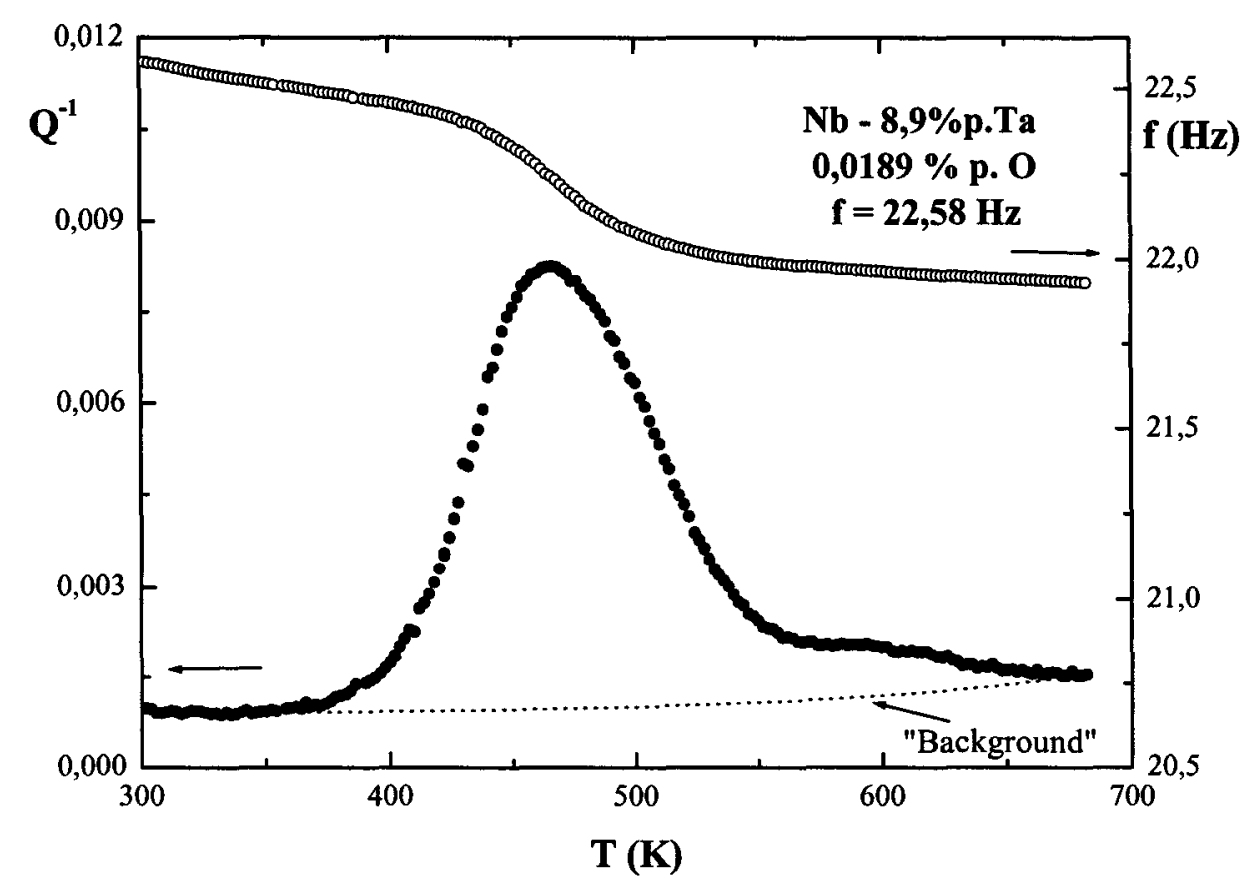

Figura 38 - Espectro de atrito interno como função da temperatura para amostra da liga $\mathrm{Nb}$ $8,9 \%$ p.Ta medido com frequiência de $22,58 \mathrm{~Hz}$, após o recozimento.

Após o recozimento houve uma alteração no comportamento do atrito interno, com o espectro de relaxação ficando bem mais resolvido. Observamos que o pico tem uma intensidade maior, pois provavelmente átomos de impurezas localizados nos contornos de grão se difundiram para o interior dos grãos, durante o recozimento.

A figura 39 mostra os espectros anelásticos com o "background" extraído obtidos após o recozimento, onde é possível observar um deslocamento do pico para a região de maior temperatura a medida que se trabalhou com frequiências maiores, caracterizando que o processo é termicamente ativado. 


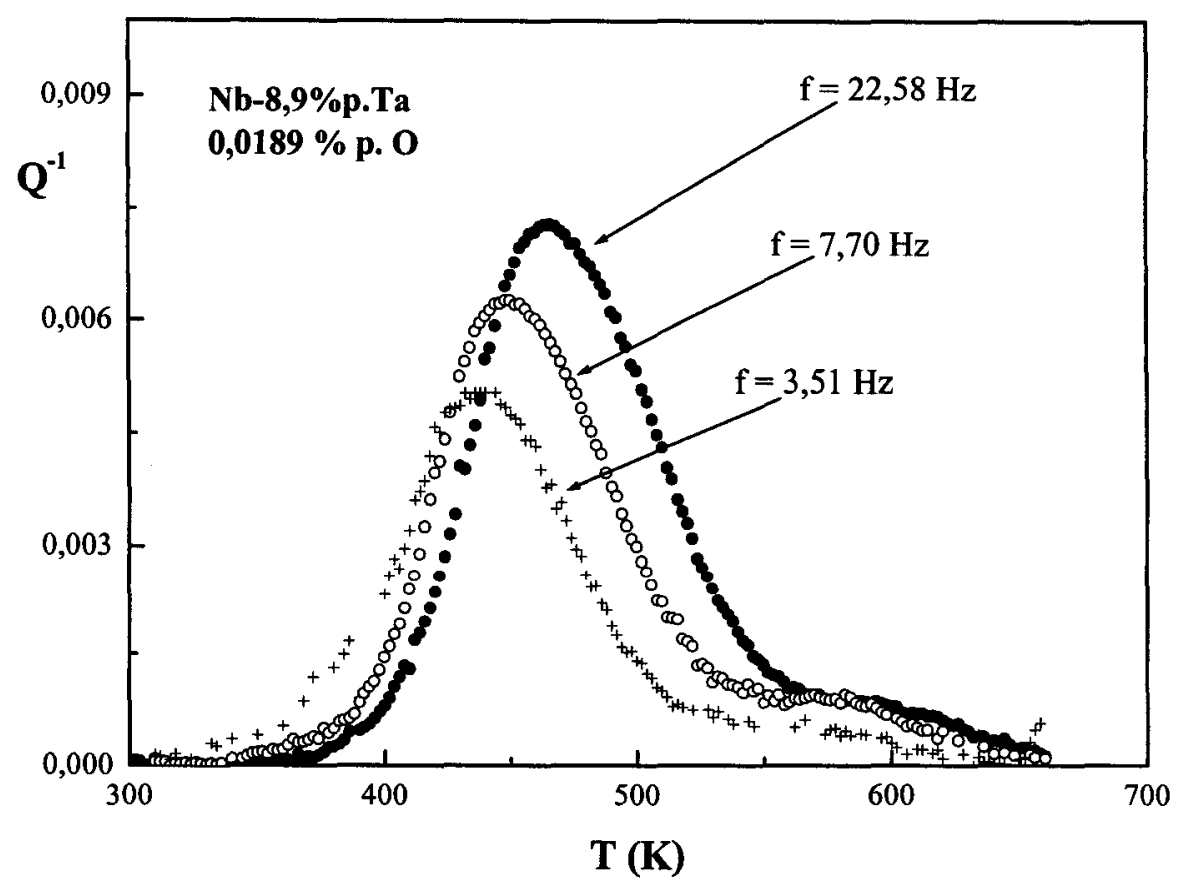

Figura 39 - Espectros anelásticos com o "background" extraído para amostra da liga Nb8,9\%p.Ta medidos com diferentes freqüências após o recozimento.

Seguindo os mesmos procedimentos utilizados nas análises anteriores, os espectros anelásticos obtidos para a amostra da liga $\mathrm{Nb}-8,9 \%$ p.Ta após o recozimento foram decompostos em seus picos constituintes. As figuras 40 a 42 mostram esta análise.

Em metais com maior quantidade de intersticiais os picos de Snoek são alargados, pois surgem interações entre os intersticiais, dando origem a picos de relaxação devido a reorientação induzida por tensão de pares e tripletos de átomos intersticiais em torno de átomos da matriz metálica.

Agora, em função do aumento da quantidade de intersticiais a estrutura de relaxação se apresenta mais larga e foram identificados quatro processos de relaxação, o primeiro processo atribuído à reorientação induzida por tensão de átomos de oxigênio em torno de 
átomos de tântalo, o segundo, atribuído à reorientação induzida por tensão de átomos de oxigênio em torno de átomos de nióbio, o terceiro, atribuído à reorientação induzida por tensão de pares de átomos de oxigênio em torno de átomos de nióbio e o quarto atribuído a reorientação induzida por tensão de átomos de nitrogênio em torno de átomos de nióbio.

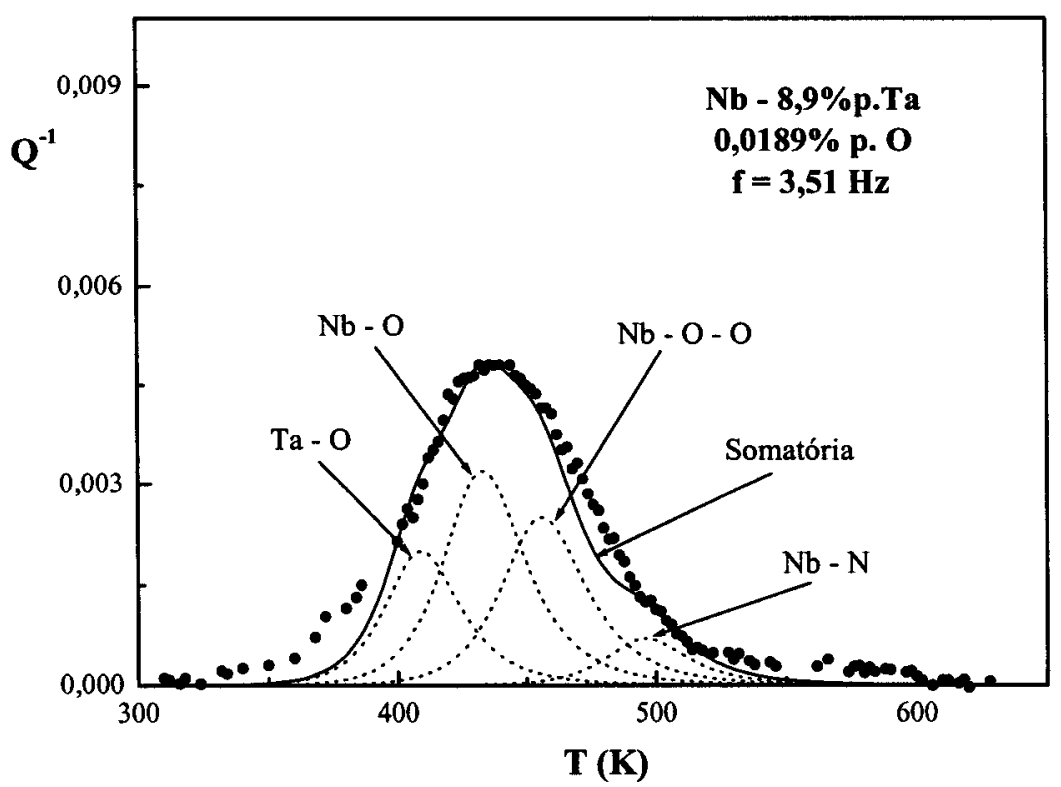

Figura 40 - Análise do espectro anelástico com "background" extraído para a amostra da liga $\mathrm{Nb}-8,9 \%$ p.Ta medido com freqüência de oscilação de $3,51 \mathrm{~Hz}$, após o recozimento, decomposto em quatro processos de relaxação.

Observamos pelas figuras das análises do espectro anelástico obtidos após o recozimento que foram encontrados os três processos identificados nas análises dos espectros obtidos para a amostra antes do recozimento e um outro processo, atribuído à reorientação induzida por tensão de pares de átomos de oxigênio em torno de átomos de nióbio, processo $\mathrm{Nb}-\mathrm{O}-\mathrm{O}$. 


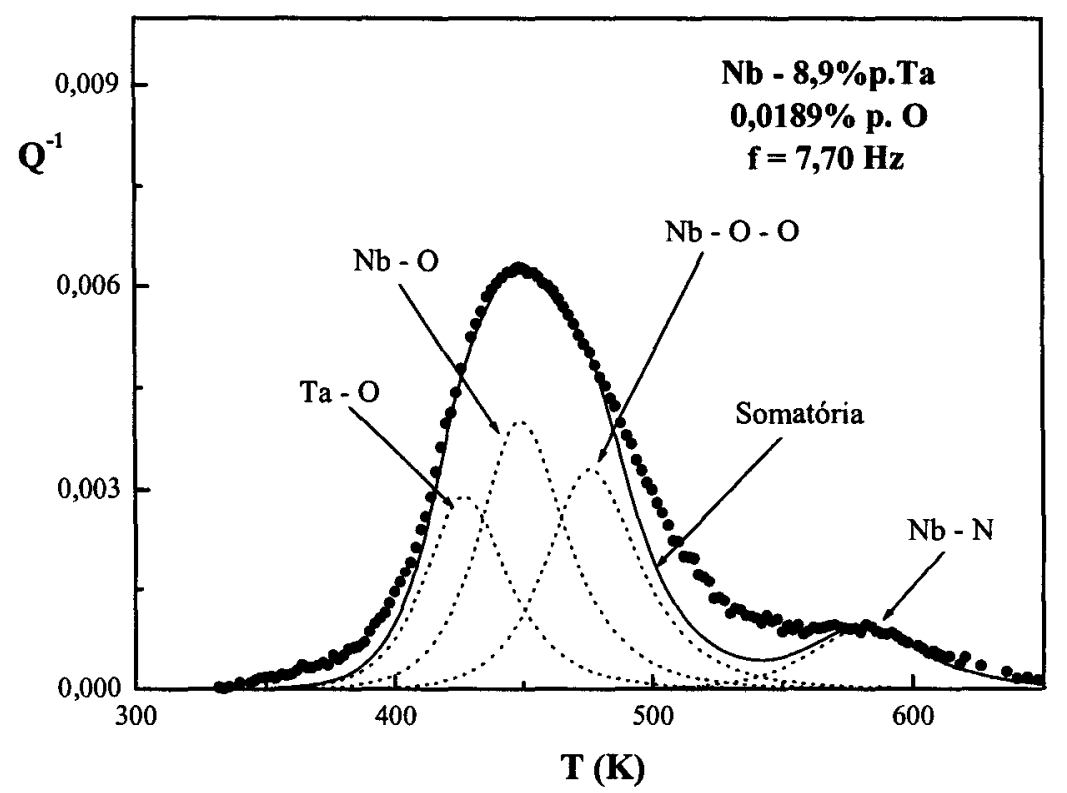

Figura 41 - Análise do espectro anelástico com "background" extraído para a amostra da liga $\mathrm{Nb}-8,9 \%$ p.Ta medido com freqüência de oscilação de $7,70 \mathrm{~Hz}$, após o recozimento, decomposto em quatro processos de relaxação.

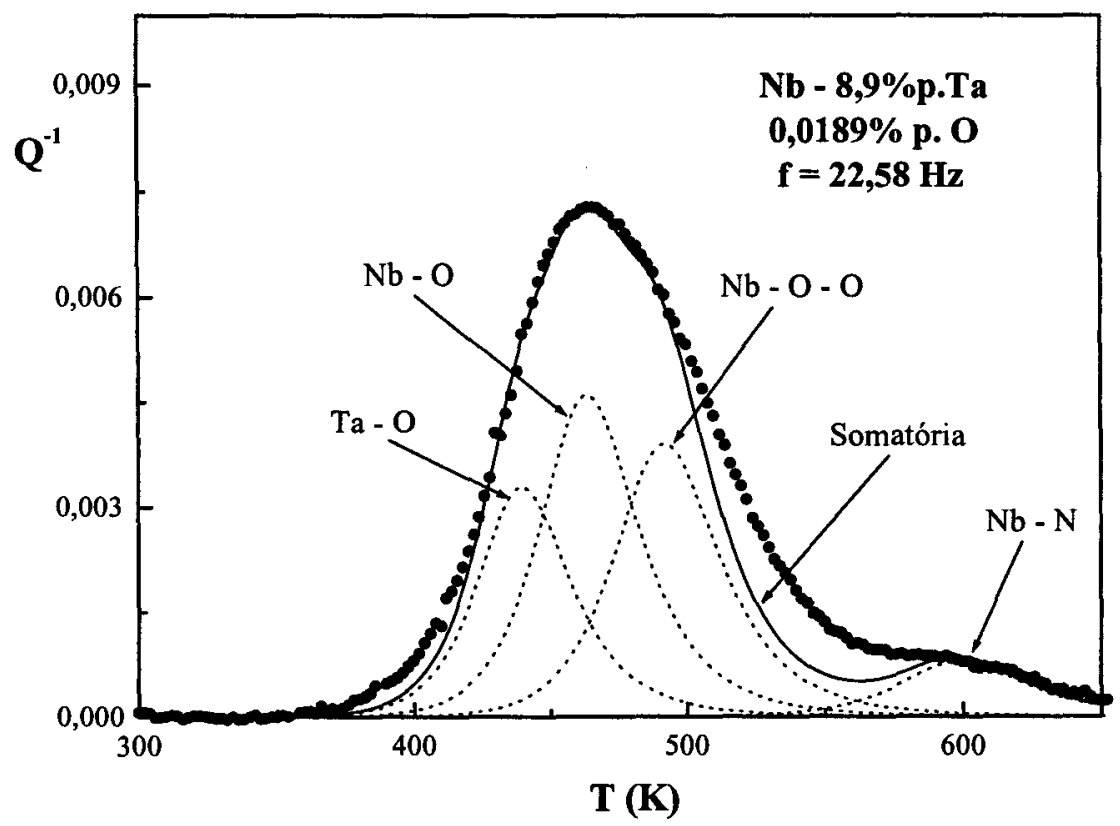

Figura 42 - Análise do espectro anelástico com "background" extraído para a amostra da liga $\mathrm{Nb}-8,9 \%$ p.Ta medido com freqüência de oscilação de $22,58 \mathrm{~Hz}$, após o recozimento, decomposto em quatro processos de relaxação. 
A decomposição dos espectros anelásticos em seus processos de relaxação constituintes mostra que o aparecimento da interação de pares de átomos de oxigênio com átomos da matriz metálica propiciou um melhor ajuste da curva teórica à curva experimental

Um ponto importante a se observar nestas figuras é que a intensidade do processo $\mathrm{Nb}$ - $\mathrm{N}$ não teve uma alteração significativa. Isso ocorre porque a concentração deste elemento intersticial não teve um aumento considerável e que existe uma tendência de que a intensidade do processo $\mathrm{Nb}-\mathrm{O}$ tenha um aumento maior que os outros processos. Os parâmetros de relaxação são apresentados na Tabela 17.

Tabela 17 - Parâmetros de relaxação (após o recozimento).

\begin{tabular}{c|c|c|c|c}
\hline \hline Processo & $\mathbf{f}(\mathbf{H z})$ & $\mathbf{Q}_{\mathbf{p}}{ }^{-1}$ & $\mathbf{T}_{\mathbf{p}}(\mathbf{K})$ & $\mathbf{E}(\mathbf{e V})$ \\
\hline \multirow{3}{*}{ Ta-O } & 3,51 & 0,0020 & 409 & 1,10 \\
& 7,70 & 0,0029 & 427 & 1,10 \\
& 22,58 & 0,0039 & 440 & 1,10 \\
\hline \multirow{3}{*}{ Nb-O } & 3,51 & 0,0032 & 433 & 1,15 \\
& 7,70 & 0,0040 & 449 & 1,15 \\
& 22,58 & 0,0046 & 464 & 1,15 \\
\hline \multirow{3}{*}{ Nb-O-O } & 3,51 & 0,0025 & 456 & 1,22 \\
& 7,70 & 0,0033 & 476 & 1,22 \\
& 22,58 & 0,0039 & 492 & 1,22 \\
\hline & 3,51 & 0,0007 & 496 & 1,52 \\
Nb-N & 7,70 & 0,0009 & 581 & 1,52 \\
& 22,58 & 0,0008 & 599 & 1,52 \\
\hline
\end{tabular}

Após as análises dos espectros anelásticos obtido para a amostra da liga $\mathrm{Nb}$ $8,9 \%$ p.Ta da maneira como recebida e após o recozimento, teve início os processos de 
dopagem com oxigênio, para verificar como o aumento da concentração de intersticiais influenciaria o espectro anelástico.

Após a primeira dopagem foi constatado pela caracterização da amostra que houve um aumento significativo na concentração de oxigênio. Os espectros anelásticos obtidos para a amostra da liga após a primeira dopagem são apresentados nas figuras 43 a 45 .

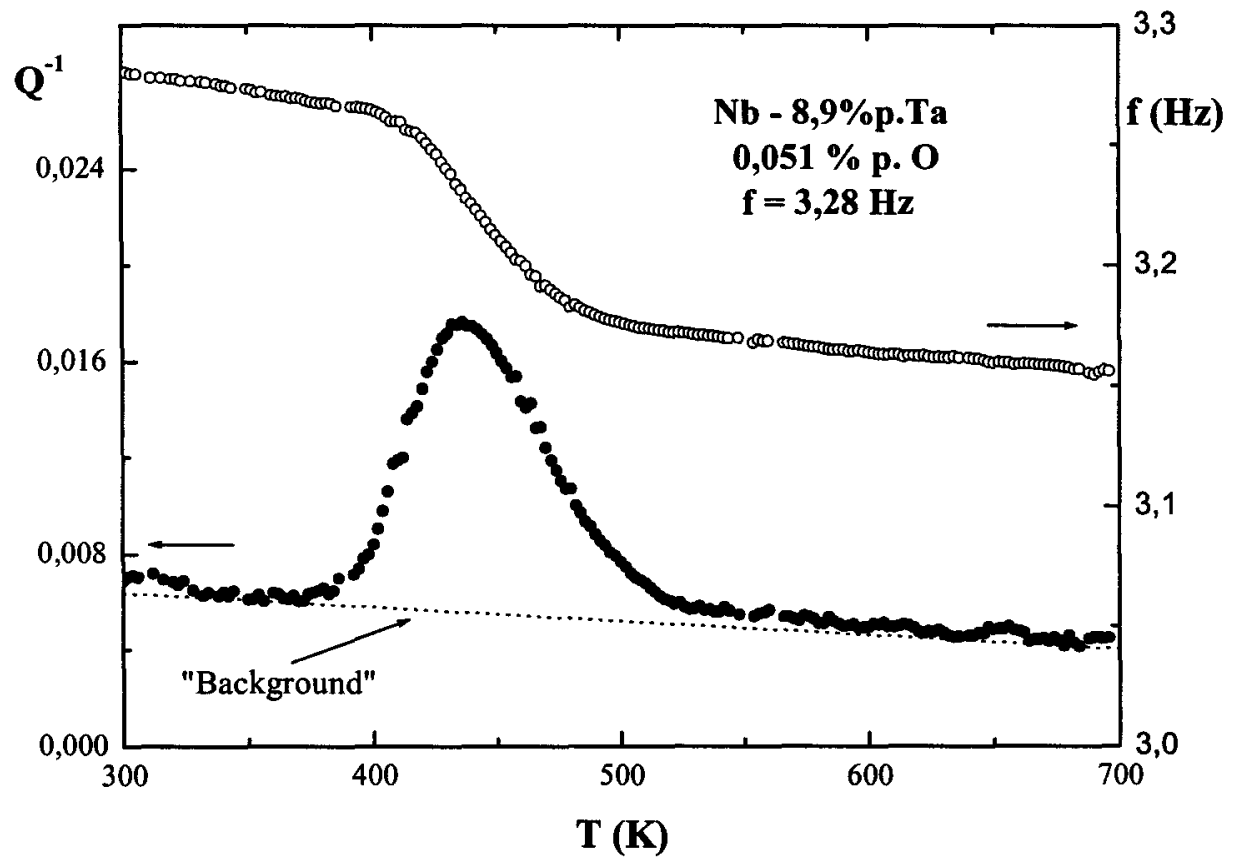

Figura 43 - Espectro de atrito interno como função da temperatura para amostra da liga Nb$8,9 \%$ p.Ta medido com freqüência de $3,28 \mathrm{~Hz}$, após a primeira dopagem. 


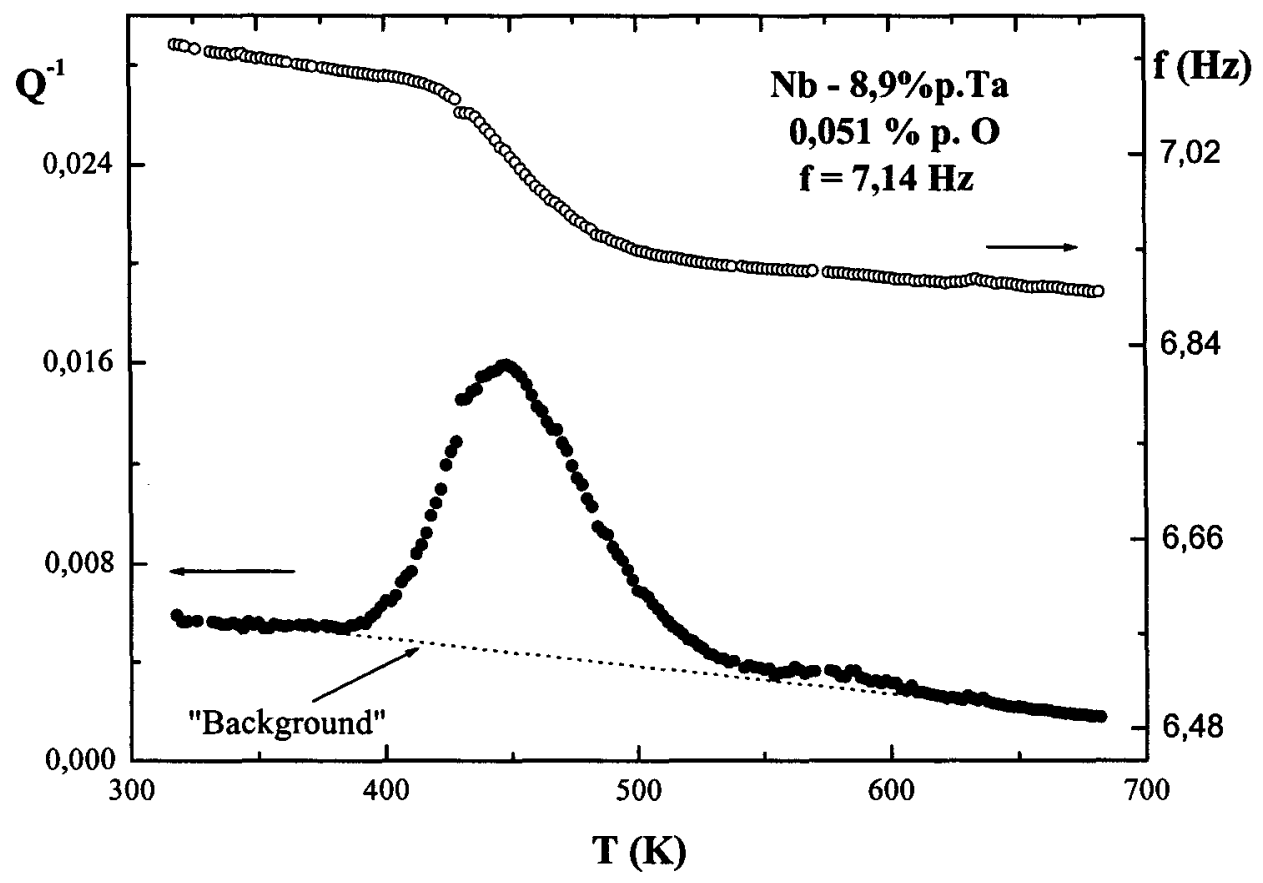

Figura 44 - Espectro de atrito interno como função da temperatura para amostra da liga Nb8,9\%p.Ta medido com freqüência de 7,14 Hz, após a primeira dopagem.

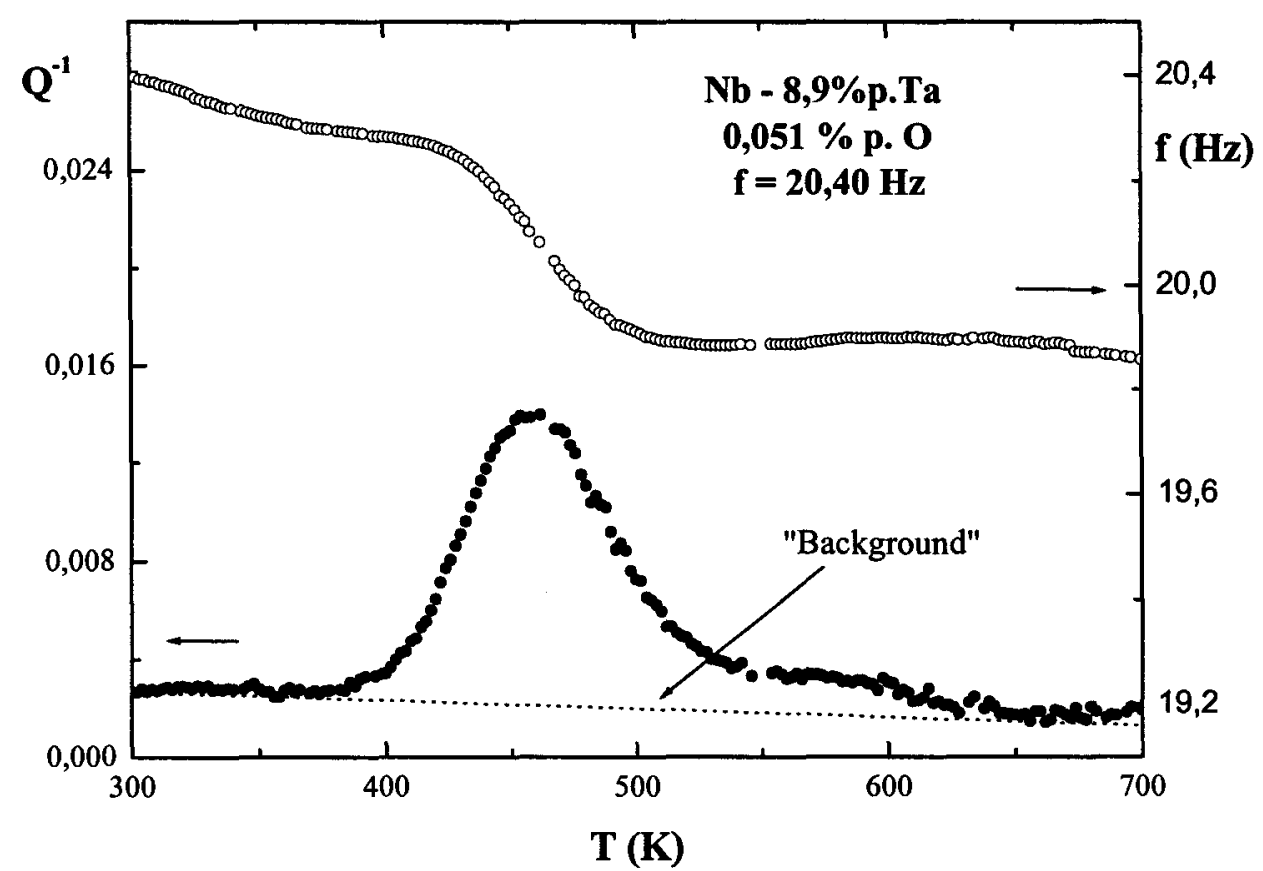

Figura 45 - Espectro de atrito interno como função da temperatura para amostra da liga Nb$8,9 \%$ p.Ta medido com freqüência de $20,40 \mathrm{~Hz}$, após a primeira dopagem. 
Pode-se observar que o espectro apresenta a estrutura de relaxação bem definida e que o pico tem uma intensidade maior em relação às medidas anteriores, o que era esperado visto que a concentração de intersticiais aumentou devido ao processo de dopagem.

A figura 46 mostra os espectros anelásticos obtidos para amostra da liga, após a primeira dopagem com o "background" extraído, na qual é possível confirmar que o processo é termicamente ativado, pois o pico se desloca para a região de maior temperatura à medida que se trabalhou com freqüências mais elevadas.

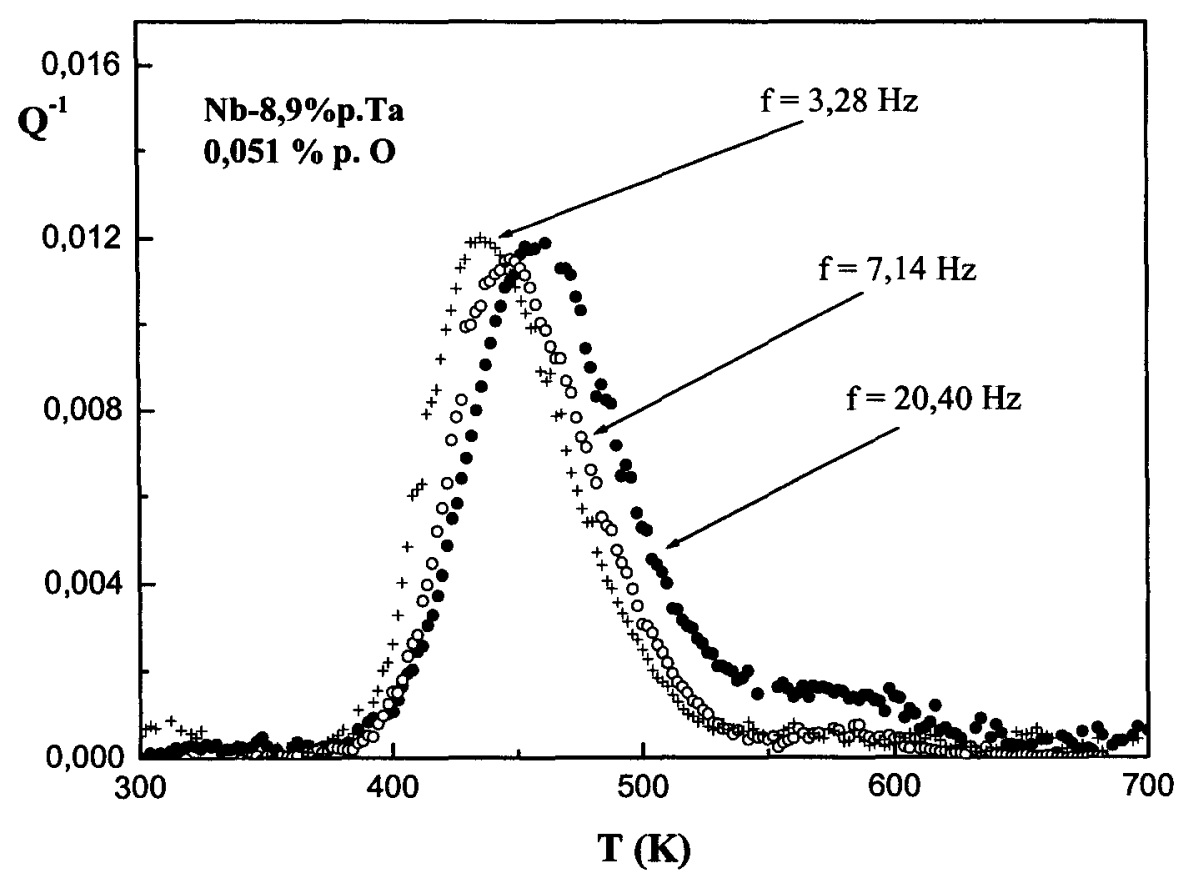

Figura 46 - Espectros anelásticos com "background" extraído para amostra da liga Nb8,9\%p.Ta medidos com diferentes freqüências após a primeira dopagem.

A curva experimental foi, então, decomposta em seus picos constituintes, as figuras 47 a 49 mostram os espectros anelásticos após a primeira dopagem, decompostos nos mesmos quatro processos de relaxação observados anteriormente. 


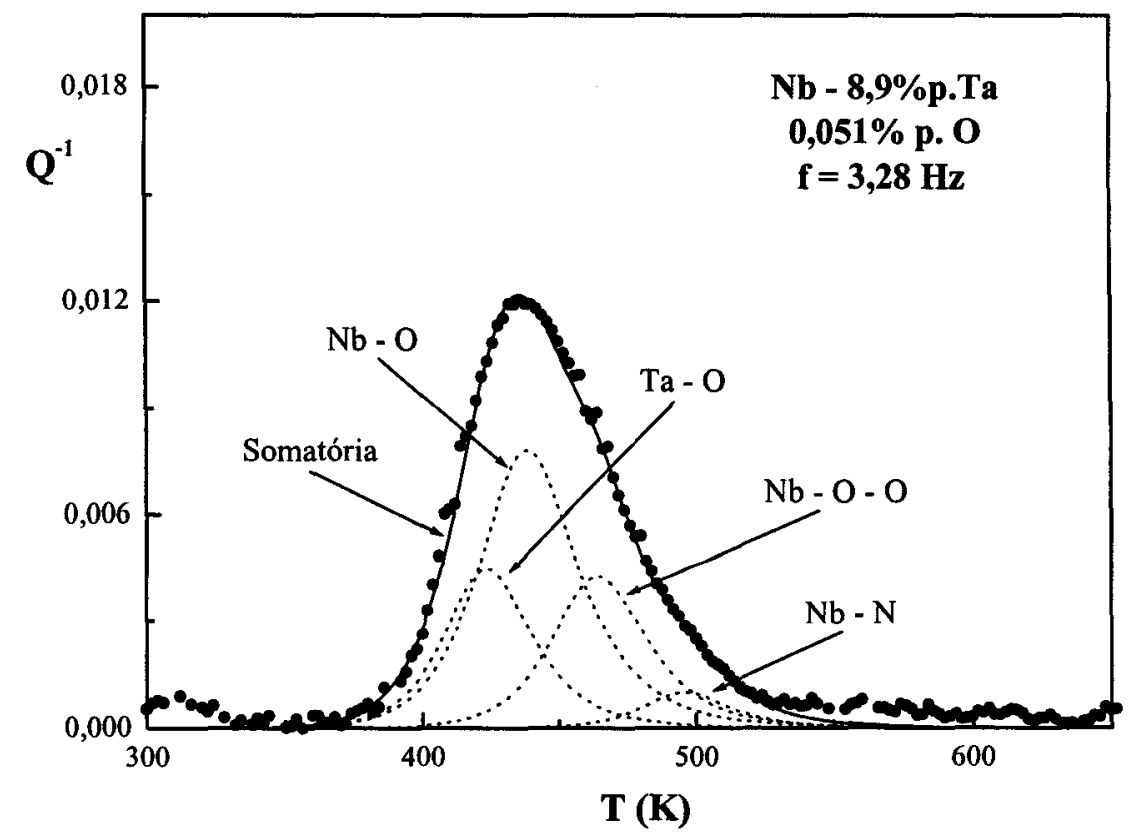

Figura 47 - Análise do espectro anelástico com "background" extraído para a amostra da liga $\mathrm{Nb}-8,9 \%$ p.Ta medido com freqüência de oscilação de $3,28 \mathrm{~Hz}$ após a primeira dopagem, decomposto em quatro processos de relaxação.

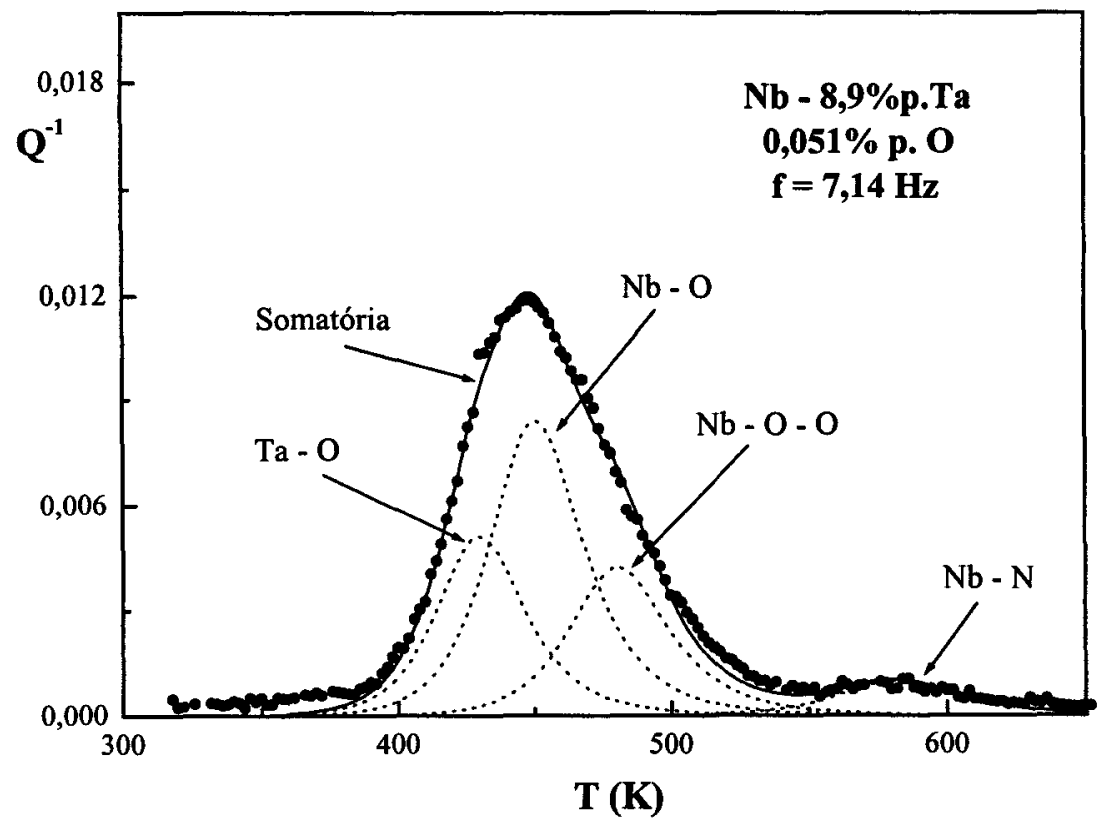

Figura 48 - Análise do espectro anelástico com "background" extraído para a amostra da liga $\mathrm{Nb}-8,9 \%$ p.Ta medido com freqüência de oscilação de $7,14 \mathrm{~Hz}$ após a primeira dopagem, decomposto em quatro processos de relaxação. 


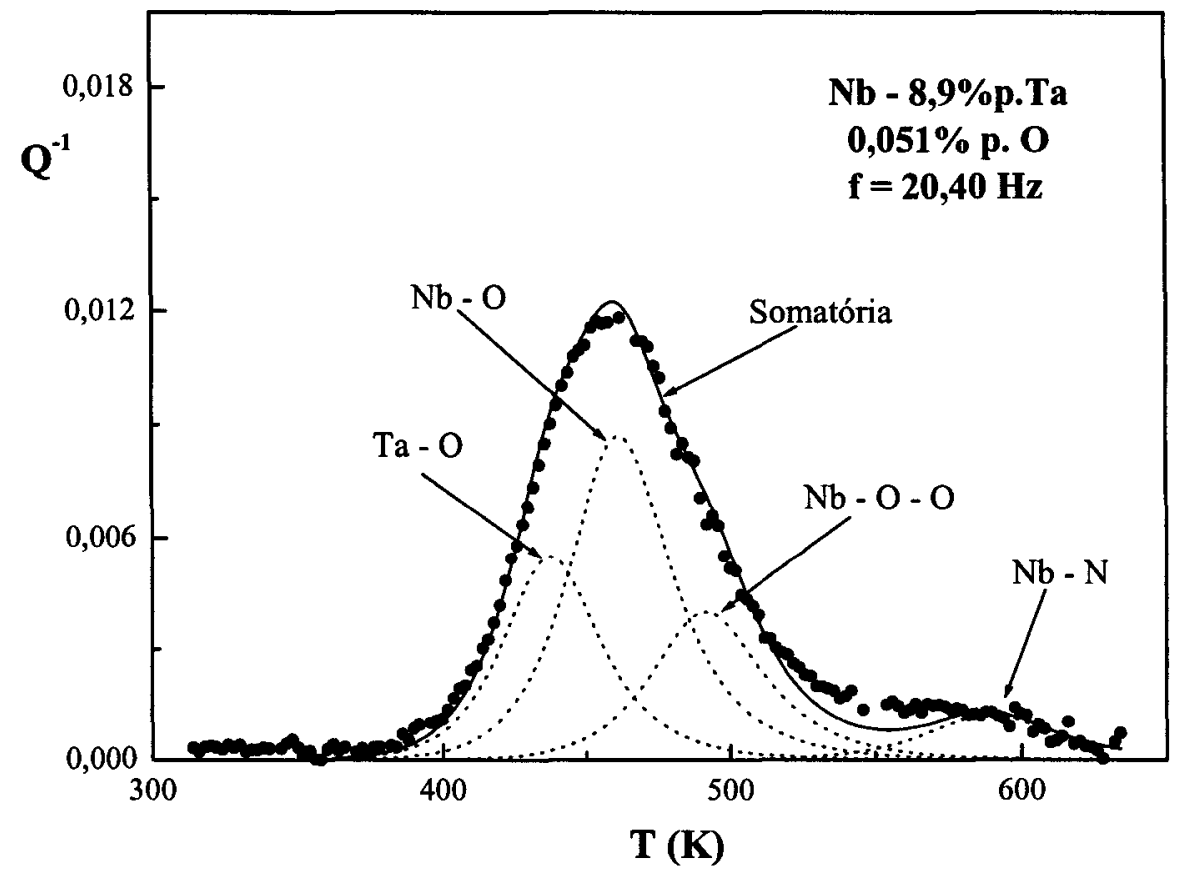

Figura 49 - Análise do espectro anelástico com "background" extraído para a amostra da liga Nb-8,9\%p.Ta medido com freqüência de oscilação de $20,40 \mathrm{~Hz}$ após a primeira dopagem, decomposto em quatro processos de relaxação.

As análises dos espectros anelásticos obtidos após a primeira dopagem, mostram que a superposição destes quatro processos ajusta-se muito bem à curva experimental. A tendência sugerida nas análises dos espectros obtidos após o recozimento, ou seja, que a intensidade do processo $\mathrm{Nb}-\mathrm{O}$ teria um aumento maior que os outros processos foi mantida. Os parâmetros de relaxação são apresentados na Tabela 18. 
Tabela 18 - Parâmetros de relaxação (após a primeira dopagem).

\begin{tabular}{c|c|c|c|c}
\hline \hline Processo & $\mathbf{f}(\mathbf{H z})$ & $\mathbf{Q}_{\mathbf{p}}{ }^{-1}$ & $\mathbf{T}_{\mathbf{p}}(\mathbf{K})$ & $\mathbf{E}(\mathbf{e V})$ \\
\hline \multirow{3}{*}{ Ta-O } & 3,28 & 0,0048 & 422 & 1,10 \\
& 7,14 & 0,0051 & 430 & 1,10 \\
& 20,40 & 0,0055 & 439 & 1,10 \\
\hline \multirow{3}{*}{ Nb-O } & 3,28 & 0,0079 & 438 & 1,15 \\
& 7,14 & 0,0084 & 450 & 1,15 \\
& 20,40 & 0,0087 & 462 & 1,15 \\
\hline \multirow{3}{*}{ Nb-O-O } & 3,28 & 0,0042 & 464 & 1,22 \\
& 7,14 & 0,0040 & 481 & 1,22 \\
& 20,40 & 0,0040 & 492 & 1,22 \\
\hline \multirow{3}{*}{ Nb-N } & 3,28 & 0,0010 & 496 & 1,52 \\
& 7,14 & 0,0010 & 582 & 1,52 \\
& 20,40 & 0,0012 & 590 & 1,52 \\
\hline
\end{tabular}

Os resultados mostram que quanto maior a concentração de intersticiais maior a intensidade do pico. Para confirmar essa tendência foram efetuadas mais algumas dopagens. Com a segunda dopagem verificou-se pelos dados apresentados na seção IV. 5. que houve um aumento na concentração de oxigênio.

Após a segunda dopagem foram obtidos os espectros anelásticos para a amostra da liga $\mathrm{Nb}-8,9 \%$ p.Ta, o que é apresentado nas figuras 50 a 52 . 


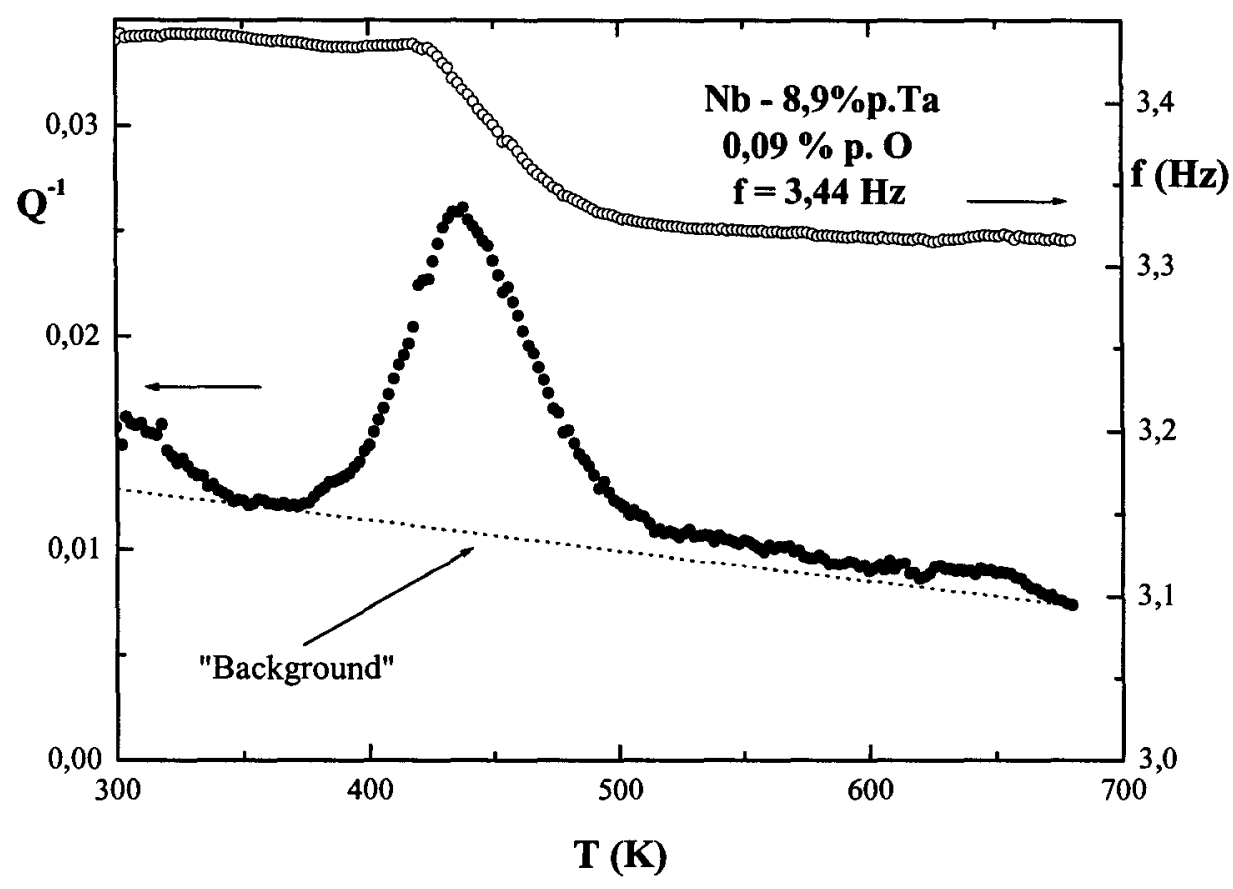

Figura 50 - Espectro de atrito interno como função da temperatura para amostra da liga Nb$8,9 \%$ p.Ta medido com frequiência de $3,44 \mathrm{~Hz}$, após a segunda dopagem.

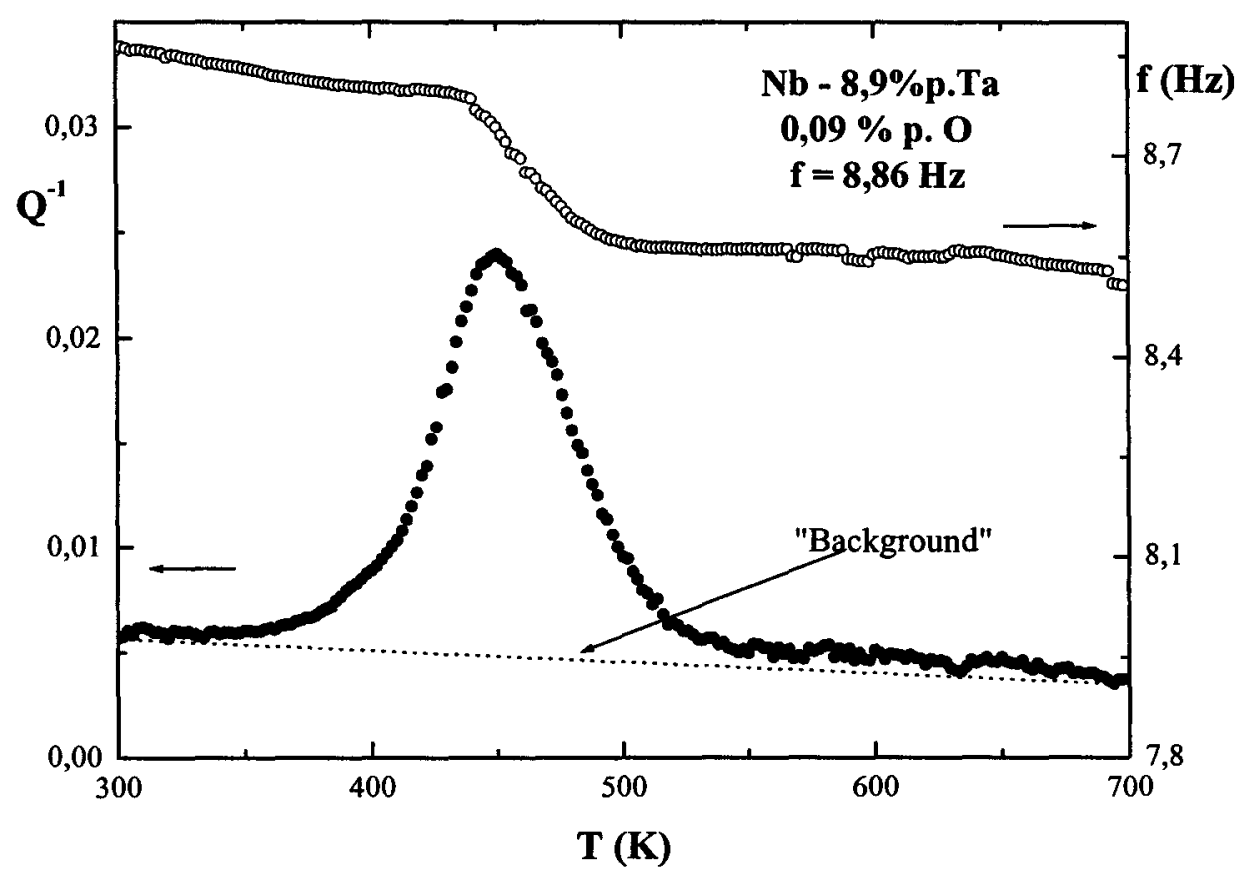

Figura 51 - Espectro de atrito interno como função da temperatura para amostra da liga Nb$8,9 \%$ p.Ta medido com freqüência de $8,86 \mathrm{~Hz}$, após a segunda dopagem. 


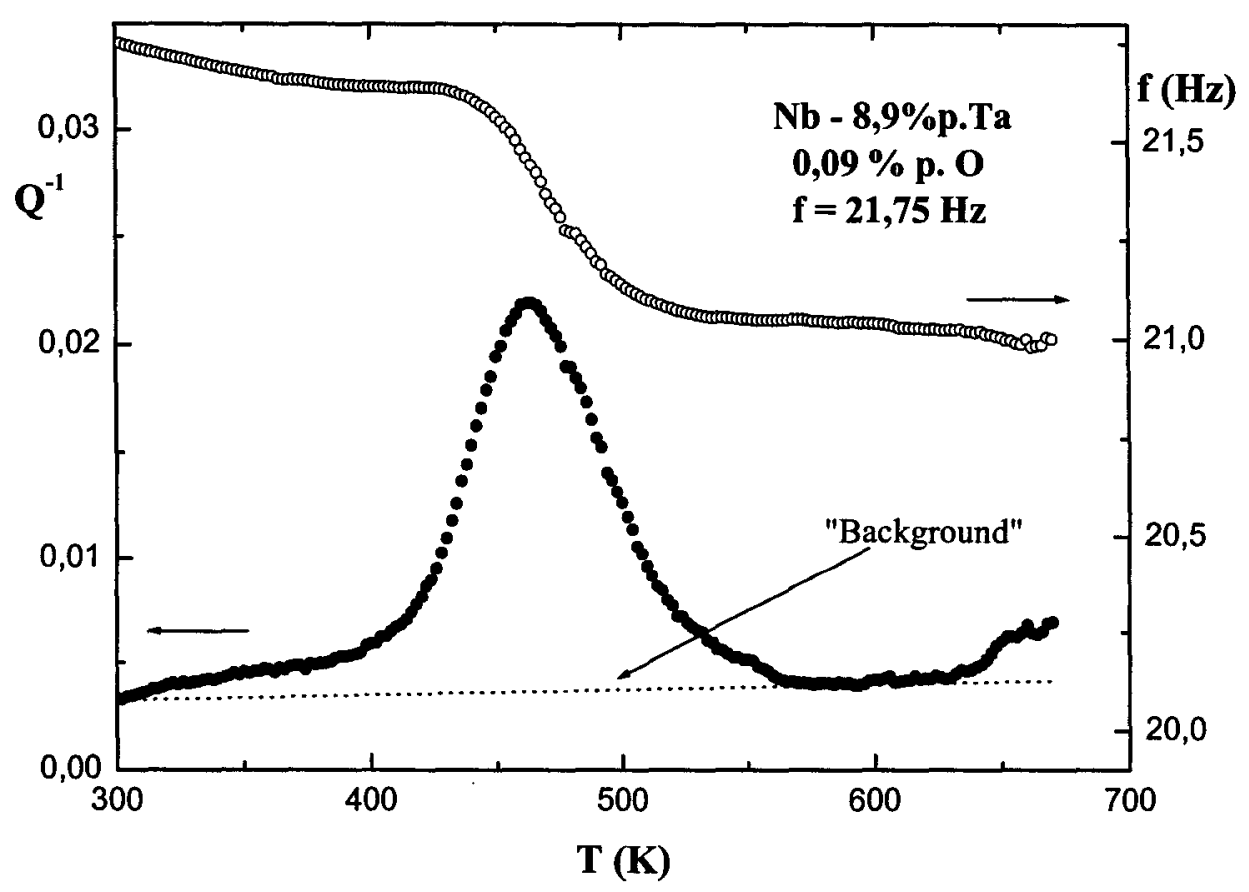

Figura 52 - Espectro de atrito interno como função da temperatura para amostra da liga $\mathrm{Nb}$ $8,9 \%$ p.Ta medido com freqüência de $21,75 \mathrm{~Hz}$, após a segunda dopagem.

Os espectros anelásticos obtidos após a segunda dopagem mostram claras estruturas de relaxação e que a intensidade do pico está aumentando, conforme se aumentou a concentração de oxigênio.

A figura 53 mostra os espectros anelásticos com "background" extraído obtidos para a amostra após a segunda dopagem, na qual verifica-se que a estrutura de relaxação é termicamente ativada. 


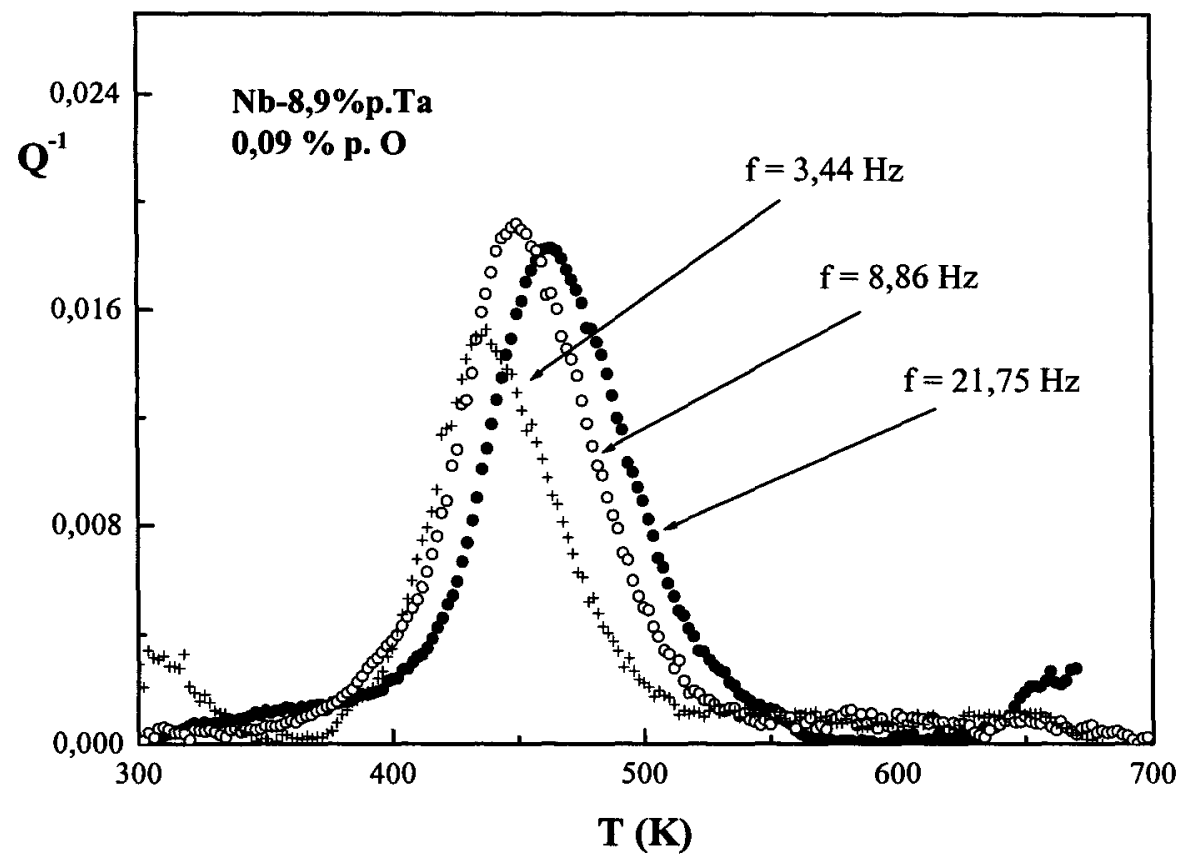

Figura 53 - Espectros anelásticos com "background" extraído para amostra da liga Nb$8,9 \%$ p.Ta medidos com diferentes freqüências após a segunda dopagem.

As curvas experimentais foram decompostas nos mesmos quatro processos de relaxação, sendo os resultados desta análise apresentados nas figuras 54 a 56 . 


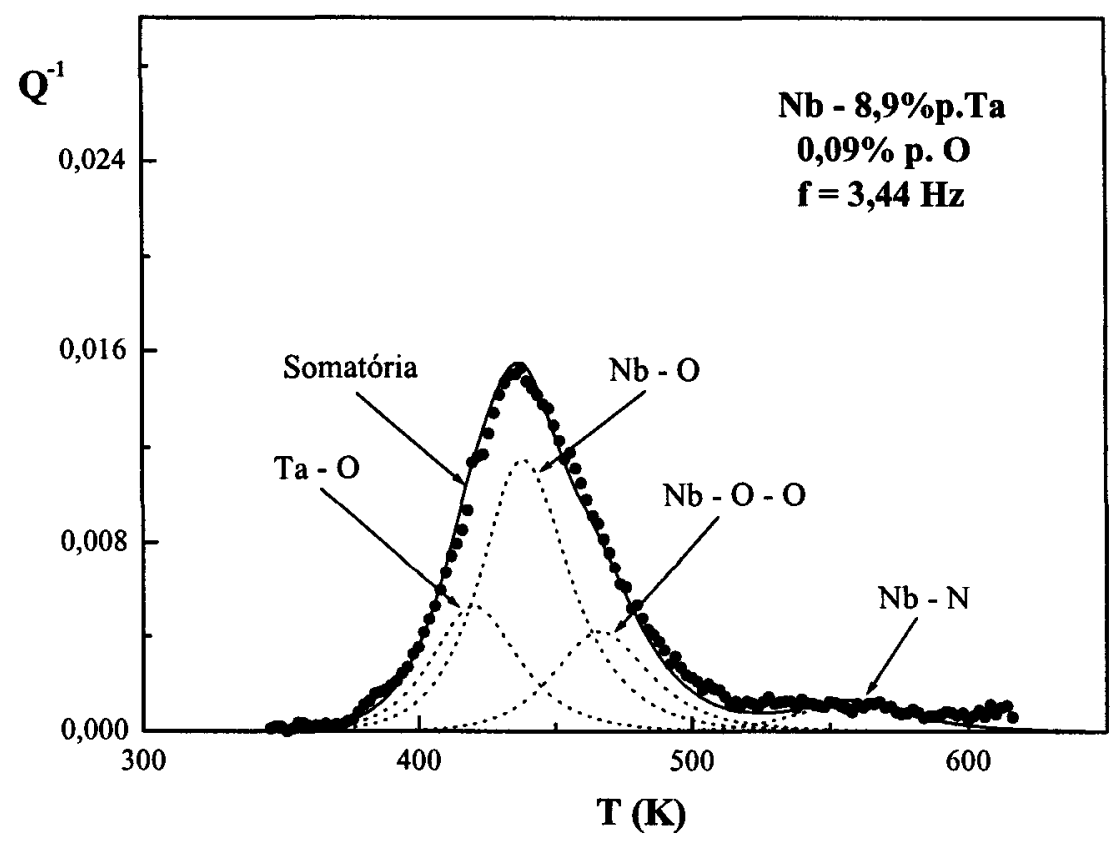

Figura 54 - Análise do espectro anelástico com "background" extraído para a amostra da liga $\mathrm{Nb}-8,9 \%$ p.Ta medido com freqüência de oscilação de $3,44 \mathrm{~Hz}$ após a segunda dopagem, decomposto em quatro processos de relaxação.

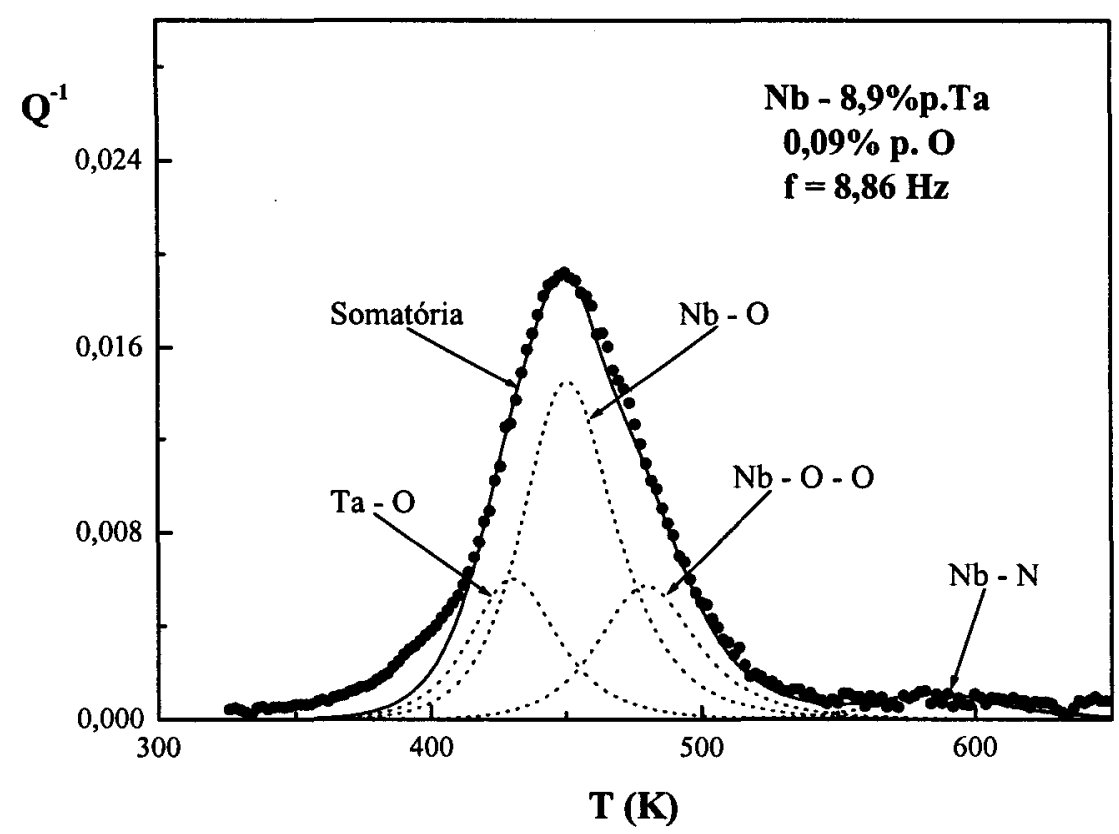

Figura 55 - Análise do espectro anelástico com "background" extraído para a amostra da liga $\mathrm{Nb}-8,9 \%$ p.Ta medido com freqüência de oscilação de $8,86 \mathrm{~Hz}$ após a segunda dopagem, decomposto em quatro processos de relaxação. 


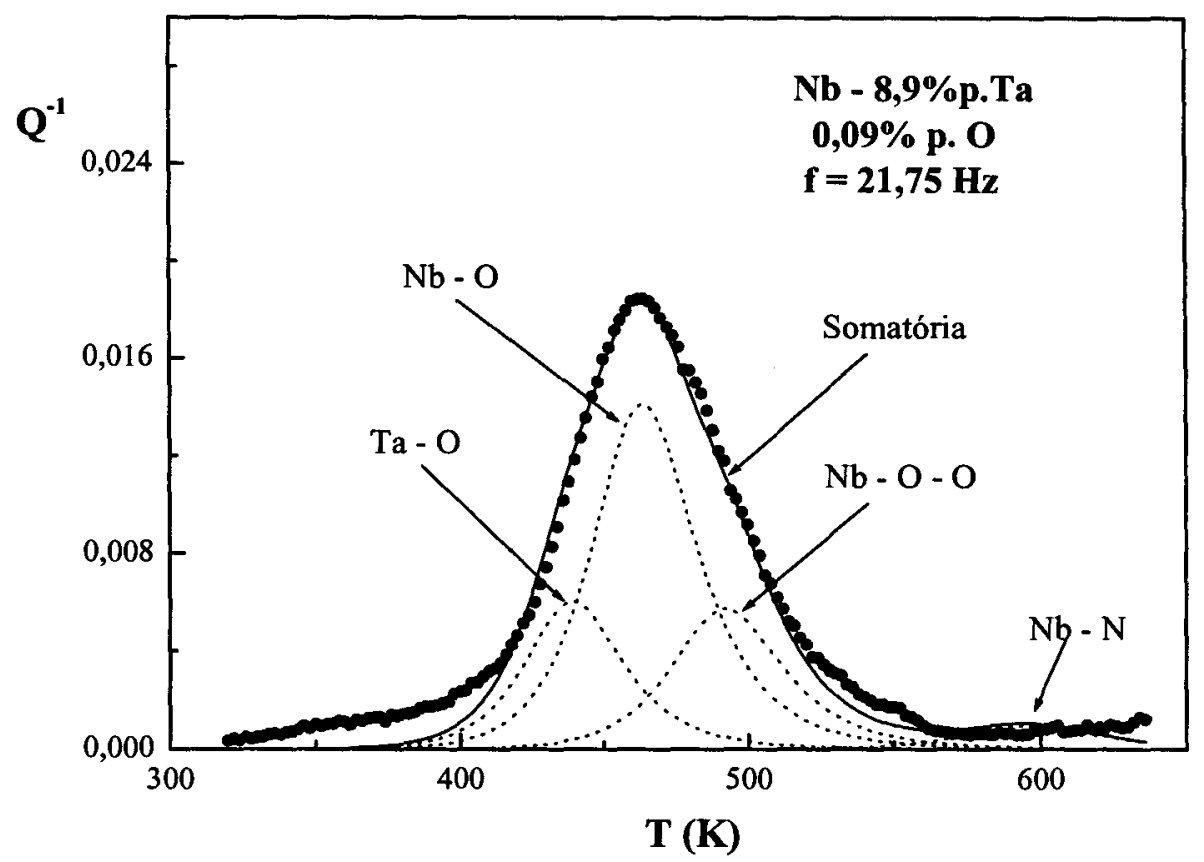

Figura 56 - Análise do espectro anelástico com "background” extraído para a amostra da liga $\mathrm{Nb}-8,9 \%$ p.Ta medido com freqüência de oscilação de $21,75 \mathrm{~Hz}$ após a segunda dopagem, decomposto em quatro processos de relaxação.

As análises dos espectros anelásticos obtidos para a amostra após a segunda dopagem, mostram que a superposição dos quatro processos encontrados ajusta-se muito bem à curva experimental. Manteve-se a tendência de que a intensidade do processo $\mathrm{Nb}-\mathrm{O}$ aumentaria mais que a dos outros processos e a intensidade do processo $\mathrm{Nb}-\mathrm{N}$ não teve uma variação significativa visto que a concentração deste elemento não aumentou. Os parâmetros de relaxação são apresentados na Tabela 19. 
Tabela 19 - Parâmetros de relaxação (após a segunda dopagem).

\begin{tabular}{c|c|c|c|c}
\hline \hline Processo & $\mathbf{f}(\mathbf{H z})$ & $\mathbf{Q}_{\mathbf{p}}^{-1}$ & $\mathbf{T}_{\mathbf{p}}(\mathbf{K})$ & $\mathbf{E}(\mathbf{e V})$ \\
\hline \multirow{3}{*}{ Ta-O } & 3,34 & 0,0044 & 419 & 1,10 \\
& 8,86 & 0,0060 & 430 & 1,10 \\
& 21,75 & 0,0060 & 439 & 1,10 \\
\hline \multirow{3}{*}{ Nb-O } & 3,34 & 0,0118 & 438 & 1,15 \\
& 8,86 & 0,0145 & 451 & 1,15 \\
& 21,75 & 0,0141 & 464 & 1,15 \\
\hline \multirow{3}{*}{ Nb-O-O } & 3,34 & 0,0047 & 466 & 1,22 \\
& 8,86 & 0,0057 & 480 & 1,22 \\
& 21,75 & 0,0057 & 492 & 1,22 \\
\hline \multirow{3}{*}{ Nb-N } & 3,34 & 0,0012 & 556 & 1,52 \\
& 8,86 & 0,0011 & 587 & 1,52 \\
& 21,75 & 0,0010 & 597 & 1,52 \\
\hline
\end{tabular}

Os dados mostram a existência de uma relação entre a quantidade de intersticiais e a intensidade do pico de relaxação, pois após cada dopagem a intensidade do processo tem aumentado.

Com a terceira dopagem, a concentração de oxigênio praticamente dobrou em relação a primeira dopagem, em seguida foram medidos os espectros anelásticos, que são apresentados nas figuras 57 a 59 . 


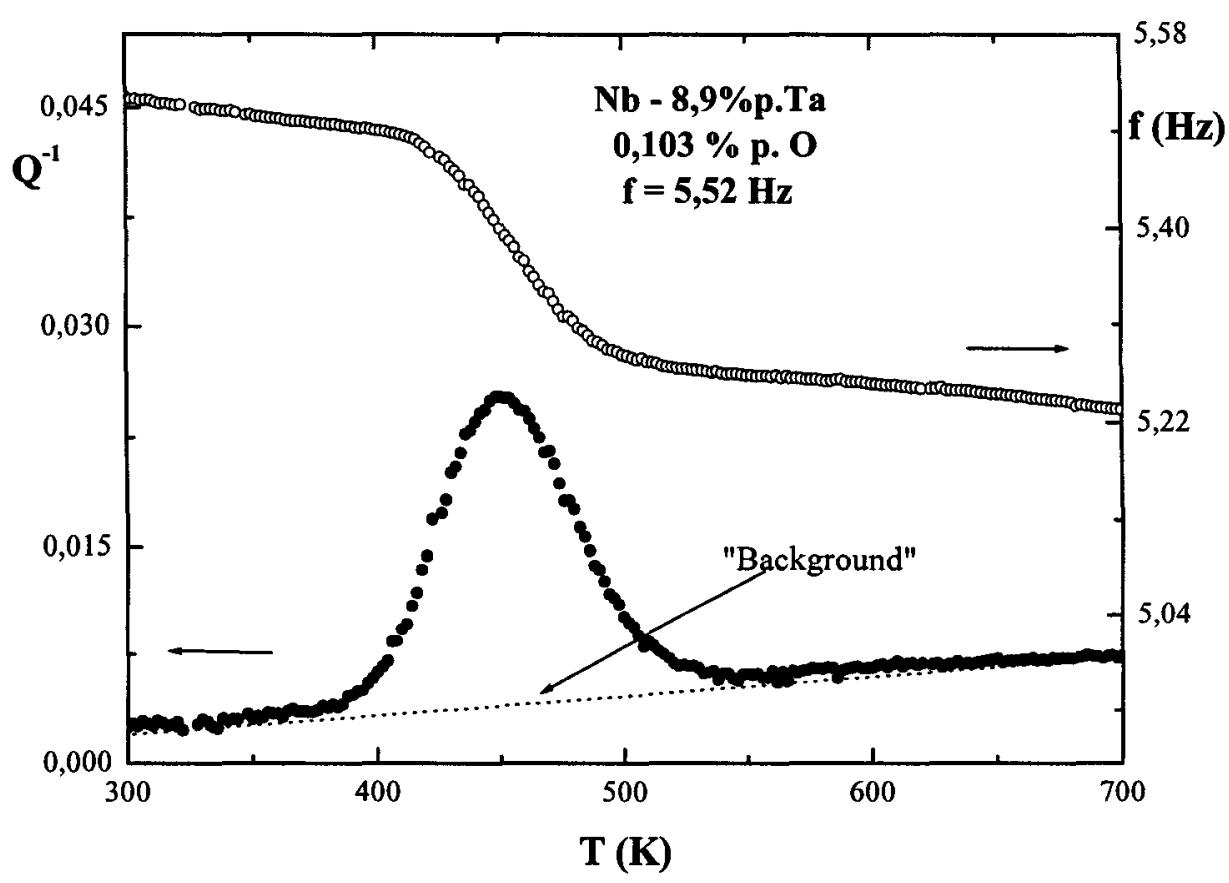

Figura 57 - Espectro de atrito interno como função da temperatura para amostra da liga Nb$8,9 \%$ p.Ta medido com frequiência de 5,52 Hz, após a terceira dopagem.

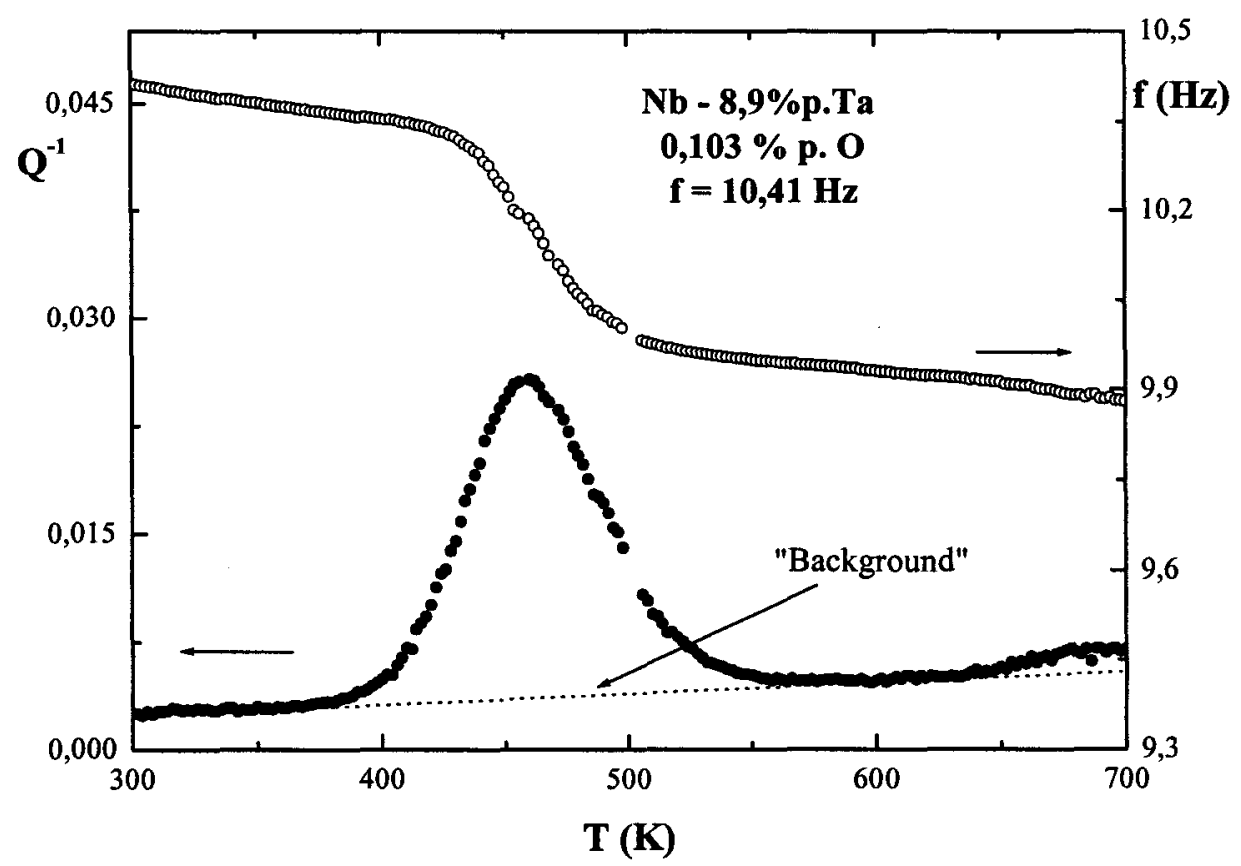

Figura 58 - Espectro de atrito interno como função da temperatura para amostra da liga Nb8,9\%p.Ta medido com freqüência de $10,41 \mathrm{~Hz}$, após a terceira dopagem. 


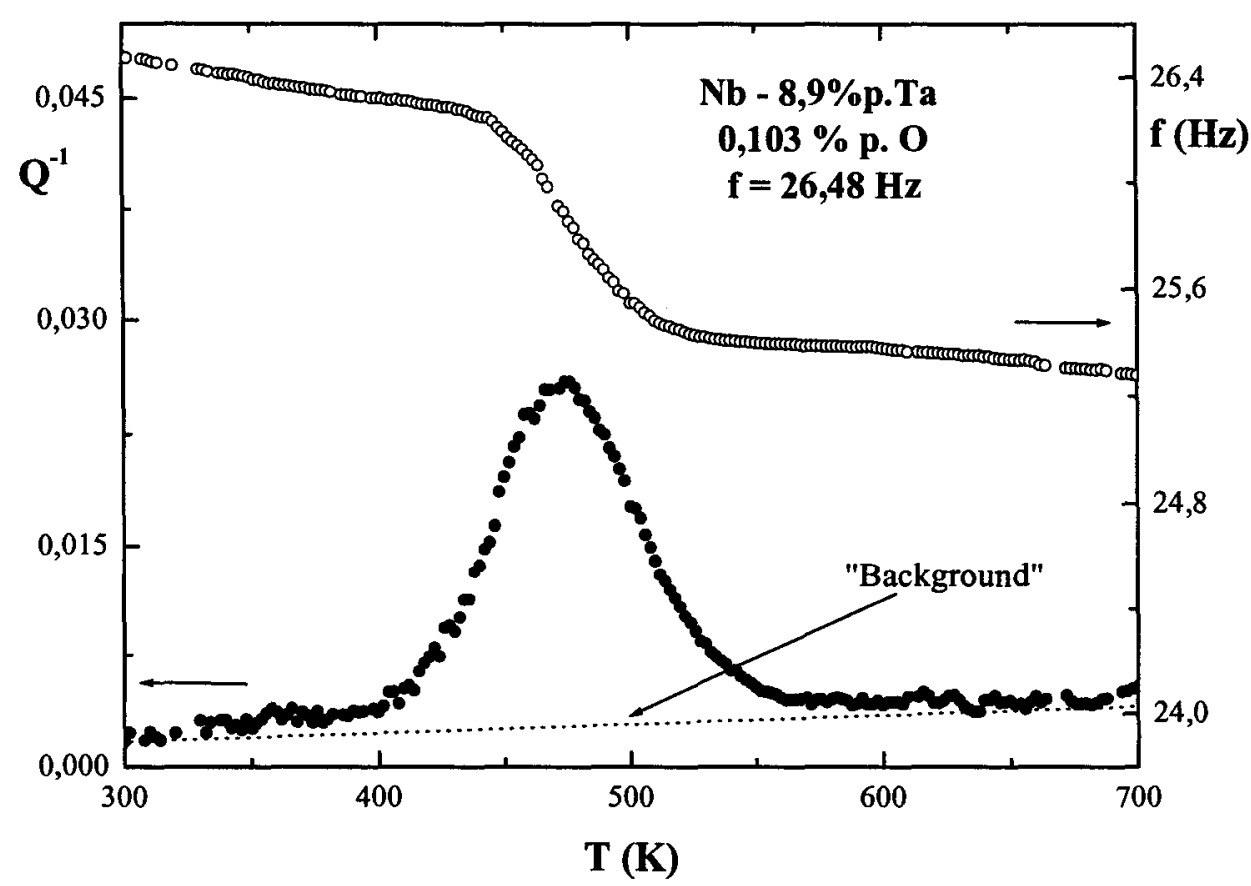

Figura 59 - Espectro de atrito interno como função da temperatura para amostra da liga Nb$8,9 \%$ p.Ta medido com freqüência de $26,48 \mathrm{~Hz}$, após a terceira dopagem.

Os espectros anelásticos obtidos para a amostra após a terceira dopagem mostram que a intensidade do pico aumenta conforme aumenta a concentração de oxigênio.

A figura 60 mostra os espectros anelásticos com "background" extraído obtidos para a amostra da liga após a terceira dopagem, onde se verifica, novamente, que a estrutura de relaxação é termicamente ativada. 


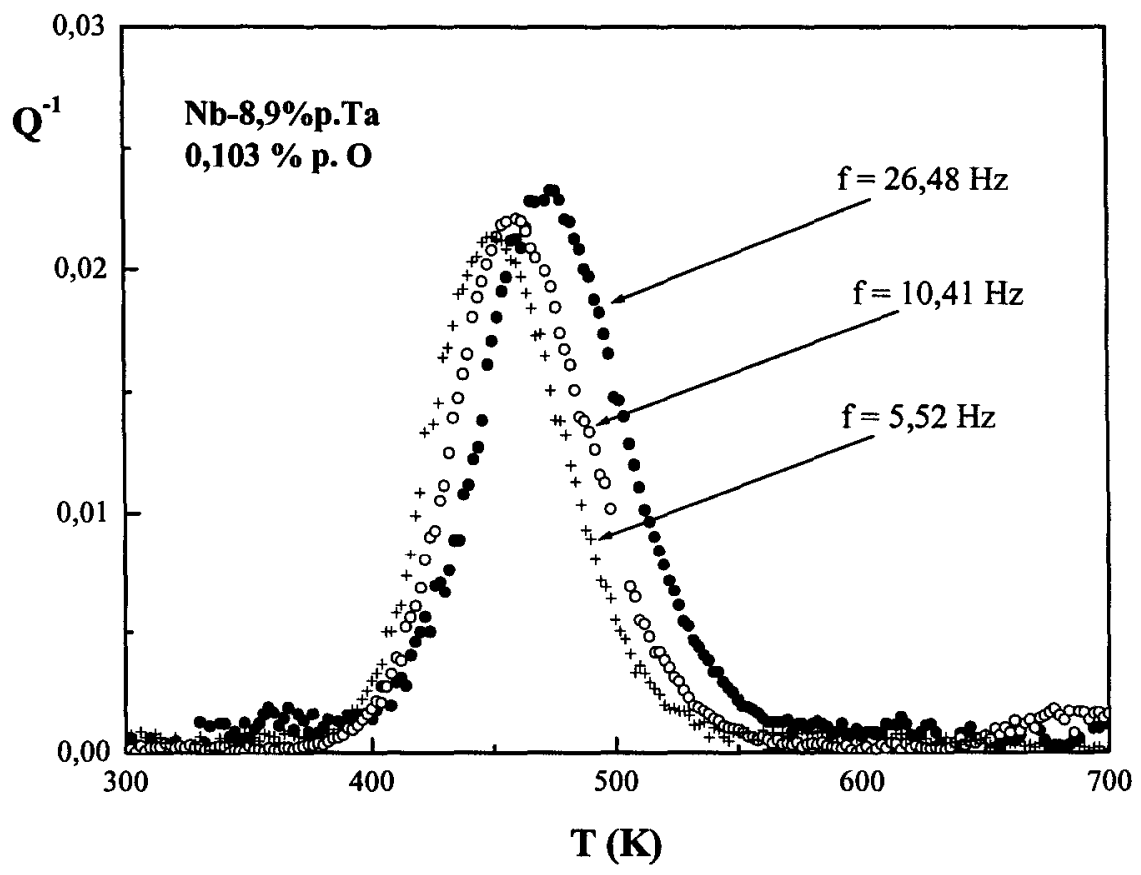

Figura 60 - Espectros anelásticos com "background" extraído para amostra da liga Nb8,9\%p.Ta medidos com diferentes freqüências após a terceira dopagem.

As figuras 61 a 62 mostram a decomposição das curvas experimentais em seus quatro picos constituintes, seguindo o mesmo procedimento utilizado anteriormente. 


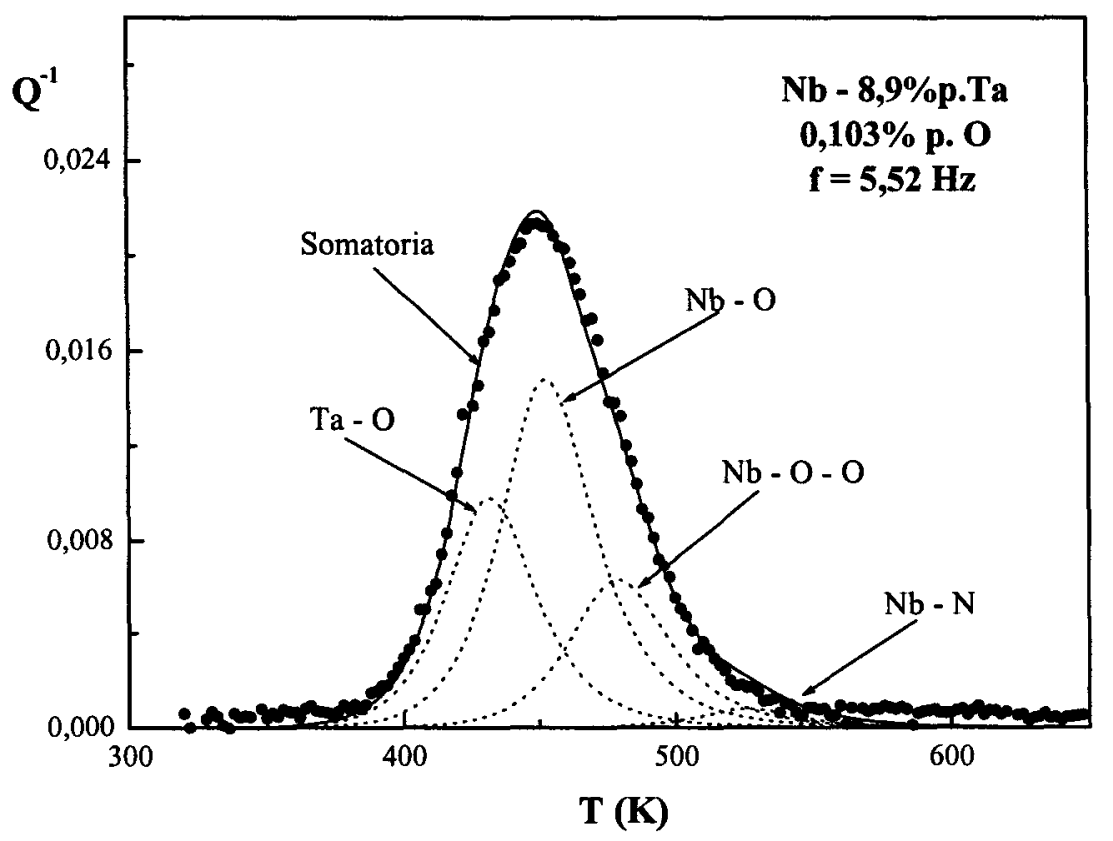

Figura 61 - Análise do espectro anelástico com "background" extraído para a amostra da liga $\mathrm{Nb}-8,9 \%$ p.Ta medido com freqüência de oscilação de $5,52 \mathrm{~Hz}$ após a terceira dopagem, decomposto em quatro processos de relaxação.

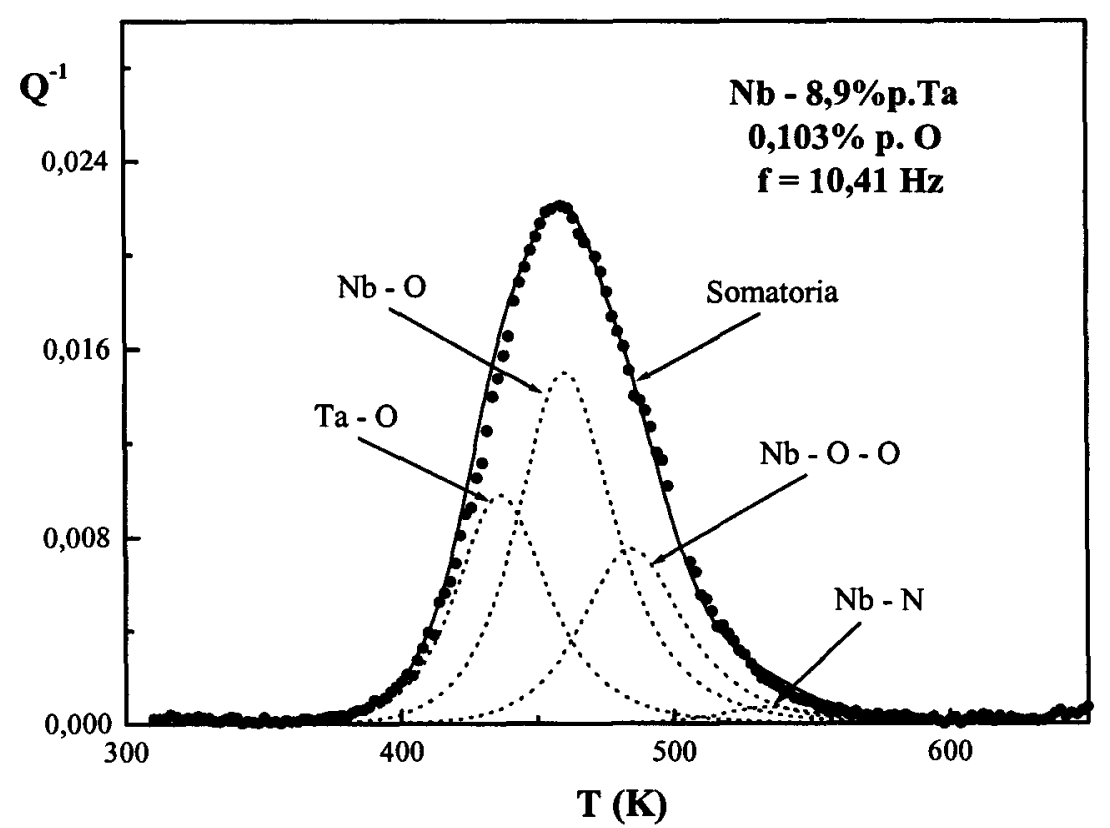

Figura 62 - Análise do espectro anelástico com "background" extraído para a amostra da liga $\mathrm{Nb}-8,9 \%$ p.Ta medido com frequiência de oscilação de $10,41 \mathrm{~Hz}$ após a terceira dopagem, decomposto em quatro processos de relaxação. 


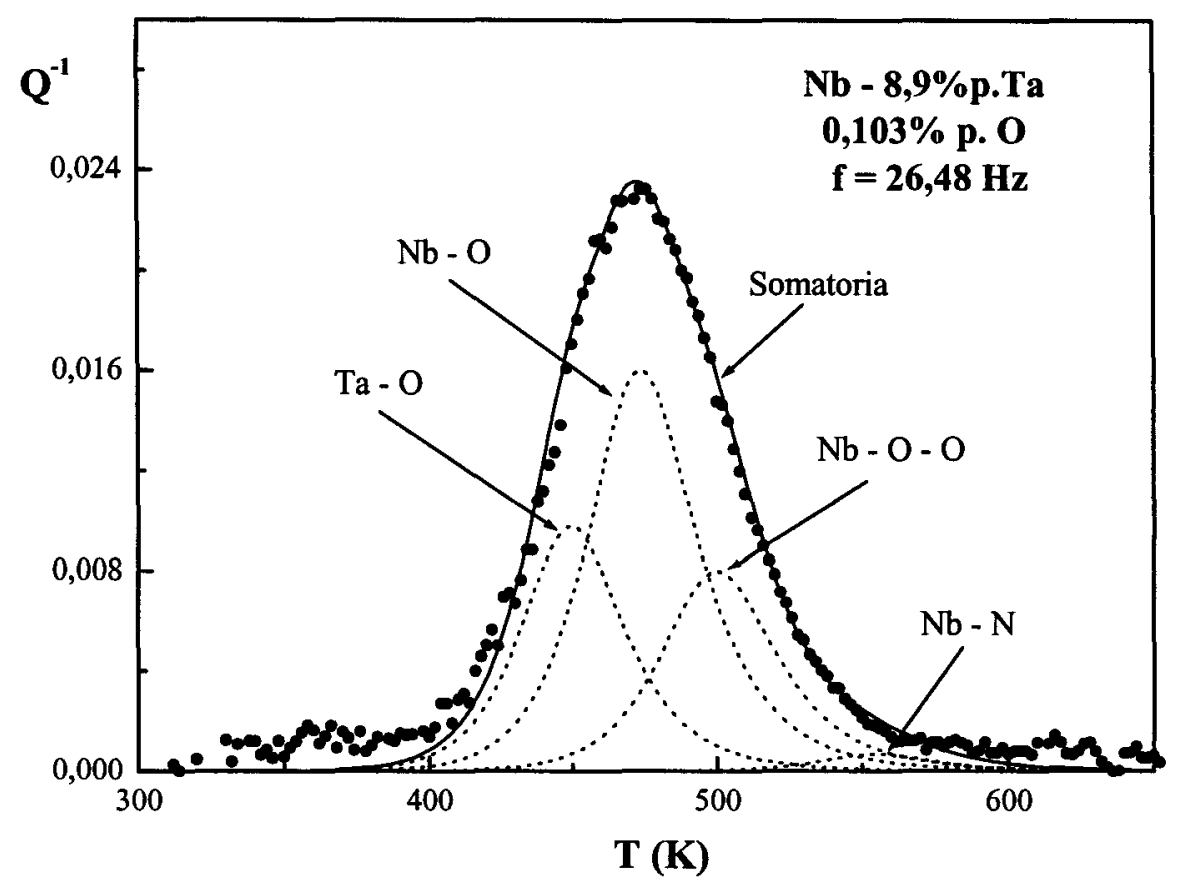

Figura 63 - Análise do espectro anelástico com "background" extraído para a amostra da liga $\mathrm{Nb}-8,9 \%$ p.Ta medido com freqüência de oscilação de $26,48 \mathrm{~Hz}$ após a terceira dopagem, decomposto em quatro processos de relaxação.

As análises dos espectros anelásticos para a amostra da liga após a terceira dopagem mostram que a superposição dos processos de relaxação encontrados ajusta-se muito bem à curva experimental. A intensidade do processo $\mathrm{Nb}-\mathrm{O}$ teve um aumento maior que a dos outros processos, confirmando a tendência sugerida anteriormente. Os parâmetros de relaxação são apresentados na Tabela 20. 
Tabela 20 - Parâmetros de relaxação (após a terceira dopagem).

\begin{tabular}{c|c|c|c|c}
\hline \hline Processo & $\mathbf{f}(\mathbf{H z})$ & $\mathbf{Q}_{\mathbf{p}}^{-1}$ & $\mathbf{T}_{\mathbf{p}}(\mathbf{K})$ & $\mathbf{E}(\mathbf{e V})$ \\
\hline \multirow{3}{*}{ Ta-O } & 5,52 & 0,0098 & 432 & 1,10 \\
& 10,41 & 0,0098 & 437 & 1,10 \\
& 26,47 & 0,0098 & 449 & 1,10 \\
\hline \multirow{3}{*}{$\mathrm{Nb-O}$} & 5,52 & 0,0148 & 453 & 1,15 \\
& 10,41 & 0,0150 & 460 & 1,15 \\
& 26,47 & 0,0160 & 474 & 1,15 \\
\hline \multirow{3}{*}{$\mathrm{Nb}-\mathrm{O}-\mathrm{O}$} & 5,52 & 0,0063 & 479 & 1,22 \\
& 10,41 & 0,0075 & 485 & 1,22 \\
& 26,47 & 0,0080 & 500 & 1,22 \\
\hline \multirow{3}{*}{$\mathrm{Nb}-\mathrm{N}$} & 5,52 & 0,0008 & 526 & 1,52 \\
& 10,41 & 0,0007 & 535 & 1,52 \\
& 26,47 & 0,0007 & 555 & 1,52 \\
\hline
\end{tabular}

Com a quarta dopagem a concentração de oxigênio teve um aumento de mais que nove vezes em relação à concentração inicial e os espectros anelásticos obtidos após esta dopagem são apresentados nas figuras 64 a 66. 


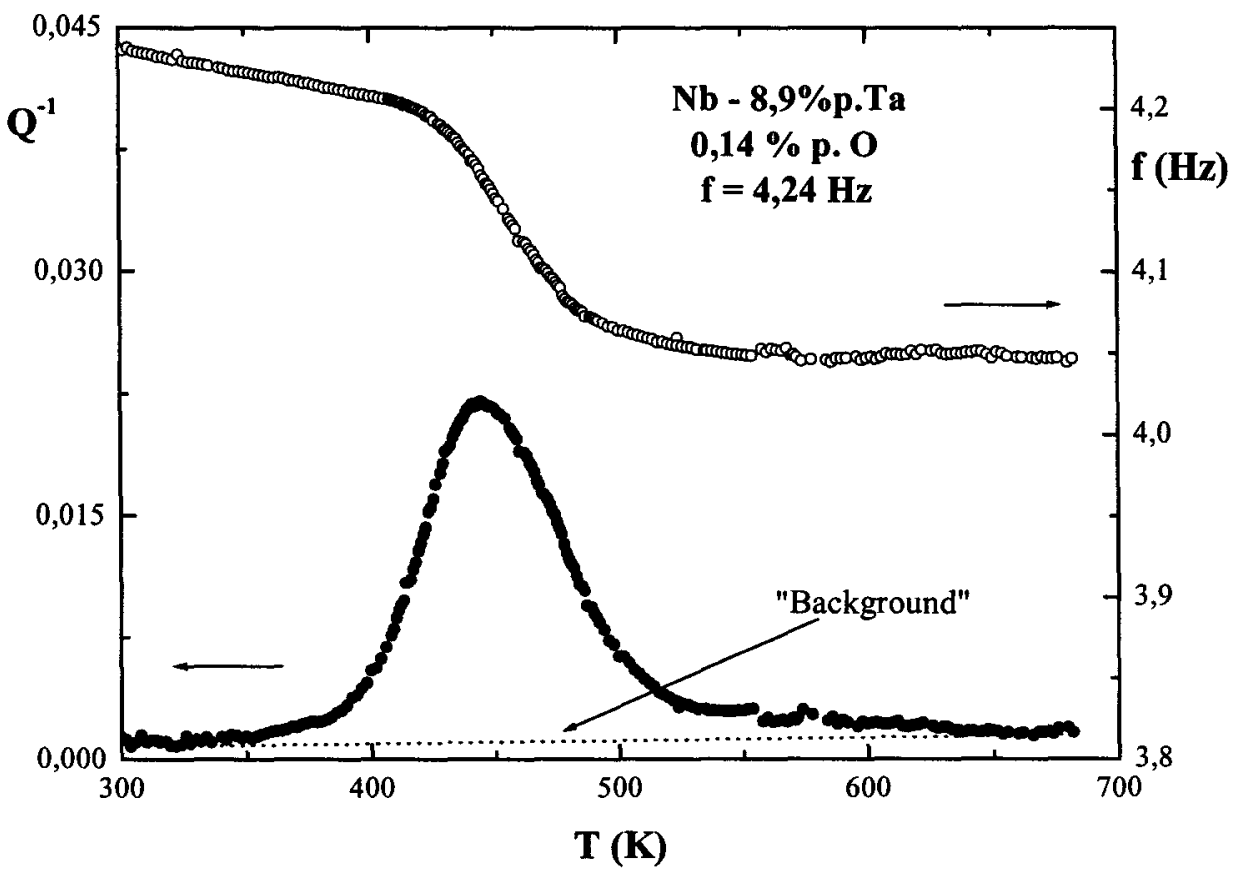

Figura 64 - Espectro de atrito interno como função da temperatura para amostra da liga Nb$8,9 \%$ p.Ta medido com frequiência de $4,24 \mathrm{~Hz}$, após a quarta dopagem.

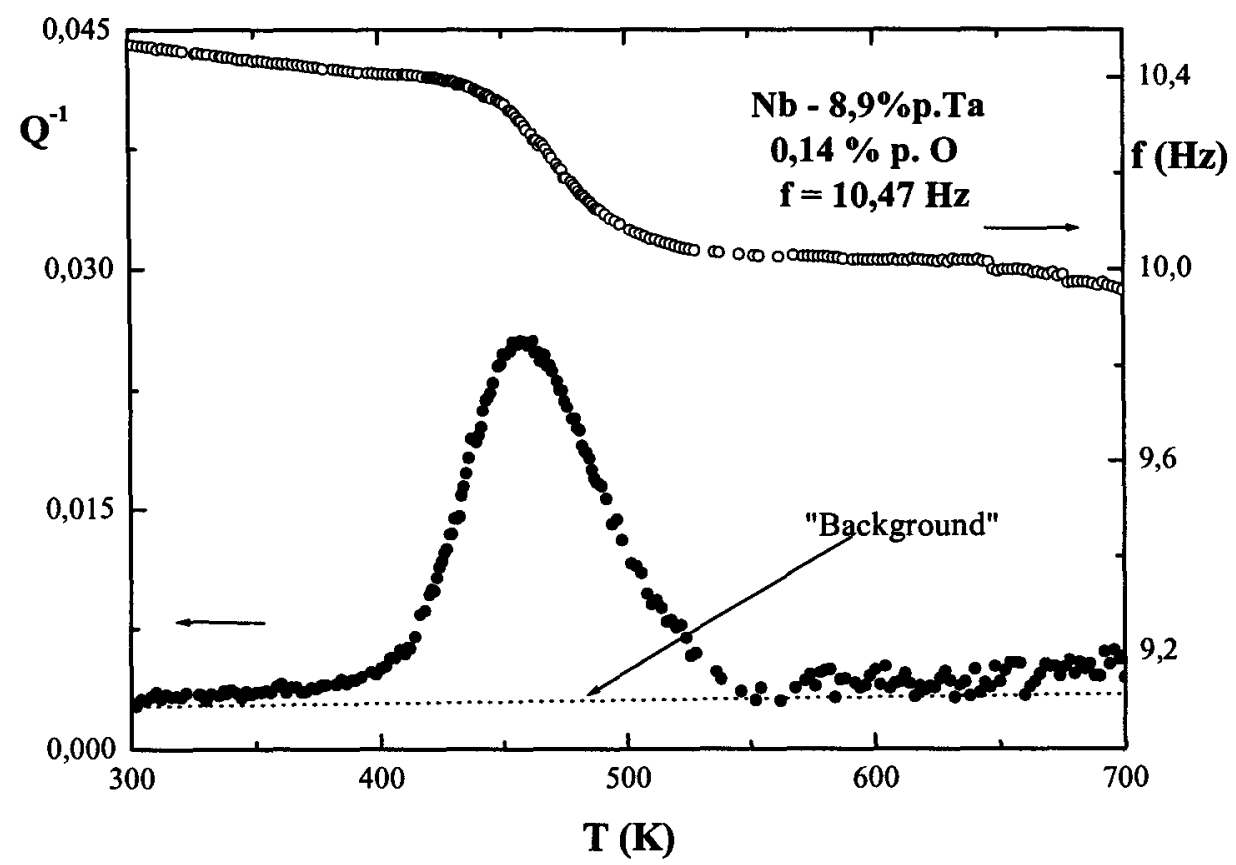

Figura 65 - Espectro de atrito interno como função da temperatura para amostra da liga $\mathrm{Nb}$ $8,9 \%$ p.Ta medido com freqüência de $10,47 \mathrm{~Hz}$, após a quarta dopagem. 


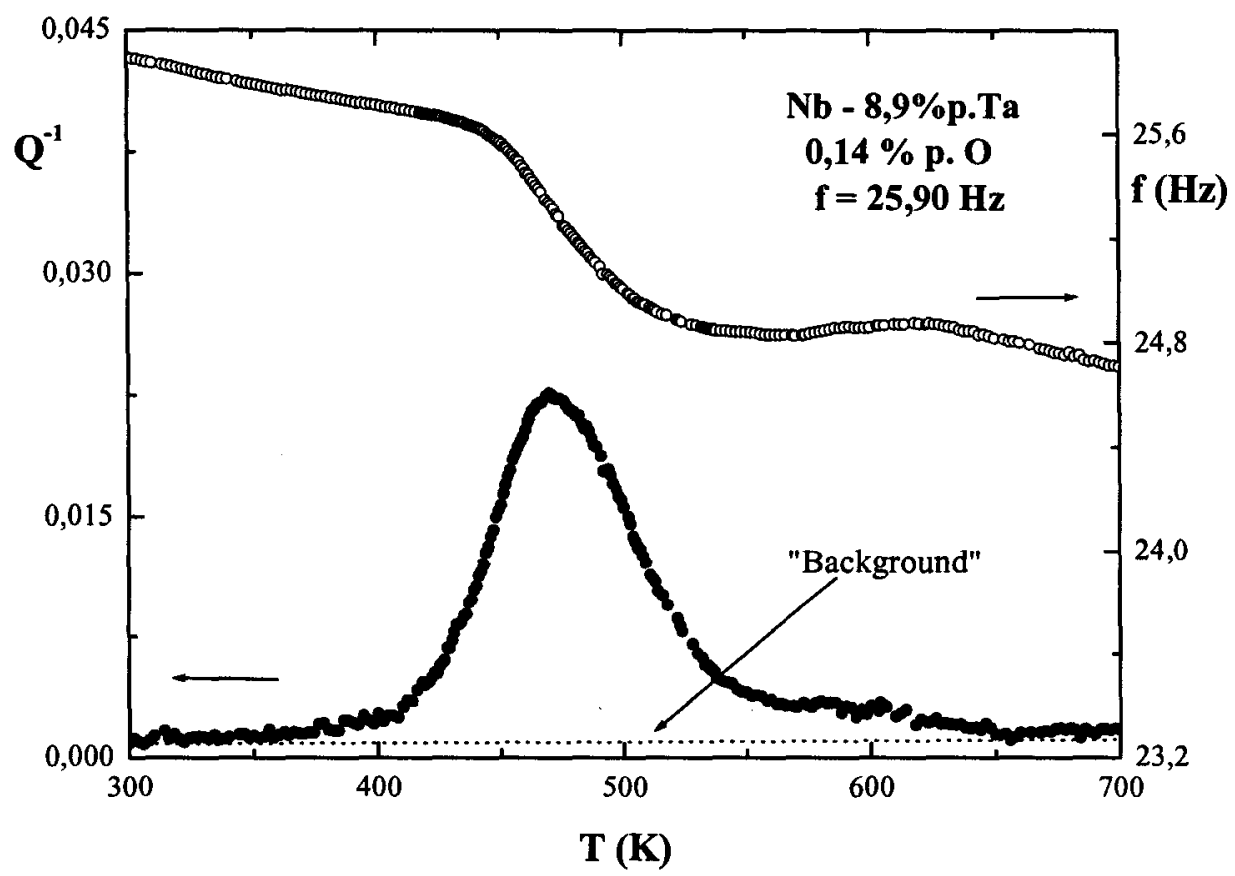

Figura 66 - Espectro de atrito interno como função da temperatura para amostra da liga Nb$8,9 \%$ p.Ta medido com freqüência de $25,90 \mathrm{~Hz}$, após a quarta dopagem.

Podemos observar pelas figuras dos espectros obtidos para a amostra após a quarta dopagem que a intensidade do pico não teve um aumento considerável, o que indica que provavelmente esta concentração de oxigênio está próxima do limite de solubilidade deste elemento na liga.

Através de dados apresentados na literatura ${ }^{50}$ foi possivel fazer uma estimativa do limite de solubilidade de oxigênio na liga $\mathrm{Nb}-8,9 \% \mathrm{p}$. Ta, sendo o valor encontrado de $0,20 \% \mathrm{p}$. de modo que, a concentração alcançada com a última dopagem realmente está próximo do limite de solubilidade de oxigênio na liga. 
A figura 67 mostra os espectros anelásticos com "background" extraído, obtidos para a amostra da liga após a quarta dopagem, medido com diferentes freqüências, na qual verifica-se que a estrutura de relaxação é termicamente ativada.

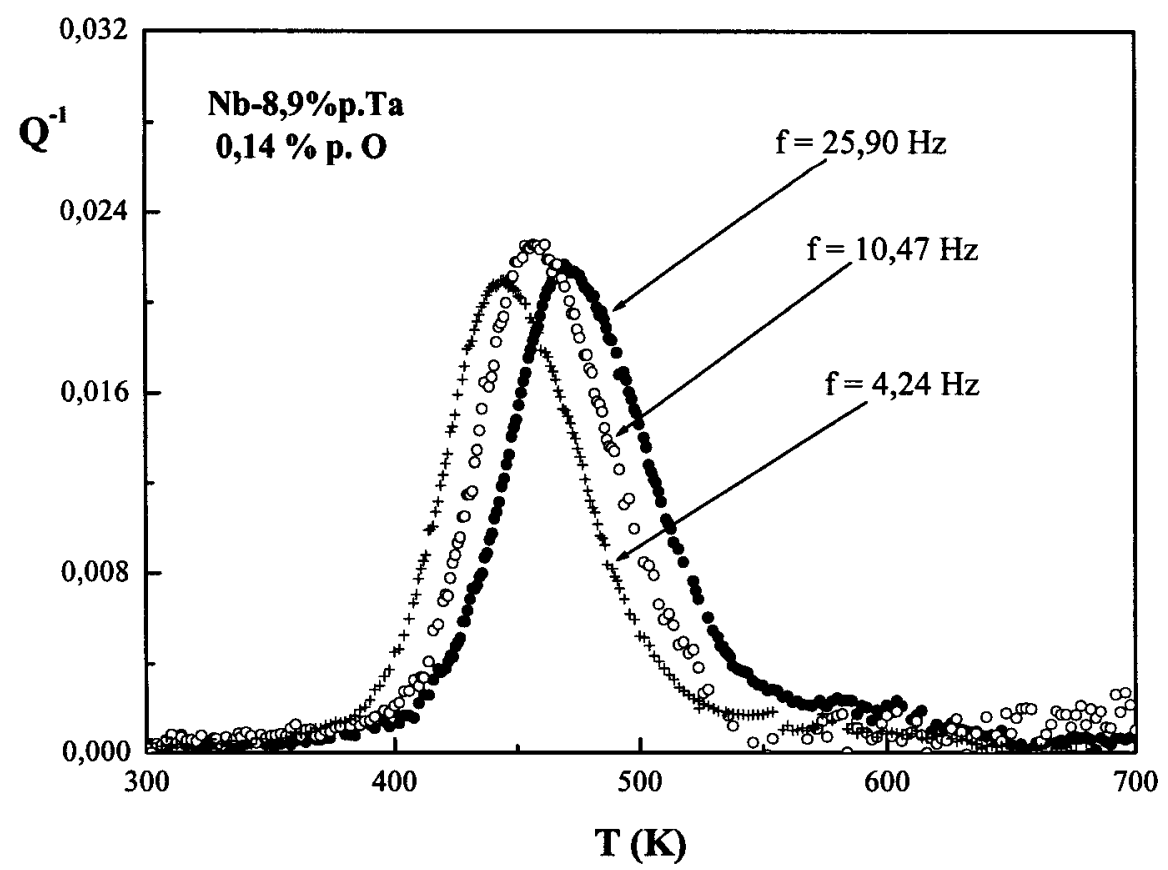

Figura 67 - Espectros anelásticos com "background" extraído para amostra da liga $\mathrm{Nb}$ 8,9\%p.Ta medidos com diferentes freqüências após a quarta dopagem.

As curvas acima foram decompostas em seus quatro picos constituintes e o resultado é apresentado nas figuras 68 a 70, seguindo o mesmo procedimento utilizado anteriormente. 


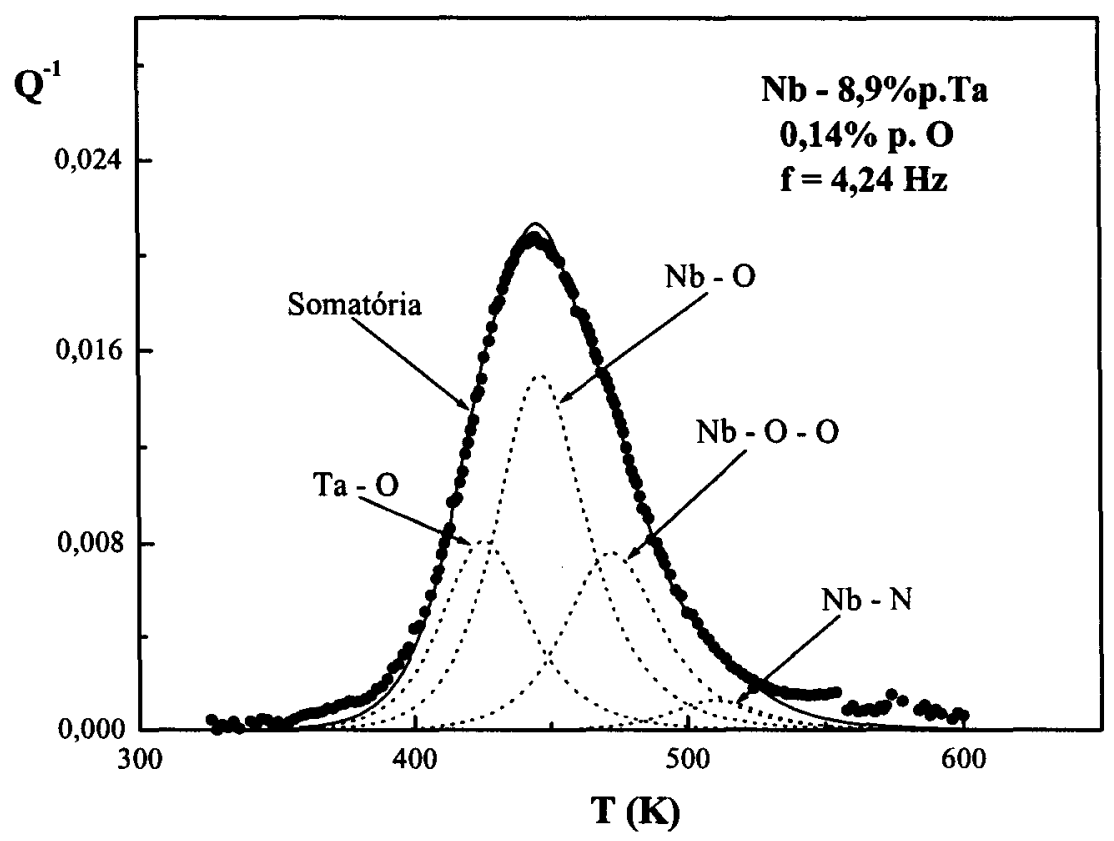

Figura 68 - Análise do espectro anelástico com "background" extraído para a amostra da liga $\mathrm{Nb}-8,9 \%$ p.Ta medido com freqüência de oscilação de $4,24 \mathrm{~Hz}$ após a quarta dopagem, decomposto em quatro processos de relaxação.

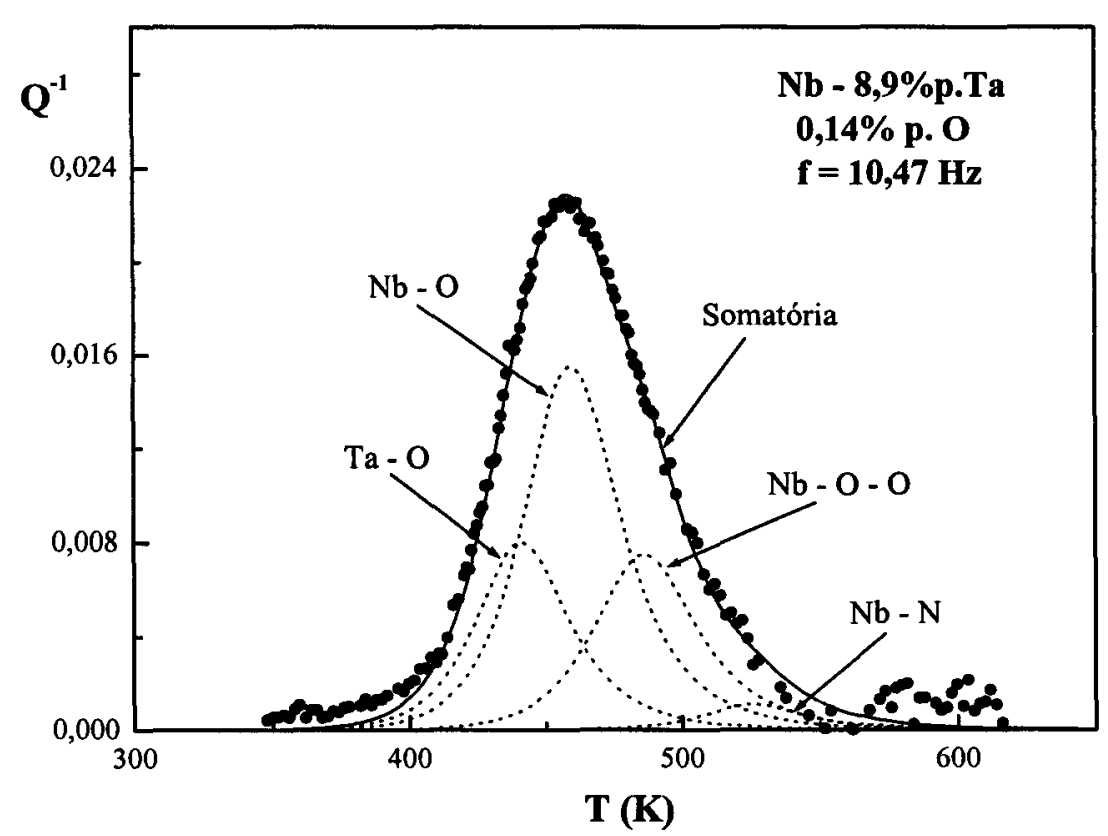

Figura 69 - Análise do espectro anelástico com "background" extraído para a amostra da liga $\mathrm{Nb}-8,9 \%$ p.Ta medido com freqüência de oscilação de $10,47 \mathrm{~Hz}$ após a quarta dopagem, decomposto em quatro processos de relaxação. 


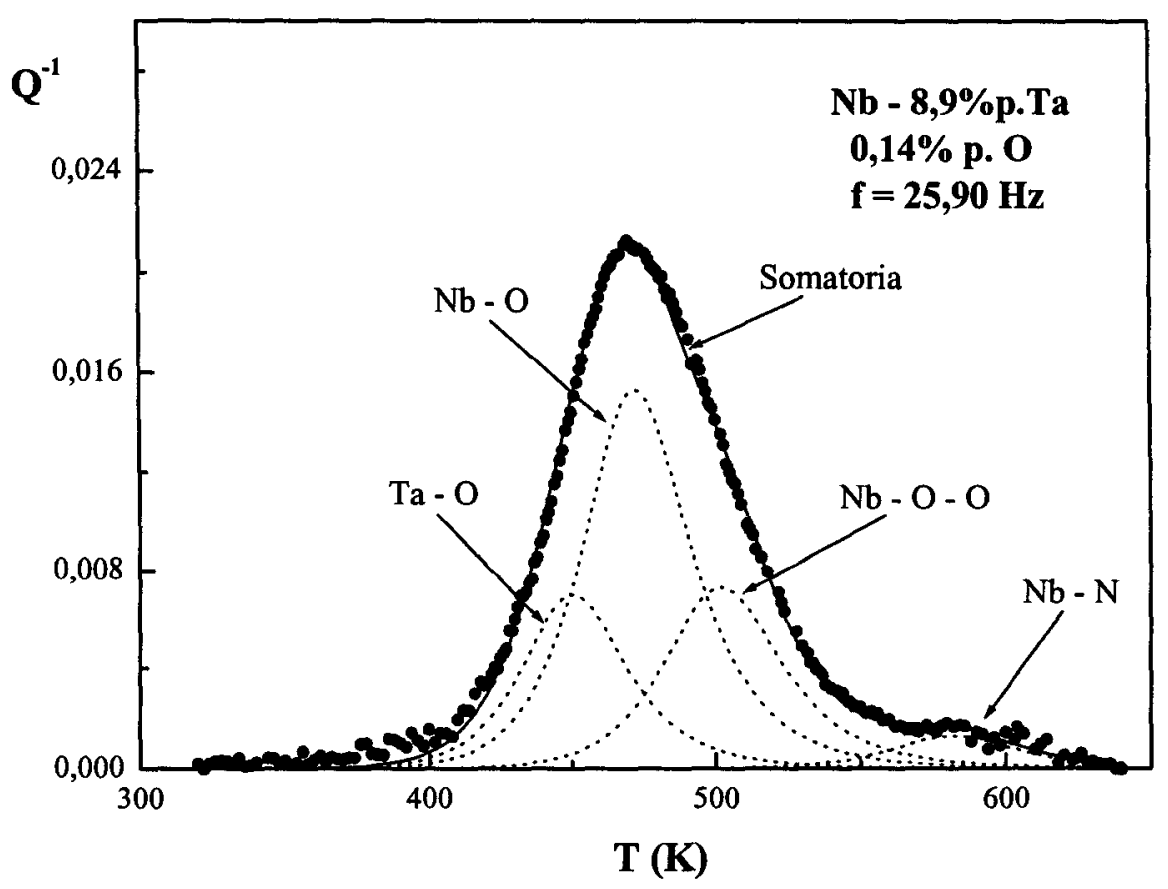

Figura 70 - Análise do espectro anelástico com "background" extraído para a amostra da liga $\mathrm{Nb}-8,9 \%$ p.Ta medido com freqüência de oscilação de $25,90 \mathrm{~Hz}$ após a quarta dopagem, decomposto em quatro processos de relaxação.

Observamos pelas análises dos espectros anelásticos obtidos para a amostra após a quarta dopagem que a superposição dos quatro processos de relaxação encontrados ajusta-se muito bem à curva experimental. Os parâmetros de relaxação são apresentados na Tabela 21 . 
Tabela 21 - Parâmetros de relaxação (após a quarta dopagem).

\begin{tabular}{c|c|c|c|c}
\hline Processo & $\mathbf{f}(\mathbf{H z})$ & $\mathbf{Q}_{\mathbf{p}}^{-1}$ & $\mathbf{T}_{\mathbf{p}}(\mathbf{K})$ & $\mathbf{E}(\mathbf{e V})$ \\
\hline \multirow{3}{*}{ Ta-O } & 4,24 & 0,0070 & 426 & 1,10 \\
& 10,47 & 0,0080 & 441 & 1,10 \\
& 25,90 & 0,0081 & 450 & 1,10 \\
\hline \multirow{3}{*}{ Nb-O } & 4,24 & 0,0150 & 447 & 1,15 \\
& 10,47 & 0,0155 & 460 & 1,15 \\
& 25,90 & 0,0153 & 472 & 1,15 \\
\hline \multirow{3}{*}{ Nb-O-O } & 4,24 & 0,0076 & 473 & 1,22 \\
& 10,47 & 0,0075 & 486 & 1,22 \\
& 25,90 & 0,0073 & 502 & 1,22 \\
\hline \multirow{3}{*}{ Nb-N } & 4,24 & 0,0013 & 510 & 1,52 \\
& 10,47 & 0,0011 & 526 & 1,52 \\
& 25,90 & 0,0013 & 582 & 1,52 \\
\hline
\end{tabular}

Os dados apresentados na tabela acima mostram que a intensidade dos processos não teve um aumento significativo após a quarta dopagem, o que indica que provavelmente tenhamos alcançado o limite de solubilidade de oxigênio para a liga.

A figura 71 mostra os espectros anelásticos medidos com freqüência de aproximadamente $3,50 \mathrm{~Hz}$ e com o "background" extraído, obtidos após cada tratamento térmico e dopagem. Pode-se observar que a da intensidade da estrutura de relaxação aumenta com o aumento da concentração de intersticiais, outra característica marcante de relaxação do tipo Snoek. 


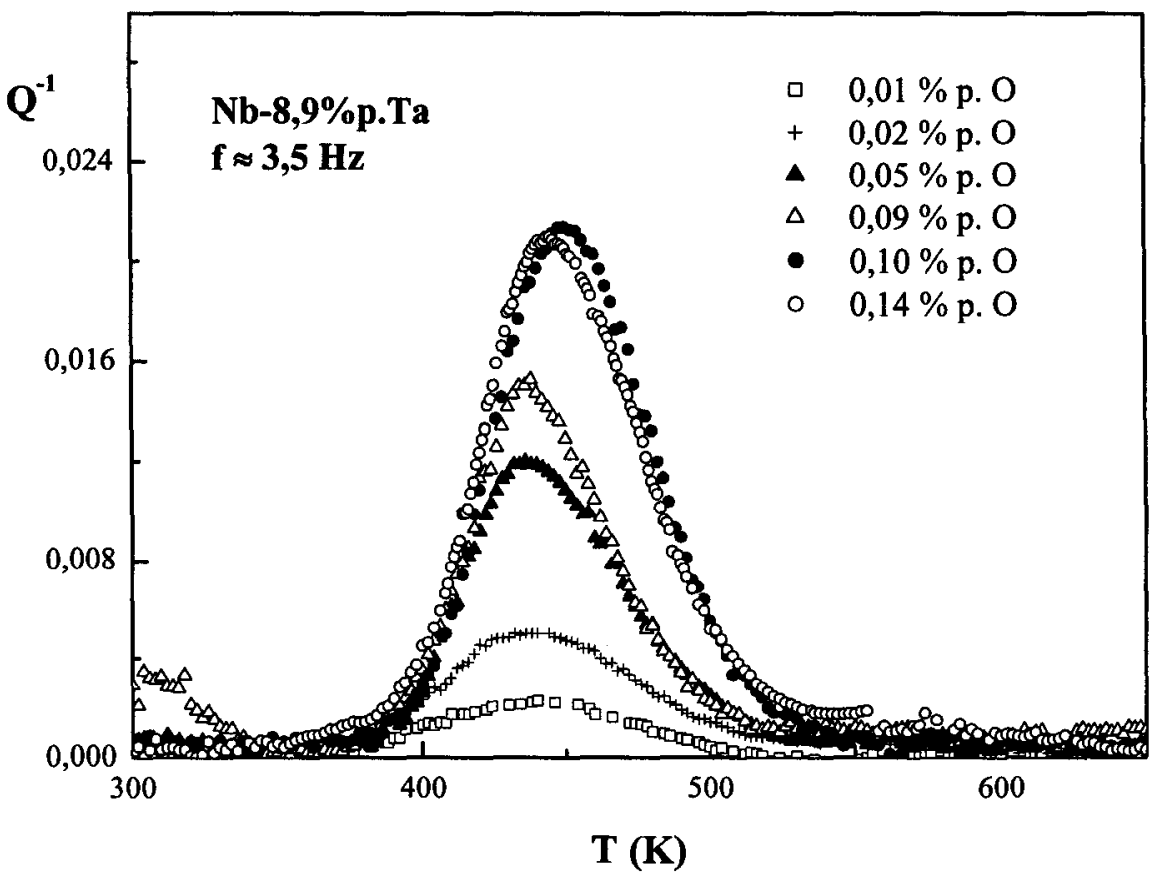

Figura 71 - Variação da intensidade do pico de relaxação com o aumento da concentração de intersticiais.

Observamos que a intensidade do pico aumenta à medida que se aumenta a concentração de intersticiais até um valor máximo, alcançado com a última dopagem. Percebe-se que o espectro anelástico com essa concentração de oxigênio praticamente não variou em relação à concentração anterior, isso porque provavelmente com essa quantidade oxigênio alcançamos o limite de solubilidade deste elemento para esta liga.

Os parâmetros de relaxação para os processos de relaxação encontrados neste trabalho estão em excelente acordo com o que é apresentado na literatura, demostrando que os processos de relaxação propostos realmente são os processos constituintes da curva experimental. 
O modelo de decomposição dos espectros anelásticos em vários processos de relaxação constitui uma importante ferramenta para a obtenção dos parâmetros de relaxação, pois o claro alargamento assimétrico observado nas curvas experimentais, sobretudo as com maiores concentrações de intersticiais, tendem a reduzir a inclinação da curva mostrada na figura 31 (Lei de Arrhenius) e conseqüentemente a energia de ativação é menor que as encontradas na literatura.

As análises realizadas nos espectros anelásticos obtidos neste trabalho mostram que a decomposição em vários processos de relaxação permite obter um curva teórica com uma boa concordância com a curva experimental, demonstrando que o modelo é muito eficaz.

A proposição da interação de pares de oxigênio com átomos de nióbio da matriz metálica, em amostras com maior quantidade de oxigênio, propiciou um ajuste muito bom da curva teórica à curva experimental, encontrando parâmetros de relaxação com excelente concordância com os dados obtidos na literatura para $\mathrm{Nb}$ e Ta puros.

Outro fator importante a se levar em conta é o "background", e dependendo de sua forma pode levar a valores ligeiramente diferentes, por isso as análises apresentadas neste trabalho foram efetuadas todas com o "background" extraído, visando minimizar as incertezas nos valores obtidos. 


\section{CAPÍTULO VI - CONSIDERAÇõES FINAIS}

Foram realizadas medidas de espectroscopia anelástica em amostras da liga $\mathrm{Nb}$ $8,9 \%$ p.Ta contendo elementos intersticiais em solução sólida, utilizando a técnica do pêndulo de torção, obtendo espectros anélasticos para uma faixa de freqüência compreendida entre 2,0 a $27,0 \mathrm{~Hz}$.

Efetuou-se a caracterização das amostras, com medidas de densidade, difração de raios $\mathrm{X}$ e análise química, onde foi possível constatar que não houve alteração estrutural significativa nas amostras analisadas.

Foram efetuadas dopagens com oxigênio na amostra conseguindo um aumento gradual na concentração de deste elemento na liga, sendo possível verificar qual a influência do aumento da concentração deste elemento nas medidas de atrito interno.

Foi possível observar estruturas de relaxação termicamente ativadas bem definidas, até mesmo com uma concentração muito baixa de elementos intersticiais. Com as sucessivas 
dopagens verificou-se que a medida que a concentração de oxigênio aumentava, também aumentava a intensidade da estrtutura de relaxação. Estas são características marcantes de processos de relaxação do tipo Snoek.

As estruturas de relaxação observadas não eram processos de relaxação simples, mais sim uma composição de vários processos. Com o aumento da concentração de oxigênio ocorreu, também, a interação de pares de átomos deste elemento com átomos de nióbio da matriz metálica.

Foram identificados os seguintes processos de relaxação:

- Reorientação induzida por tensão de átomos de oxigênio em torno de átomos de tântalo, processo $\mathrm{Ta}-\mathrm{O}$.

- Reorientação induzida por tensão de átomos de oxigênio em torno de átomos de nióbio, processo $\mathrm{Nb}-\mathrm{O}$.

- Reorientação induzida por tensão de pares de átomos de oxigênio em torno de átomos de nióbio, processo $\mathrm{Nb}-\mathrm{O}-\mathrm{O}$.

- Reorientação induzida por tensão de átomos de nitrogênio em torno de átomos de nióbio, processo $\mathrm{Nb}-\mathrm{O}$.

$\mathrm{O}$ processo $\mathrm{Nb}-\mathrm{O}-\mathrm{O}$ não foi encontrado no espectro obtido para a amostra como recebida, pois a concentração deste elemento era muito baixa. $\mathrm{E}$ com o aumento da concentração de oxigênio obtido com as dopagens foi possível observar este tipo de interação. 
As tabelas 22 a 25 apresentam os parâmetros de relaxação obtidos neste trabalho e alguns encontrados na literatura, para as diferentes concentrações de oxigênio. Onde observase uma excelente concordância entre estes valores e os encontrados na literatura

Tabela 22 - Parâmetros de relaxação para o processo Ta - O.

\begin{tabular}{|c|c|c|c|c|c|c|}
\hline Processo & Condição & $\mathbf{f}(\mathbf{H z})$ & $Q_{p}^{-1}$ & $\mathbf{T}_{\mathbf{p}}(\mathbf{K})$ & $\mathbf{E}(\mathrm{eV})$ & Ref. \\
\hline \multirow{20}{*}{$\mathrm{Ta}-\mathrm{O}$} & \multirow{3}{*}{ Sem tratamento } & 2,45 & 0,0013 & 415 & \multirow{18}{*}{1,10} & \multirow{18}{*}{ Este } \\
\hline & & 4,80 & 0,0095 & 425 & & \\
\hline & & 15,53 & 0,0007 & 459 & & \\
\hline & \multirow{3}{*}{ Recozimento } & 3,51 & 0,0020 & 409 & & \\
\hline & & 7,70 & 0,0029 & 427 & & \\
\hline & & 22,58 & 0,0039 & 440 & & \\
\hline & \multirow{3}{*}{$1^{\underline{a}}$ dopagem } & 3,28 & 0,0048 & 422 & & \\
\hline & & 7,14 & 0,0051 & 430 & & \\
\hline & & 20,40 & 0,0055 & 439 & & \\
\hline & \multirow{3}{*}{$2^{\mathrm{a}}$ dopagem } & 3,34 & 0,0044 & 419 & & \\
\hline & & 8,86 & 0,0060 & 430 & & \\
\hline & & 21,75 & 0,0060 & 439 & & \\
\hline & \multirow{3}{*}{$3^{\mathrm{a}}$ dopagem } & 5,52 & 0,0098 & 432 & & \\
\hline & & 10,41 & 0,0098 & 437 & & \\
\hline & & 26,47 & 0,0098 & 449 & & \\
\hline & \multirow{3}{*}{$4^{\mathrm{a}}$ dopagem } & 4,24 & 0,0070 & 426 & & \\
\hline & & 10,47 & 0,0080 & 441 & & \\
\hline & & 25,90 & 0,0081 & 450 & & \\
\hline & $\mathrm{Ta}$ & - & - & - & 1,10 & 19 \\
\hline & $\mathrm{Ta}$ & - & - & - & 1,10 & 42 \\
\hline
\end{tabular}


Tabela 23 - Parâmetros de relaxação para o processo $\mathrm{Nb}-\mathrm{O}$.

\begin{tabular}{|c|c|c|c|c|c|c|}
\hline Processo & Condição & $\mathbf{f}(\mathbf{H z})$ & $\mathbf{Q}_{\mathbf{p}}^{-1}$ & $\mathbf{T}_{\mathrm{p}}(\mathbf{K})$ & $\mathrm{E}(\mathrm{eV})$ & Ref. \\
\hline \multirow{7}{*}{$\mathrm{Nb}-\mathrm{O}$} & Sem tratamento & $\begin{array}{r}2,45 \\
4,80 \\
15,53\end{array}$ & $\begin{array}{l}0,0018 \\
0,0013 \\
0,0009\end{array}$ & $\begin{array}{l}442 \\
453 \\
485\end{array}$ & \multirow{6}{*}{1,15} & \multirow{6}{*}{ Este } \\
\hline & Recozimento & $\begin{array}{c}3,51 \\
7,70 \\
22,58\end{array}$ & $\begin{array}{l}0,0032 \\
0,0040 \\
0,0046\end{array}$ & $\begin{array}{l}433 \\
449 \\
464\end{array}$ & & \\
\hline & $1^{\mathrm{a}}$ dopagem & $\begin{array}{c}3,28 \\
7,14 \\
20,40\end{array}$ & $\begin{array}{l}0,0079 \\
0,0084 \\
0,0087\end{array}$ & $\begin{array}{l}438 \\
450 \\
462\end{array}$ & & \\
\hline & $2^{\underline{a}}$ dopagem & $\begin{array}{c}3,34 \\
8,86 \\
21,75\end{array}$ & $\begin{array}{l}0,0118 \\
0,0145 \\
0,0141\end{array}$ & $\begin{array}{l}438 \\
451 \\
464\end{array}$ & & \\
\hline & $3^{\underline{a}}$ dopagem & $\begin{array}{c}5,52 \\
10,41 \\
26,47\end{array}$ & $\begin{array}{l}0,0148 \\
0,0150 \\
0,0160\end{array}$ & $\begin{array}{l}453 \\
460 \\
474\end{array}$ & & \\
\hline & $4^{\underline{a}}$ dopagem & $\begin{array}{c}4,24 \\
10,47 \\
25,90\end{array}$ & $\begin{array}{l}0,0150 \\
0,0155 \\
0,0153\end{array}$ & $\begin{array}{l}447 \\
460 \\
472\end{array}$ & & \\
\hline & $\begin{array}{l}\mathrm{Nb} \\
\mathrm{Nb}\end{array}$ & & & & $\begin{array}{l}1,15 \\
1,16\end{array}$ & $\begin{array}{l}19 \\
42\end{array}$ \\
\hline
\end{tabular}


Tabela 24 - Parâmetros de relaxação para o processo $\mathrm{Nb}-\mathrm{O}-\mathrm{O}$.

\begin{tabular}{|c|c|c|c|c|c|c|}
\hline Processo & Condição & f (Hz) & $\mathbf{Q}_{\mathrm{p}}^{-1}$ & $\mathbf{T}_{\mathrm{p}}(\mathrm{K})$ & $E(e V)$ & Ref. \\
\hline \multirow{7}{*}{$\mathrm{Nb}-\mathrm{O}-\mathrm{O}$} & Sem tratamento & $\begin{array}{r}2,45 \\
4,80 \\
15,53\end{array}$ & $\begin{array}{l}- \\
- \\
-\end{array}$ & $\begin{array}{l}- \\
- \\
-\end{array}$ & \multirow{6}{*}{1,22} & \multirow{6}{*}{ Este } \\
\hline & Recozimento & $\begin{array}{c}3,51 \\
7,70 \\
22,58\end{array}$ & $\begin{array}{l}0,0025 \\
0,0033 \\
0,0039\end{array}$ & $\begin{array}{l}456 \\
476 \\
492\end{array}$ & & \\
\hline & $1^{\mathrm{a}}$ dopagem & $\begin{array}{c}3,28 \\
7,14 \\
20,40\end{array}$ & $\begin{array}{l}0,0042 \\
0,0040 \\
0,0040\end{array}$ & $\begin{array}{l}464 \\
481 \\
492\end{array}$ & & \\
\hline & $2^{\mathbf{a}}$ dopagem & $\begin{array}{c}3,34 \\
8,86 \\
21,75\end{array}$ & $\begin{array}{l}0,0047 \\
0,0057 \\
0,0057\end{array}$ & $\begin{array}{l}466 \\
480 \\
492\end{array}$ & & \\
\hline & $3^{\mathbf{a}}$ dopagem & $\begin{array}{c}5,52 \\
10,41 \\
26,47\end{array}$ & $\begin{array}{l}0,0063 \\
0,0075 \\
0,0080\end{array}$ & $\begin{array}{l}479 \\
485 \\
500\end{array}$ & & \\
\hline & $4^{\mathrm{a}}$ dopagem & $\begin{array}{c}4,24 \\
10,47 \\
25,90\end{array}$ & $\begin{array}{l}0,0076 \\
0,0075 \\
0,0073\end{array}$ & $\begin{array}{l}473 \\
486 \\
502\end{array}$ & & \\
\hline & $\begin{array}{l}\mathrm{Nb} \\
\mathrm{Nb}\end{array}$ & & & & $\begin{array}{l}1,22 \\
1,24\end{array}$ & $\begin{array}{c}6 \\
19\end{array}$ \\
\hline
\end{tabular}


Tabela 25 - Parâmetros de relaxação para o processo $\mathrm{Nb}-\mathrm{N}$.

\begin{tabular}{|c|c|c|c|c|c|c|}
\hline Processo & Condição & $\mathbf{f}(\mathbf{H z})$ & $\mathbf{Q}_{\mathbf{p}}^{-1}$ & $T_{p}(K)$ & $E(e V)$ & Ref. \\
\hline \multirow{7}{*}{$\mathrm{Nb}-\mathrm{N}$} & Sem tratamento & $\begin{array}{r}2,45 \\
4,80 \\
15,53\end{array}$ & $\begin{array}{l}0,0008 \\
0,0006 \\
0,0006\end{array}$ & $\begin{array}{l}469 \\
479 \\
516\end{array}$ & \multirow{6}{*}{1,52} & \multirow{6}{*}{ Este } \\
\hline & Recozimento & $\begin{array}{c}3,51 \\
7,70 \\
22,58\end{array}$ & $\begin{array}{l}0,0007 \\
0,0009 \\
0,0008\end{array}$ & $\begin{array}{l}496 \\
581 \\
599\end{array}$ & & \\
\hline & $1^{\mathrm{a}}$ dopagem & $\begin{array}{c}3,28 \\
7,14 \\
20,40\end{array}$ & $\begin{array}{l}0,0010 \\
0,0010 \\
0,0012\end{array}$ & $\begin{array}{l}496 \\
582 \\
590\end{array}$ & & \\
\hline & $2^{\mathrm{a}}$ dopagem & $\begin{array}{c}3,34 \\
8,86 \\
21,75\end{array}$ & $\begin{array}{l}0,0012 \\
0,0011 \\
0,0010\end{array}$ & $\begin{array}{l}556 \\
587 \\
597\end{array}$ & & \\
\hline & $3^{\mathrm{a}}$ dopagem & $\begin{array}{c}5,52 \\
10,41 \\
26,47\end{array}$ & $\begin{array}{l}0,0008 \\
0,0007 \\
0,0007\end{array}$ & $\begin{array}{l}526 \\
535 \\
555\end{array}$ & & \\
\hline & $4^{\mathrm{a}}$ dopagem & $\begin{array}{c}4,24 \\
10,47 \\
25,90\end{array}$ & $\begin{array}{l}0,0013 \\
0,0011 \\
0,0013\end{array}$ & $\begin{array}{l}510 \\
526 \\
582\end{array}$ & & \\
\hline & $\begin{array}{l}\mathrm{Nb} \\
\mathrm{Nb}\end{array}$ & & & & $\begin{array}{l}1,51 \\
1,51\end{array}$ & $\begin{array}{c}6 \\
19\end{array}$ \\
\hline
\end{tabular}

Uma sugestão para trabalhos futuros seria a dopagem das amostras com nitrogênio e verificar como o aumento destes intersticiais, combinado com o oxigênio já existente na liga influenciaria as medidas de atrito interno.

Também a dopagem das amostras com outros elementos, como hidrogênio ou carbono, realizar medidas de espectroscopia anelástica em baixas temperaturas para verificar se existe algum processo nessa região de temperatura. 


\section{REFERÊNCIAS}

1. RODRIGUES, J. de A. Fundamentos da reação metal-gás In: Gases em Metais e Ligas Fundamentos e aplicações na engenharia, EDC, Rio de Janeiro, 1994.

2. GRANDINI, C. R. Estudo do multi-espectro de relaxação anelástica devido à defeitos intersticiais em ligas de nb-zr e nb-ti. 1988, Dissertação (Mestrado em Física Básica) Instituto de Física e Química de São Carlos, Universidade de São Paulo, São Carlos.

3. SCALVI, R. M. F. Relaxações Anelásticas Devido à Reorientação Induzida por Tensão de Defeitos pontuais em Nióbio e Tântalo. 1993, Dissertação (mestrado em Física Aplicada) Instituto de Física e Química de São Carlos, Universidade de São Paulo, São Carlos.

4. FROM, E.; HÖRZ. G. International Metals Reviews, nº 5-6, 1980.

5. ZENER, C. Elasticity and Anelasticity of Metals, University of Chicago Press, 1948.

6. SZKOPIAK, Z. C. J. de Physique, v. 32, p. C2-1, 1971.

7. NOWICK, A. S.; BERRY, B. S. Anelastic Relaxation in Crystalline Solids, Academic Press, New York, 1972. 
8. NUMAKURA, H.; KOIWA, M. J. de Physique IV $\underline{6}$, C8-97 1996.

9. GRANDINI,C. R.; SCALVI, R. M. F.; OLIVEIRA, A. R. G.; Florêncio, O.; TEJIMA, H.; JORDÃO, J. A. R. Revista Brasileira de Física Aplicada e Instrumentação, 10, 133 1995.

10. BOTTA F'., W. J.; FLORÊNCIO,O.; GRANDINI, C. R.; TEJIMA, H.; JORDÃO, J. A. R. Acta Metall. et Mater., $\underline{\text { 38, }} 3911990$.

11. FLORÊNCIO, O.; BOTTA F ${ }^{O}$., W. J.; GRANDINI,C. R.; TEJIMA, H.; JORDÃO, J. A. R. J. Alloys Comp., 211, 371994.

12. GRANDINI, C. R.; FLORÊNCIO, O.; BOTTA F ${ }^{\circ}$., W. J.; TEJIMA H.; JORDÃO, J. A. R. J. Alloys Comp., 211, 2261994.

13. FLORÊNCIO, O.; FREITAS,W. A.; BOTTA F ${ }^{\circ}$.,W. J.; GRANDINI, C. R.; JORDÃO, J. A. R., J. de Physique IV, $\underline{6}$, C8-123 1996.

14. GRANDINI, C. R. Difusão e Relaxação Anelástica devido ao Hidrogênio em Solução Sólida em Ligas de Nióbio-Titânio e Nióbio-Zircônio. 1993, Tese (Doutorado em Física Básica) Instituto de Física e Química de São Carlos, Universidade de São Paulo, São Carlos.

15. SNOEK, J. L. Physica, v. 8, p. 711, 1941.

16. NUMAKURA, H.; YOTSUI, G.; KOIWA, M. Acta Metal. Mater., v. 43, p. 705, 1995.

17. HANECZOK, G. Phil. Mag. A, v. 78, p. 845, 1998.

18. WELLER, M.; HANECZOK, G.; DIEHL, J. Phys. Stat. Sol. (b), v. 172, p. 145, 1992.

19. AHMAD, M. S.; SZKOPIAK, Z. C. J. Phys. Chem. Solids, v. 31, p. 1799, 1970. 
20. DEPARTAMENTO NACIONAL DE PRODUÇÃO MINERAL Disponível em: <http://www.dnpm.gov.br >. Acesso em 24 julho 2003.

21. OHTSUKA, T.; KIMURA, Y. Physica 55, p. 562, 1971.

22. SZKOPIAK, Z. C. Nuovo Cimento, v. 33, p. 293, 1976.

23. IKUSHIMA, A.; MIZUSAKI, T. J. Phys. Chem. Solids, v. 30, p. 873, 1969.

24. KRISHNAN, R.; GARG, S. P.; KRISHNAMURTHY, N. J. Alloy Phase Diagrams, 3(1), p. $2773,1982$.

25. MACHADO, J. P. B. Desenvolvimento de supercondutor multifilamentar de (Nb,Ta)3Sn para aplicação em sistema de geração de energia por magnetohidrodinâmica (MHD) 2001, Dissertação (Mestrado em Engenharia de Materiais) Faculdade de Engenharia Química de Lorena, Lorena.

26. HANECZOK, G.; WELLER, M. J. of Less-Com. Metals 159, 2691990.

27. WELlER, M.; LI, G. Y.; ZHANG, J. X.; KÊ, T. S. Acta Metallurgica, v. 29, p. 1047, 1981.

28. WELLER, M.; ZHANG, J. X.; LI, G. Y.; KÊ, T. S.; DIEHL, J. Acta Metallurgica, v. 29, p. $1055,1981$.

29. AVILLEZ, Roberto R. Termodinâmica dos sistemas metal-gás In: Gases em Metais e Ligas - Fundamentos e aplicações na engenharia, EDC, Rio de Janeiro, 1994.

30. BAKKER, H. Tracer Diffusion in Concentrated Alloys In: Diffusion in Cristalline Solids, Academic Press, New York, 1984.

31. SMITH, W. F. Princípios de Ciência de Engenharia dos Materiais, McGraw-Hill, Portugal, 1998. 
32. VAN VLACK, L. H. Princípios de Ciência e Tecnologia dos Materiais, Campus, Rio de Janeiro, 1984.

33. ASKELAND, D. R.; PHULÉ, P. P. The Science and Engineering of Materials, $4^{\underline{a}}$ edição, Brooks/Cole-Thomson Learning, California, 2003.

34. CRANK, J. The mathematics of diffusion, $2^{\underline{a}}$ edição, Claredon Press, Oxford, 1975.

35. Instruction Manual, Density Determination Kit, Ohaus Corporation.

36. HALLIDAY, D.; RESNICK, R.; MERRILL, J.; Fundamentos de Física 2 Livros Técnicos e Científicos Editora, Rio de Janeiro 1992.

37. CULLITY, B. D. Elements of X - Ray Diffraction, Addison-Wesley Publishing Company, Inc, Amsterdam 1978.

38. SNYDER, R. L. X-Ray Diffraction In Materials Science and Technology: a comprehensive treatment, VCH, New York 1992.

39. GUlyaEV, A. Physical Metallurgy, volume 1, Mir Publishers, Moscou, 1980.

40. MORTON, M. E.; LOTT, S. A.; STAINSBY, D. F. J. Sci. Instrum., v. 40, p. 441, 1963.

41. DE BATIST, R. Internal Friction of Structural Defects in Crystalline Solids, NorthHolland Publishing Company, New York, 1972.

42. HANECZOK, G; RASEK, J. Defect and Diffusion Forum, v. 188-190, p. 3, 2001.

43. BLANTER, M. S.; FRADKOV, M. Ya. Phys. Met. Metall, v. 69, p. 72, 1990.

44. NIEMEYER, T. C.; ALMEIDA, L. H.; GRANDINI, C. R.; FLORÊNCIO, O. Revista Brasileira de Aplicações de Vácuo, v. 22, p. 34, 2003.

45. POVOLO, F. Phys. Stat. Sol. (a), 103, p. 693, 1987. 
46. MIURA R.; OTA, K.; YOSHIMI, K.; HANADA, S. Philosophical Magazine, v. 83, p. $2343,2003$.

47. NIEMEYER, T. C. Estudo da Interação do Oxigênio Intersticial com a Matriz Metálica em ligas de Nb - 0,3\%pTi, 2003, Dissertação (Mestrado em Ciência e Engenharia de Materiais) Área de Interunidades em Ciência e Engenharia de Materiais, Universidade de São Paulo, São Carlos.

48. HANECZOK, G.; WELleR, M.; DIEHL, J. Phys. Stat. Sol., v. 172, p. 557, 1992.

49. NOGUEIRA, R. A.; NIEMEYER, T. C.; GRANDINI, C. R.; FLORÊNCIO, O. Materials Research, v. 6, 2003.

50. LAUF, R.; ALRSTETTER, C. Scripta Metallurgica, 11, p. 983, 1977. 